ANGÉLICA DE SOUZA ALVES DE PAULA

\title{
Normalização e indicadores de impacto: implicações entre os periódicos brasileiros indexados na SciELO e WoS
}

Dissertação apresentado ao Programa de PósGraduação em Ciência da Informação da Escola de Comunicações e Artes da Universidade de São Paulo (PPGCI-ECA-USP) para obtenção do título de mestre em Ciência da Informação.

Área de Concentração: Cultura e Informação

Linha de Pesquisa: Gestão de Dispositivos de Informação

Orientador: Prof. Dr. Rogério Mugnaini

SÃO PAULO 
Autorizo a reprodução e divulgação total ou parcial deste trabalho, por qualquer meio convencional ou eletrônico, para fins de estudo e pesquisa, desde que citada a fonte.

O presente trabalho foi realizado com apoio da Coordenação de Aperfeiçoamento de Pessoal de Nível Superior - Brasil (CAPES) - Código de Financiamento 001.

Catalogação na Publicação

Serviço de Biblioteca e Documentação

Escola de Comunicações e Artes da Universidade de São Paulo

Dados fornecidos pelo(a) autor(a)

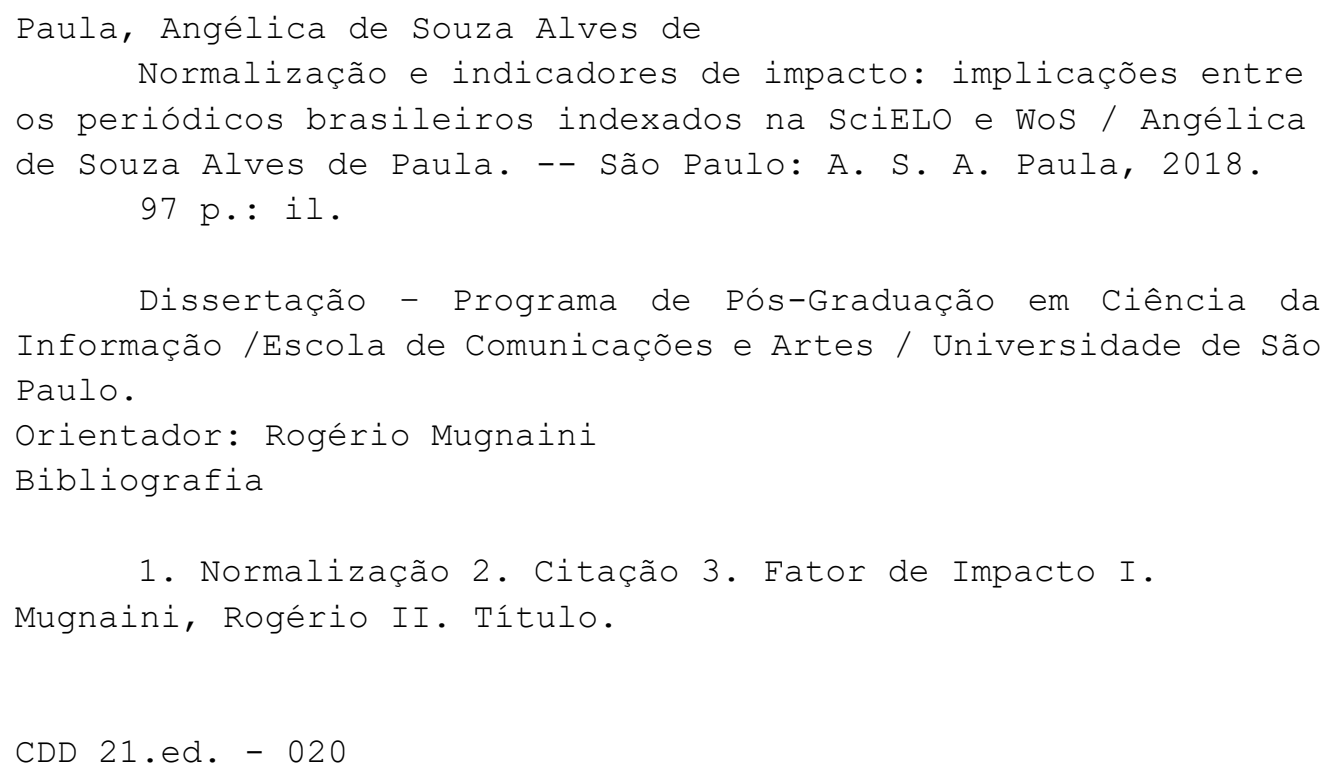




\section{FOLHA DE APROVAÇÃO}

PAULA, Angélica de Souza Alves de. Normalização e indicadores de impacto: implicações entre os periódicos brasileiros indexados na SciELO e WoS. 2018. 97 f. Dissertação (Mestrado em Ciência da Informação) - Escola de Comunicações e Artes, Universidade de São Paulo, São Paulo, 2018.

Aprovado em: 13/12/2018

\section{BANCA EXAMINADORA}

Prof. Dr. Rogério Mugnaini

Universidade de São Paulo, Escola de Comunicações e Artes

Prof ${ }^{\underline{a}}$ Dra Mirian Rejowski

Universidade de São Paulo, Escola de Comunicações e Artes

Prof. Dr. Marcelo dos Santos

Universidade de São Paulo, Escola de Comunicações e Artes 


\section{AGRADECIMENTOS}

Mais um ciclo se passou (e muito rápido!) e, assim como nos agradecimentos do meu Trabalho de Conclusão de Curso, volto a repetir: Deus é bom, em todo o tempo, e Seu amor e misericórdia me constrangem completamente! Foram inúmeras dificuldades, os dias mais difíceis da minha vida até agora, mas que me proporcionaram muito crescimento, aprendizagem e gratidão.

Foram muitas lutas, mas nunca me faltaram o apoio e supervisão. Neste quesito, o Prof. Rogério Mugnaini se mostrou singular, apesar de todos os apuros que o fiz passar por conta das minhas dificuldades, limitações, compromissos, prazos apertados e surpresas da vida ao longo do caminho. Minha oração é que o Senhor possa honrá-lo cada vez mais!

Também não teria conseguido concluir esta etapa sem a torcida, incentivo e apoio quase incondicional dos Profs. Silvio Arruda Vasconcellos e Solange Maria Gennari, da FMVZ/USP, nos últimos cinco anos.

Nos últimos meses do mestrado, o encerramento da bolsa CAPES tornou necessário meu retorno ao mercado de trabalho e tive a benção de ser contratada por uma organização de prestígio, para atuar na área que é a minha paixão: avaliação de periódicos! Apesar da diminuição do meu tempo para desenvolvimento da pesquisa, esse fato foi extremamente importante para eu me lembrar das minhas motivações primárias deste estudo! Além disso, pude contar com a compreensão dos meus colegas e supervisores, o que foi fundamental!

Por último, não posso deixar de agradecer à minha família e igreja (Comunidade Hebrom), por suas constantes orações pela minha vida! 


\section{RESUMO}

PAUlA, Angélica de Souza Alves de. Normalização e indicadores de impacto: implicações entre os periódicos brasileiros indexados na SciELO e WoS. 2018. 97 f. Dissertação (Mestrado em Ciência da Informação) - Escola de Comunicações e Artes, Universidade de São Paulo, São Paulo, 2018.

Além de ser um filtro para selecionar e legitimar o caráter científico do que é publicado, a citação é um meio de distribuir créditos e reconhecimento. Com o surgimento dos índices de citação, novas possibilidades se abriram para avaliação de produção científica por meio de indicadores. Dentre eles, o Fator de Impacto é o mais utilizado para aferir o impacto de um periódico, sendo calculado em termos do número de citações que tal periódico alcança, tomando como fonte de informação as referências de todos os periódicos catalogados numa base de dados. Neste contexto, a normalização também é primordial, por garantir a transferência da informação científica em padrão específico, sendo assim responsável direta da qualidade dos estudos bibliométricos, e consequentemente, na avaliação da produção científica. 0 objetivo geral do trabalho foi contribuir com a discussão sobre a importância da normalização no uso de indicadores para avaliação de periódicos científicos. Os objetivos específicos foram: a) analisar a distribuição das referências bibliográficas de periódicos ao longo do tempo, no que diz respeito ao nível de normalização das referências e seu impacto na análise de citações, considerando ainda a obsolescência e tipologia documental; b) realizar análise comparativa entre áreas. Através da análise das citações feitas, no período de 2011 a 2015, pelos periódicos brasileiros indexados na SciELO e WoS, foi possível verificar a o aumento de citações a periódicos ante outros tipos documentais, constatar o cumprimento das recomendações quanto ao uso de referências atualizadas e utilização cada vez menor de autocitação. No entanto, ainda que indexados em bases criteriosas e rigorosas e possuírem bibliotecários em suas equipes, a taxa de erros de normalização ainda é pronunciada.

Palavras-chave: Citação. Referências bibliográficas. Normalização. SciELO. Web of Science. 


\begin{abstract}
PAULA, Angélica de Souza Alves de. Normalization and impact indicators: implications among Brazilian journals indexed in SciELO and WoS. 2018. 97 p. Thesis (Master in Information Science) - Escola de Comunicações e Artes, Universidade de São Paulo, São Paulo, 2018.
\end{abstract}

In addition to being a filter to select and legitimize the scientific character of what is published, citation is a means of distributing credits and recognition. With the appearance of citation indexes, new possibilities were opened for the evaluation of scientific production through indicators. Among them, the Impact Factor is the most used to gauge the impact of a periodical, being calculated in terms of the number of citations that periodic reaches, taking as reference information the references of all the periodicals cataloged in a database. In this context, standardization is also paramount, since it guarantees the transfer of scientific information in a specific pattern, being therefore directly responsible for the quality of bibliometric studies, and consequently, for the evaluation of scientific production. The general objective of the study was to contribute to the discussion about the importance of standardization in the use of indicators for the evaluation of scientific journals. The specific objectives were: a) to analyze the distribution of bibliographical references of periodicals over time, regarding the level of normalization of references and their impact in the analysis of citations, considering also the obsolescence and typology of documents; b) perform a comparative analysis between areas. Through the analysis of the citations made in the period from 2011 to 2015 by the Brazilian journals indexed in SciELO and WoS, it was possible to verify the increase of citations to periodicals compared to other documentary types, to verify compliance with the recommendations regarding the use of updated references and use less and less selfciting. However, although indexed on a strict and rigorous basis and have librarians in their teams, the error rate of normalization is still pronounced.

Keywords: Citation. References. Normalization. SciELO. Web of Science. 


\section{LISTA DE FIGURAS}

Figura 1 - Etapas de avaliação no fluxo da comunicação científica ..........................................17

Figura 2 - Indicadores de Input e Output no fluxo da Comunicação Científica ..................... 18

Figura 3 - Erros mais comuns em referências .............................................................................. 36

Figura 4 - Distribuição das citações à forma "J PEDIAT" em artigos da base SciELO segundo ano e volume citados 39 


\section{LISTA DE TABELAS}

Tabela 1 - Quantidade de periódicos brasileiros indexados no SciELO por grande área - São Paulo - janeiro 2019 . .47

Tabela 2 - Citações da área de Ciências Agrárias por tipo de documento e por ano ..........................51

Tabela 3 - Citações da área de Ciências Agrárias com até 5 anos (índice de Price) ............................51

Tabela 4 - Citações a periódicos, por ano, da área de Ciências Agrárias ................................................52

Tabela 5 - Citações da área de Ciências Biológicas por tipo de documento e por ano........................55

Tabela 6 - Citações da área de Ciências Biológicas com até 5 anos (índice de Price) .........................55

Tabela 7 - Citações a periódicos, por ano, da área de Ciências Biológicas..............................................56

Tabela 8 - Citações da área de Ciências da Saúde por tipo de documento e por ano ...........................59

Tabela 9 - Citações da área de Ciências da Saúde com até 5 anos (índice de Price)...........................60

Tabela 10 - Citações a periódicos, por ano, da área de Ciências da Saúde ............................................60

Tabela 11 - Citações da área de Ciências Exatas e da Terra por tipo de documento e por ano......62

Tabela 12 - Citações da área de Ciências Exatas e da Terra com até 5 anos (índice de Price) .......62

Tabela 13 - Citações a periódicos, por ano, da área de Ciências Exatas e da Terra............................63

Tabela 14 - Citações da área de Ciências Humanas por tipo de documento e por ano .....................65

Tabela 15 - Citações da área de Ciências Humanas com até 5 anos (índice de Price) ........................65

Tabela 16 - Citações a periódicos, por ano, da área de Ciências Humanas ............................................66

Tabela 17 - Citações da área de Ciências Sociais Aplicadas por tipo de documento e por ano ......67

Tabela 18 - Citações da área de Ciências Sociais Aplicadas com até 5 anos (índice de Price)........68

Tabela 19 - Citações a periódicos, por ano, da área de Ciências Sociais Aplicadas ............................68

Tabela 20 - Citações da área de Engenharias por tipo de documento e por ano.................................70

Tabela 21 - Citações da área de Engenharias com até 5 anos (índice de Price) ...................................70

Tabela 22 - Citações a periódicos, por ano, da área de Engenharias......................................................71

Tabela 23 - Citações da área de Linguística, Letras e Artes por tipo de documento e por ano ......72

Tabela 24 - Citações da área de Linguística, Letras e Artes com até 5 anos (índice de Price) .........72

Tabela 25 - Citações a periódicos, por ano, da área de Linguística, Letras e Artes .............................73

Tabela 26 - Citações da área Multidisciplinar por tipo de documento e por ano...................................75

Tabela 27 - Citações da área Multidisciplinar com até 5 anos (índice de Price) .................................75

Tabela 28 - Citações a periódicos, por ano, da área Multidisciplinar......................................................76

Tabela 29 - Periódicos que indicam título abreviado oficial e a presença de bibliotecários e revisores em sua equipe editorial - 2018 ………….......................................................................77

Tabela 30 - Indicação da norma para elaboração das referências bibliográficas - 2018 .................78

Tabela 31 - Indicação de padrão para citação - 2018 …………………………………………................78

Tabela 32 - Recomendações quanto às referências bibliográficas - 2018 …………………………......78

Tabela 33 - Percentual quanto ao tipo documental citado - 2011-2015 .............................................79

Tabela 34 - Citações normalizadas entre os periódicos da amostra - 2011 a 2015 ...........................80

Tabela 35 - Citações normalizadas dentro da janela de 2 anos do FI - 2011 a 2015 ..........................80

Tabela 36 - Autocitação dos periódicos da amostra, de acordo com a normalização - 2011 a 2015

Tabela 37 - Percentual de citações normalizadas a periódicos, com até 5 anos (índice de Price) 2011 a 2015 


\section{LISTA DE ABREVIATURAS E SIGLAS}

ABNT - Associação Brasileira de Normas Técnicas

APA - American Psychological Association

CAPES - Coordenação de Aperfeiçoamento de Pessoal de Nível Superior

DOI - Digital object identifier

FI - Fator de Impacto

IBICT - Instituto Brasileiro de Ciência e Tecnologia

ICMJE - International Committee of Medical Journal Editors

ISO - International Organization for Standardization

LILACS - Literatura Latino-Americana e do Caribe em Ciências da Saúde

NBR - Norma Brasileira

OJS - Open Journal Systems

PKP - Public Knowledge Project

SciELO - Scientific Electronic Library Online

SEER - Sistema Eletrônico de Editoração de Revistas

UNESCO - Organização das Nações Unidas para a Educação, a Ciência e a Cultura

WoS - Web of Science

XML - eXtensible Markup Language 


\section{SUMÁRIO}

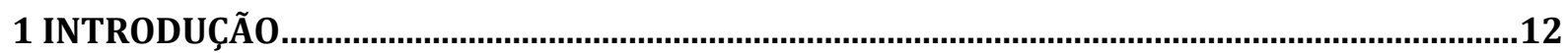

2 PROCESSOS AVALIATIVOS NO FLUXO DA COMUNICAÇÃO CIENTÍFICA.................................15

2.1 Comunidade Científica .................................................................................................................

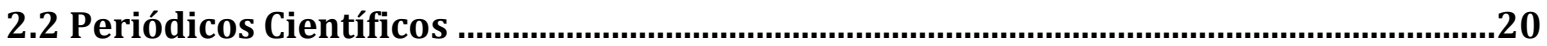

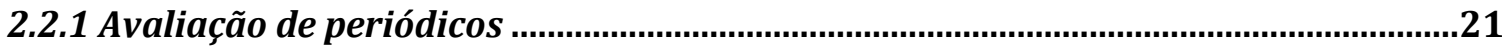

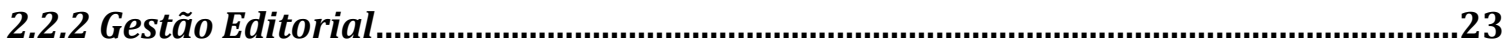

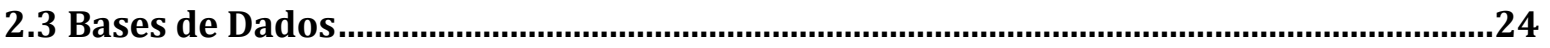

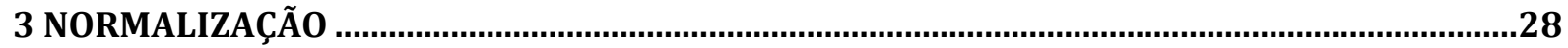

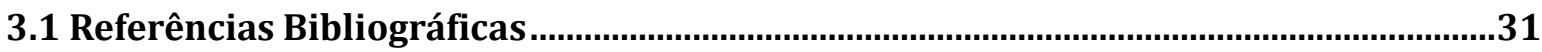

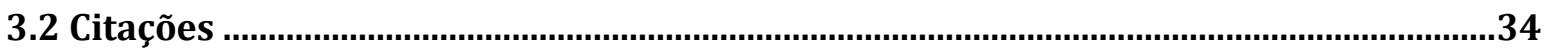

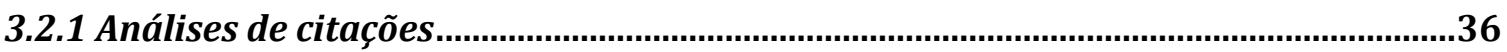

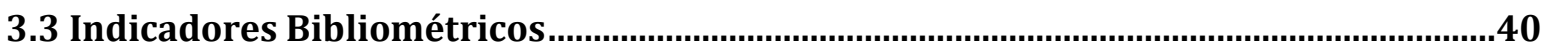

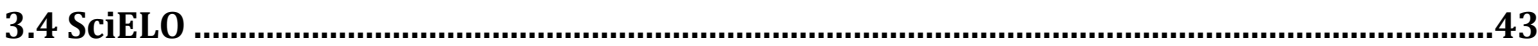

4 METODOLOGIA

5 RESULTADOS

5.1 Caracterização dos periódicos da amostra segundo área..................................................48

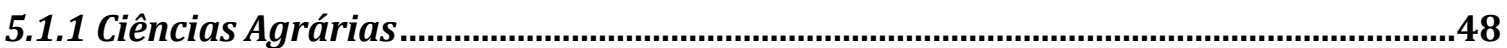

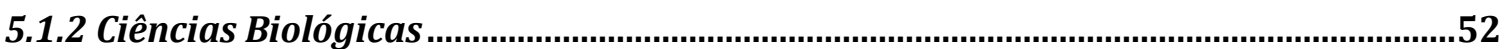

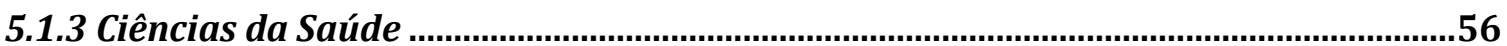

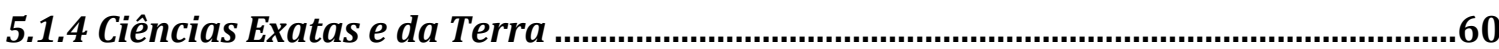

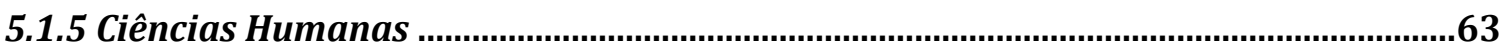

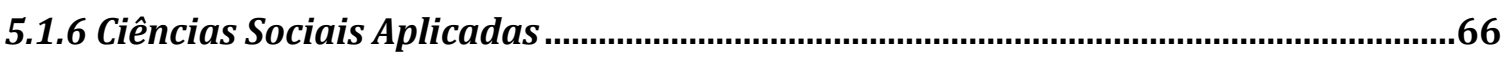

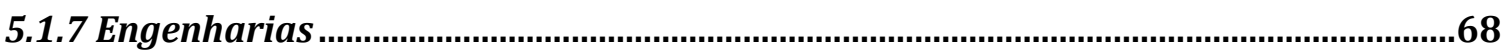

5.1.8 Linguística, Letras e Artes ...................................................................................

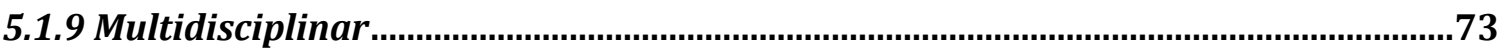

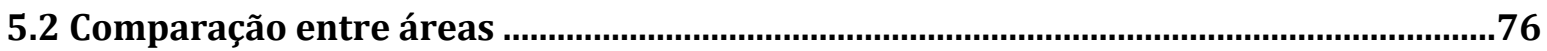

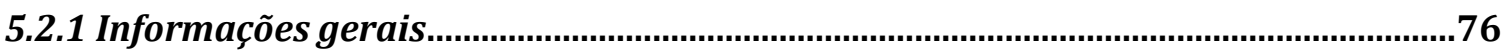

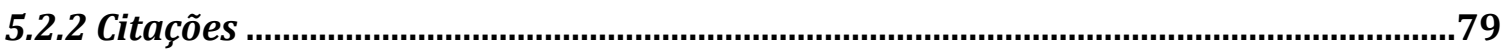

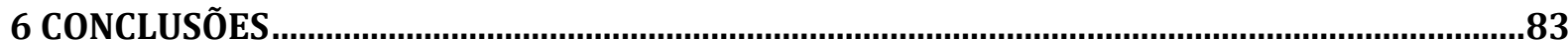

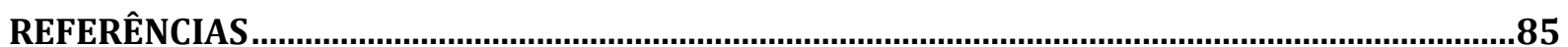

Apêndice A - Porcentagem de citações normalizadas entre os periódicos da amostra .......95

Apêndice B - Citações recebidas pelos periódicos da amostra ..............................................98 



\section{INTRODUÇÃo}

Atualmente, com o uso crescente de indicadores como forma de medir a Ciência e seus atores, a citação tem sido a maior moeda de troca, mas, para que esta seja formada, disseminada e utilizada corretamente, é necessária a observância da normalização atividade presente em quase todas as instâncias no fluxo da comunicação científica.

Dias (2008) revela que a normalização documentária, mediante de suas regras e métodos, traz mais qualidade e padronização, e sustenta que a falta da mesma dificulta a recuperação das fontes utilizadas para elaboração da pesquisa acadêmica. Assim, a normalização surge como um fator que não só confere a qualidade, mas que também facilita a transferência da informação científica, pois através dela pode-se identificar um documento com mais precisão.

0 artigo científico é amplamente reconhecido como canal de comunicação formal da informação científica e, por isso, é constantemente submetido a avaliações de qualidade por todo o ciclo da comunicação científica, uma vez que é insumo e produto de pesquisas. Num cenário no qual a comunicação tem se efetivado por meios eletrônicos e os pesquisadores não precisam mais de intermediários para realização de suas buscas, erros basilares são definitivos para o sucesso ou insucesso na recuperação destes artigos.

Conforme será apresentado no decorrer da dissertação, a maioria dos autores que se propuseram a estudar os critérios de avaliação e seleção dos artigos científicos concluem que o não cumprimento dos padrões estabelecidos, muito mais que dificuldades econômicas ou práticas, se dá pelo desconhecimento destes padrões.

Este tema foi motivado pelo fato da autora trabalhar no processo de seleção e avaliação de uma base de dados e por ter sido membro da equipe editorial de um periódico científico por cinco anos, em virtude das atividades desenvolvidas na rotina editorial deste. Do mesmo modo, a participação em eventos direcionados para editores de periódicos científicos colaborou de maneira relevante na elaboração desta pesquisa, na qual pretende-se descrever a importância da normalização bibliográfica e seu impacto e implicações em todo o processo comunicacional da ciência, a fim de que ela seja vista como algo benéfico e facilitador, e não cerceador. 
Ao longo da graduação, momento que realizou um estágio com atividades relacionadas à editoria de um periódico científico e uma pesquisa de iniciação científica sobre avaliação de indicadores bibliométricos de periódicos, observou-se que, apesar do nível de desenvolvimento alcançado pelos periódicos científicos, os problemas com normalização ainda são uma realidade. No entanto, muito se discute sobre a normalização em questão de formatação e instrução aos autores e, mais ainda, sobre as limitações do Fator de Impacto, mas pouco se relaciona a falta de normalização ao Fator de Impacto, apesar do fato já haver sido alertado por seu criador (GARFIELD, 1972), que recomendou a padronização e normalização de todas as formas de um título e suas abreviaturas.

Além das motivações apontadas acima, este foi o tema do trabalho de conclusão de curso da autora, que se concentrou apenas num pequeno número de periódicos da área de Enfermagem. Apesar de ter sido uma pesquisa breve, desenvolvida em curto prazo e não exaustiva, teve um alcance considerável e os editores dos periódicos analisados, assim como participantes da banca examinadora, consideraram de extrema valia dar continuidade ao estudo de uma forma mais abrangente.

Nesse contexto, são apresentados os objetivos do trabalho:

\section{Objetivo Geral}

Contribuir com a discussão sobre a importância da normalização e o uso de indicadores para avaliação de periódicos científicos.

\section{Objetivos específicos}

a) analisar a distribuição das referências bibliográficas de periódicos ao longo do tempo, no que diz respeito ao nível de normalização das referências e seu impacto na análise de citações, considerando ainda a obsolescência e tipologia documental;

b) realizar análise comparativa entre áreas.

Os capítulos desta dissertação serão detalhados os processos presentes no fluxo da comunicação científica, tendo o artigo científico como produto o periódico científico 
como canal de divulgação. Em seguida, será apresentado um breve capítulo sobre normalização. Então, serão apresentados a metodologia e os resultados da coleta das citações concedidas e recebidas pelos periódicos brasileiros indexados na SciELO e WoS, no período de 2011 a 2015, seguido por uma discussão a respeito dos mesmos. 


\section{PROCESSOS AVALIATIVOS NO FLUXO DA COMUNICAÇÃO CIENTÍFICA}

0 termo "comunicação científica" diz respeito à troca de informações entre cientistas (KAPLAN; STORER, 1968) e busca retratar todo o fluxo informacional de produção, disseminação e uso das informações científicas (GARVEY, 1979). É um sistema que retroalimenta a si próprio e que "[...] envolve a construção, comunicação e uso do conhecimento científico" (WEITZEL, 2006), ou seja, a informação científica é o insumo para novas pesquisas e o produto destas, definido por Spinak (1998) como uma espiral de "informação-criação-informação". Logo, o pesquisador é gerador, disseminador e usuário da informação científica.

Weisman (1972) afirma que o sistema de informação científica sempre existiu, remontando ao período da Antiguidade, a chamada Academia. Côrtes (2006) confirma ao dizer que, desde a Grécia Antiga, os documentos escritos já eram utilizados na comunicação científica, apesar de parecer que antigamente a transmissão do conhecimento tenha se dado somente de forma oral. Meadows (1999) explica que esta suposição se deve ao fato do conhecimento ter tido maior destaque a partir do século XVII devido às descobertas científicas que aconteceram nesta época.

Teóricos e historiadores da Ciência, como Ziman (1979), designam-na como "conhecimento público". Nesse ponto de vista, a Ciência só se efetiva materialmente quando o cientista publica os resultados de suas pesquisas, prestando-se à contestação e à crítica dos pares. Enquanto as descobertas de um trabalho intelectual não forem expostas e passarem por algum critério de avaliação, dificilmente a informação científica será reconhecida como tal (MEADOWS, 1999, vii), ou seja, um conteúdo para ser considerado científico, necessariamente, precisa ser avaliado.

\section{Para Merton (1970), a palavra Ciência}

É usada geralmente para indicar: (1) um conjunto de métodos característicos por meio dos quais os conhecimentos são comprovados; (2) um acervo de conhecimentos acumulados, provenientes da aplicação desses métodos; (3) um conjunto de valores e costumes culturais que governam as atividades chamadas científicas; ou, (4) qualquer combinação dos itens anteriores. (MERTON, 1970, p. 652). 
O processo de comunicação dentro da Ciência é visto como principal base para o funcionamento das pesquisas e atividades que visam à criação de novos conhecimentos (ZIMAN, 1979; MEADOWS, 1999).

No contexto da Sociedade da Informação, a produção, disseminação, transmissão, aplicação e manipulação de informações são atividades econômicas significativas. Desta forma, tornam-se necessários parâmetros de confiabilidade e a abundante oferta de informação impõe análise e seleção.

Para Davyt e Velho (2000), a avaliação é elemento complementar do processo de elaboração do conhecimento científico e suas raízes podem ser identificadas com o advento da própria Ciência.

A avaliação é uma atividade primordial para assegurar e manter a qualidade dos serviços classificados e "[...] resultado da necessidade de aferir os logros do alto investimento que os países investem em Ciência e tecnologia” (MUGNAINI, 2011, p. 43). Além do mais, "[...] não basta publicar: é fundamental que o material produzido seja localizado, lido e aceito, ou seja, avaliado" (BARBALHO, 2005, p. 6).

No processo da comunicação científica, a produção de informação científica passa por diversos processos avaliativos, também chamados de filtros por Castro (2011), elaborados com o objetivo de selecionar e legitimar o caráter científico do que é publicado, e cada uma destas etapas tem critérios e objetivos distintos. A primeira avaliação é a do próprio periódico científico, realizado através das diretrizes para autores e da revisão por pares; o segundo é o das bases indexadoras, com seus próprios critérios de seleção; o terceiro é o da citação pela comunidade científica, que gera os indicadores de citação e que são determinantes para a quarta etapa de avaliação, que é a comunidade científica, que faz uso deste artigo para a geração de novas pesquisas (Figura 1).

A maior parte dos modelos de avaliação contempla basicamente um mesmo núcleo de elementos, adaptando apenas o grau de exigência e obrigatoriedade o atendimento a cada um deles (GONÇALVES; RAMOS; CASTRO, 2006).

Le Pair (1995) acredita que a avaliação seja a própria atividade científica pois os pesquisadores, ao buscar respostas aos problemas, avaliam conceitos, dados extraídos e teorias já elucidadas por seus pares anteriormente. Cientistas, bem como instituições empresariais e organizações públicas, têm recorrido à avaliação como meio para garantir o aperfeiçoamento e desenvolvimento constantes de suas áreas, atividades e negócios. 
Galembeck, em 1990, advertia sobre a improbabilidade da evolução sem a ocorrência de avaliações sistemáticas do ensino e produção científica.

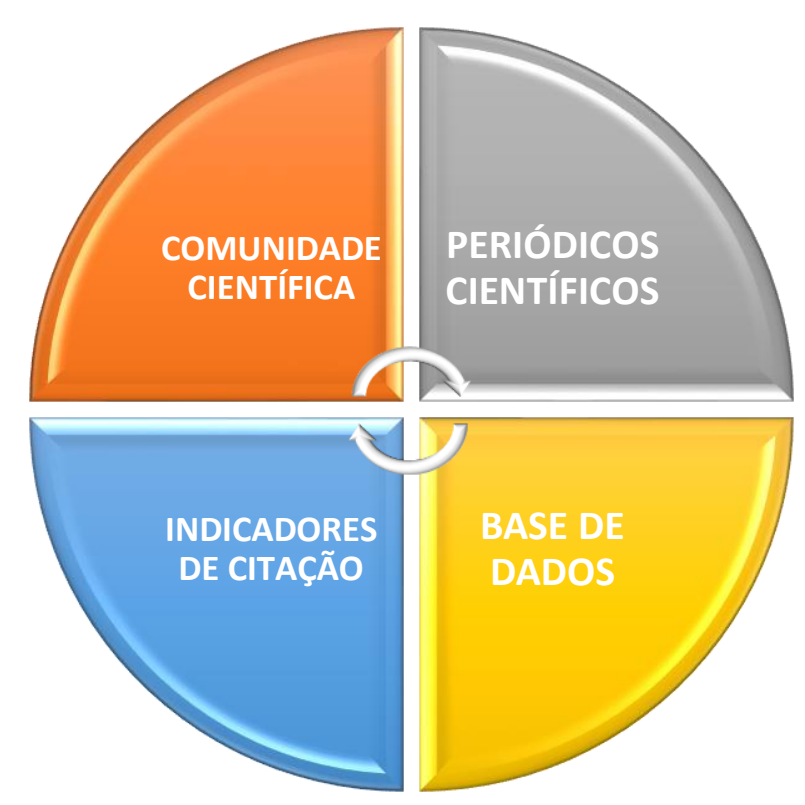

Figura 1 - Etapas de avaliação no fluxo da comunicação científica

Nota-se, a partir da década de 60, uma vez que a Ciência se tornou determinante para o desenvolvimento econômico e social de qualquer país, um interesse gradativo na coleta de informações a respeito de todo o processo das atividades de Ciência e Tecnologia (C\&T), para que estas sejam engendradas, monitoradas e avaliadas (NORONHA; MARICATO, 2008).

No fluxo da geração do conhecimento científico podem-se considerar, de forma bem genérica, duas ocasiões na sua avaliação, que caracterizam os indicadores de Input (insumo) e Output (produto / resultado) (Figura 2).

Os indicadores de input são os insumos necessários a consolidação da comunidade científica e as condições para a efetivação de suas investigações. Já nos indicadores de output, "[...] têm-se a validação do conhecimento gerado, comprovada com a aceitação pelos pares (disseminação) e pela sociedade (divulgação)" (NORONHA; MARICATO, 2008). 


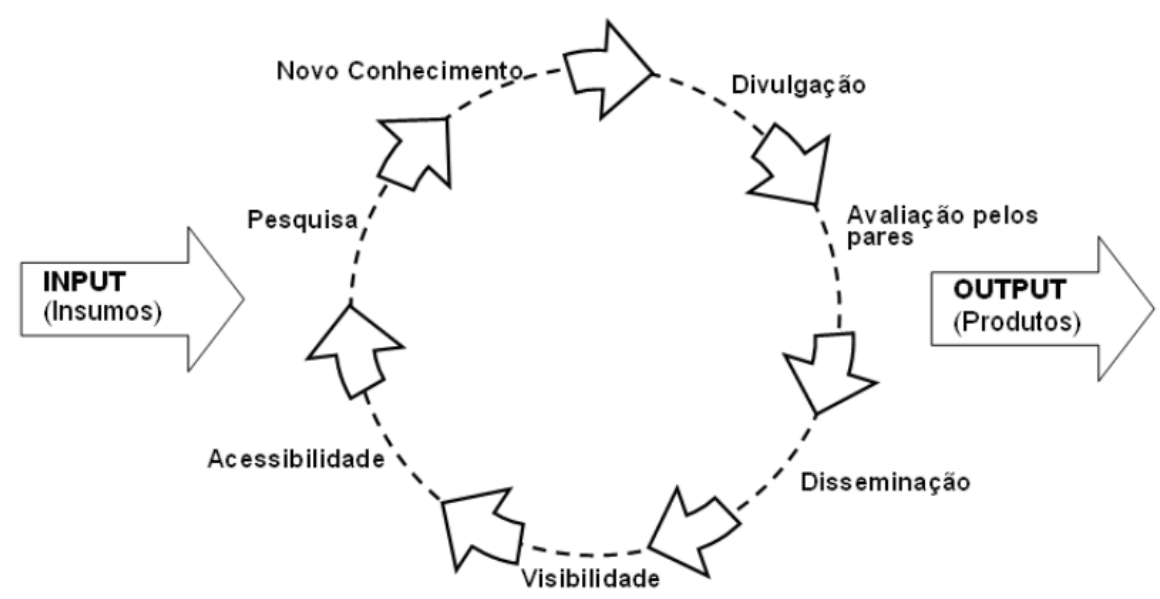

Figura 2 - Indicadores de Input e Output no fluxo da Comunicação Científica Fonte: (NORONHA; MARICATO, 2008)

Avaliações a respeito da qualidade dos artigos mostram que metade deles contêm erros estatísticos e, quase a mesma porcentagem, em se tratando sobre o impacto, nunca chegam a ser citados ou sequer consultados (TRZESNIACK, 2001). Outros aspectos como irregularidade na publicação, deficiência na normalização, não-indexação em bases internacionais e questões referentes ao idioma, também merecem a atenção da comunidade científica (YAMAMOTO et al., 2002).

De acordo com Yamamoto et al. (2002), as iniciativas de avaliação de periódicos surgem no início da década de 1960, precedidas por um modelo desenvolvido pela UNESCO. No Brasil, baseadas numa proposta de Braga e Oberhofer (1982), algumas sugestões para o desenvolvimento de um sistema eficiente de avaliação de periódicos começaram a ser realizadas na década de 1990 (CASTRO; FERREIRA; VIDILI, 1996; CASTRO; NEGRÃO; ZAHER, 1996; KRZYZANOWSKI; FERREIRA, 1998). Constataram-se vários pontos em comum nessas avaliações, especialmente acerca dos parâmetros que mensuraram os periódicos e lhes deram uma classificação, e estes são, basicamente, relacionados com os aspectos de conteúdo e normalização.

\subsection{Comunidade Científica}

O cientista exerce, ao mesmo tempo, o papel de produtor, distribuidor e consumidor de informação científica incorporado às suas práticas profissionais e acadêmicas. Essa é uma característica que fundamenta a base do sistema de comunicação 
científica (WEITZEL, 2006, p. 98). Uma vez que a atividade de pesquisa é consumidora e produtora de informação (CURTY; BOCCATO, 2005), o pesquisador é tanto consumidor como produtor de informação científica, retroalimentando todo o fluxo.

A comunidade científica - nas pessoas do pesquisador autor, leitor, editor e revisor - está presente em todas as instâncias do fluxo da comunicação científica. Desde o início da sua investigação, o pesquisador já faz uma avaliação para selecionar quais trabalhos utilizará para embasar e sustentar a sua tese.

Ao escrever sua pesquisa para fins de publicação, os autores, primeiramente, escolhem o periódico ao qual submeterão seu artigo. No caso da comunidade científica brasileira, normalmente essa escolha se dá não apenas levando em conta a temática, objetivos e a classificação do periódico, mas também a classificação atribuída pelo Qualis, e também o Fator de Impacto. Deve-se mencionar ainda a observância das bases nas quais o periódico está indexado. Então, feita a escolha, os autores adaptam seu manuscrito às diretrizes estabelecidas pelo periódico selecionado.

No processo de avaliação dentro do periódico, o artigo passará por uma análise inicial realizada pelos editores, que verificarão se o mesmo está dentro do escopo e se cumpre as exigências mínimas para, então, solicitar a apreciação de dois ou mais pareceristas (peer review). Segundo Greene (1998), somente pesquisadores produtivos têm habilidade para avaliar e indicar outros para emitirem pareceres.

De acordo com Gonçalves, Ramos e Castro (2006), a avaliação pelos pares é o processo que oficializa a seleção de trabalhos, valida a metodologia científica utilizada e a relevância e qualidade dos resultados e discussões apresentados. Ela deve, ainda, servir para melhorar a qualidade dos artigos, detectar erros, fraudes e condutas não-científicas. Para Tagler (1989), um dos fatores principais da qualidade de uma revista é o processo de revisão pelos pares.

A publicação em periódicos que contam com o auxílio de avaliadores renomados proporciona autoridade e confiabilidade ao artigo, uma vez que a aprovação dos especialistas representa a aprovação da comunidade científica (MUELLER, 2007).

Uma vez aceito, o artigo é publicado e, para se manter o fluxo, passará pela avaliação dos pesquisadores leitores, que podem utilizá-lo em suas próprias pesquisas, voltando ao início do ciclo. 
Com o encorajamento do acesso aberto, a visibilidade dos periódicos aumentou substancialmente, proporcionando maior acesso à informação que pode ser consumida e citada. Este acesso viabiliza, também, a organização de uma rede de pesquisadores com trocas de experiências e conhecimento, trabalhando de forma complementar (UNESCO, 2005, p. 128).

\subsection{Periódicos Científicos}

Para Meadows (1999), a comunicação da pesquisa é tão vital quanto a própria pesquisa. Silva, Santos e Prazeres (2011) concordam com esta colocação ao afirmarem que:

a publicação é o principal estímulo concedido aos pesquisadores em prol da evolução científica e visibilidade profissional e dos trabalhos [...] e este intercâmbio representa o sustento de toda a atividade científica. (SILVA; SANTOS; PRAZERES, 2011, p. 70).

Os periódicos foram considerados por alguns autores (MIKHAILOV; CHERNYI; GILIAREVSKI, 1984 apud FROHMANN, 2000) como a mais importante fonte e meio de informação científica e que, sem os documentos científicos, a Ciência não pode existir.

Desde o início, os encargos elementares dos periódicos científicos são o registro e a disseminação do conhecimento científico, o que favorece a comunicação entre pesquisadores e comunidades científicas, contribuindo para a evolução, melhoria e avanços científicos. Apesar das variações entre as áreas, o periódico normalmente é o canal formal predominantemente utilizado no processo de comunicação científica, ademais de ser um recurso de sistematização das atividades científicas e reconhecimento dos pesquisadores.

De acordo com a Associação Brasileira de Normas Técnicas (2003), uma publicação periódica científica é:

Um dos tipos de publicações seriadas, que se apresenta sob a forma de revista, boletim, anuário etc., editada em fascículos com designação numérica e/ou cronológica, em intervalos pré-fixados (periodicidade), por tempo indeterminado, com a colaboração, em geral, de diversas pessoas, tratando de assuntos diversos, dentro de uma política editorial definida, e que é objeto de Número Internacional Normalizado (ISSN) (ABNT, 2003, p. 2). 
Os periódicos atuam como filtro do que se publica, valorizam a pesquisa e originalidade, conservam a memória e constituem-se em base para o início de novas pesquisas. Destaca-se, também, a sua aplicação para análise de cursos de pós-graduação, cessão de bolsas, ascensão funcional, entre outros e assim provêm indicadores relevantes para atividades decisivas.

Cunha (1973), há pouco mais de quarenta anos, argumentou sobre a necessidade de se estipular padrões formais que assegurassem uma verdadeira qualidade em todas as etapas do processo científico. Em 1978, O’Connor e Van Orden (BUDD, 1989), ao estudar os altos índices de rejeição (entre 60 e 70\%) em periódicos norte-americanos de diversos campos do conhecimento, concluíram que este índice era fortemente determinado pela falta de esclarecimento editorial acerca dos parâmetros de qualidade formal estabelecidos para publicação.

\subsubsection{Avaliação de periódicos}

A qualidade de um periódico científico não é um valor de fácil mensuração ou completamente tangível, uma vez que sua estrutura é formada por um conjunto de vários aspectos, como conteúdo, forma de apresentação, normalização e produção editorial (GONÇALVES; RAMOS; CASTRO, 2006).

Inicialmente, a avaliação de periódicos servia como ferramenta para o desenvolvimento de coleções em bibliotecas, surgindo a partir da necessidade de uma estrutura comunicacional que possibilitasse maior transparência da informação em ampla escala e da necessidade genuína de trocas de experiências científicas dos cientistas (WEITZEL, 2006, p. 84). No entanto, ela foi convertida num instrumento bastante utilizado, tanto pelas agências de fomento - para deliberação de apoio aos periódicos -, como pelos principais índices internacionais - para admissão de títulos em seu banco de dados. Ademais, certifica e confere crédito às publicações, permitindo, à comunidade acadêmica identificar os periódicos científicos que melhor se adequem às suas necessidades (SANTOS, 2010). 
Os estudos sobre avaliação de periódicos se expandiram no Brasil a partir da década de 1960 e Ferreira e Krzyzanowski (2003), ao elencar principais estudos entre os anos de 1960 e 1999, concluíram que as avaliações propostas focavam nos mesmos critérios de qualidade), mudando apenas o grau de exigência no atendimento de cada um deles: aspectos de conteúdo (intrínsecos ou de mérito) e aspectos de forma (extrínsecos ou de desempenho).

Desde 1977, a Coordenação de Aperfeiçoamento de Pessoal do Ensino Superior (Capes) vem desenvolvendo continuamente seu sistema de Avaliação da Pós-graduação (MOREIRA; HORTALE; HARTZ, 2004; SPAGNOLO; SOUZA, 2004) e a pesquisa e a produção científica são, dos diversos aspectos avaliados, os mais valorizados pela maioria das áreas (FONSECA, 2001; SOUZA; PAULA, 2002). Num primeiro momento, o resultado era informado apenas às instituições avaliadas, e era expressa em conceitos: A (muito bom), B (bom), C (regular), D (fraco) e E (insuficiente). Em 1990, os conceitos foram substituídos por notas (de 1 a 5), além de serem incluídos no processo de avaliação alguns indicadores quantitativos, como a quantidade de artigos publicados pelos programas (FERREIRA; MOREIRA, 2001; CAPES, 2011). Em 1998, com a padronização da ficha de avaliação, todas as áreas de avaliação deveriam analisar os mesmos quesitos embora pudessem utilizar, no processo, diferentes tipos de indicadores. Esta ficha incluía sete quesitos: a proposta do programa, o corpo docente, as atividades de pesquisa, as atividades de formação, o corpo discente, as teses e dissertações e a produção intelectual (BARATA, 2016).

Sentiu-se, então, a necessidade de qualificar a produção dos programas e não mais apenas contabilizar o número de artigos publicados, que a cada triênio de avaliação era mais expressivo e tornou impraticável a manutenção deste tipo de avaliação. Logo, a alternativa aplicada foi a classificação dos periódicos científicos, presumindo-se que a aceitação de um artigo por um periódico indexado e com sistema de peer review garantia, de certo modo, a sua qualidade. Ainda, pressupôs-se que periódicos com circulação internacional e maior impacto na comunidade acadêmica teriam processos de seleção mais competitivos e, em consequência, os artigos selecionados por eles teriam qualidade e relevância (LINDSEY, 1989).

A classificação de periódicos é realizada pelas áreas de avaliação e passa por processo anual de atualização. Esses veículos são enquadrados em estratos indicativos da qualidade - A1, o mais elevado; A2; B1; B2; B3; B4; B5; C - com peso zero. 0 aplicativo que 
permite a consulta ao Qualis das áreas, bem como a divulgação dos critérios utilizados (Documentos de Área) para a classificação de periódicos é a plataforma Sucupira.

É importante ressaltar, conforme destaca Barata (2016), que:

[...] o Qualis não é uma base de indexação de periódicos [...] visto que o Qualis só existe como ferramenta para a avaliação de programas. Estar ou não na lista do Qualis significa tão somente que algum dos alunos ou professores dos programas credenciados publicaram artigos naqueles periódicos. Do mesmo modo, o Qualis Periódicos não é uma base bibliométrica e não permite o cálculo de nenhuma medida de impacto dos periódicos nele incluídos. Sendo assim, o Qualis Periódicos não deve ser considerado como uma fonte adequada de classificação da qualidade dos periódicos científicos para outros fins que não a avaliação dos programas de pós-graduação. Por uma série de características [...], a classificação de uma revista no Qualis não pode ser usada fora de seu contexto, sob pena de produzir mais problemas do que soluções. (BARATA, 2016, p. 16-17).

O processo avaliativo estabelecido pelo Qualis fez com que a comunidade científica tenha a sua disposição a classificação que cada periódico utilizado para publicação (por docentes e alunos inseridos na pós-graduação) recebeu. Tal classificação é realizada em cada área, sendo atualizada a cada ciclo avaliativo (e ainda com atualizações intermediárias). Como todo processo avaliativo é alvo de muitas críticas por parte da comunidade (MUGNAINI, 2015; VOGEL, 2015), e não por acaso, exige que cautelas sejam recomendadas pela própria diretora de avaliação da Capes (BARATA, 2016). Mas este não é um aspecto exclusivo do Qualis, já que mundialmente o Fator de Impacto vem sendo utilizado e criticado pela comunidade científica, considerando seu uso em processos avaliativos, conforme se verá mais adiante.

\subsubsection{Gestão Editorial}

A gestão de um periódico científico, impresso ou eletrônico, é um trabalho multifacetário que abrange aspectos formais na apresentação, conteúdo científico e gestão administrativa. Trzesniak (2009) estima que cada manuscrito submetido a um periódico demanda de 15 a 30 operações editoriais para se converter em artigo. Pelas contas do autor, para transformar 100 artigos, são 800 passos, contando com o auxílio de uma equipe experiente. As principais etapas que a compõe esse fluxo são:

- Recepção de manuscrito para publicação; 
- Pré-seleção;

- Seleção de avaliadores;

- Encaminhamento aos avaliadores;

- Acompanhamento do processo de revisão por pares;

- Contato com os autores sobre comentários dos avaliadores;

- Aprovação ou rejeição para publicação;

- Revisão do texto;

- Normalização;

- Diagramação;

- Revisão gráfica;

- Publicação e/ou disponibilização na internet;

- Publicação em redes sociais;

- Envio de metadados às bases indexadoras.

A partir dos anos 1990, com o uso crescente da informação eletrônica e de redes, verificou-se um grande rompimento no modo de editoração e disseminação de informações, sobretudo da produção científica (FACHIN, 2002). No Brasil, o gerenciamento eletrônico foi possibilitado em larga escala pelo uso do SEER (Sistema Eletrônico de Editoração de Revistas), programa baseado em software livre desenvolvido pelo Public Knowledge Project (PKP) do Canadá, traduzido e distribuído pelo Instituto Brasileiro de Ciência e Tecnologia (IBICT).

Para Targino e Garcia (2008) os sistemas de gerenciamento eletrônico do fluxo de manuscritos possibilitam maior velocidade no processo editorial, uma vez que os artigos são recebidos, submetidos à avaliação e disponibilizados na internet tão logo seja aprovado, uma vez que o processo é inteiramente eletrônico. Outra vantagem dos é o melhor controle das etapas do processo editorial, que podem ser acompanhadas, inclusive, por todos os envolvidos no processo, auxiliando no controle de prazos de modo eficaz, e permitindo, entre outros, o acompanhamento do número de acessos, comentários e citações recebidas e concedidas Miranda (2012).

\subsection{Bases de Dados}


De acordo com Silva, Ramos e Noronha (2006), as bases de dados são originalmente resultantes da necessidade de controle, disseminação e acesso à informação. Uma vez que as bases não são apenas armazenadoras de informação, visto que selecionam seu conteúdo, além de oferecerem indicadores bibliométricos permitindo a manipulação de informação para aferição destes -, bem como a possibilidade de se gerar novos indicadores, estes aspectos expressam a utilidade destas em processos avaliativos.

A demanda de avaliação de periódicos brasileiros pelos indexadores data de 1980, com a criação da LILACS (Literatura Latino Americana em Ciências da Saúde), com características mais exaustivas que seletivas. Então, em 1996, a BIREME, desta vez em parceria com a FAPESP, cria a SciELO, de características mais seletivas, o que aumentou a visibilidade e importância dada ao tema da avaliação de periódicos científicos brasileiros (TRZESNIAK, 2006).

Castro (2011) e Sales (2013) afirmam que a maioria das bases de dados possuem critérios e que são aplicados por Comitês de Seleção e o conhecimento destes critérios permite entender as diferenças e importância de cada base. São comuns à grande maioria os seguintes critérios: qualidade científica estabelecida pela revisão pelos pares; representatividade do corpo editorial; tipo de conteúdo que abrange; regularidade de publicação; frequência de publicação; normalização; idioma.

Os primeiros serviços de indexação surgiram como iniciativas particulares de indivíduos preocupados com o controle e acesso à informação científica, logo após a invenção da imprensa. No entanto, assim como uma biblioteca física não pode manter, por questões de espaço e financeiras, toda produção publicada, estes índices se viram obrigados a se especializarem e tornarem-se seletivos, dado o aumento da quantidade de artigos publicados. Já o início do século XX, surgem as bases de dados automatizadas, uma evolução dos índices impressos (BICAS; ROTHER; BRAGA, 2002; CASTRO, 2011).

De acordo com Barbalho (2005), cada base de dados estabelece os seus princípios para a inserção dos títulos, com base os objetivos a que se propõe, o público-alvo a que pretende atingir e as áreas de interesse que contempla. Os requisitos básicos são: 
- publicar, preferencialmente contribuições originais, que consolidem avanços o conhecimento científico, evidenciando a relevância da publicação;

- incluir, o comitê editorial, profissionais reconhecidos, oriundos de distintas instituições do País e, se possível, do exterior;

- imprimir transparência aos processos avaliativos, divulgando dados, como: procedimentos, datas de chegada dos originais, de revisão e de aprovação;

- apresentar porcentagem significativa de textos de autores reconhecidos, acional e internacionalmente;

- publicar um úmero elevado de artigos originais, em cada fascículo;

- prover um trabalho editorial de qualidade, envolvendo: estilo conciso, linguagem científica, uso correto do idioma, resumo, descritores, figuras e tabelas claras e concisas, normalização das referências, entre outros itens;

- cumprir os prazos estabelecidos;

- proporcionar ampla divulgação e reconhecimento por instituições da área, de modo a garantir um elevado índice de citação.

Ferreira (2005) desmembra estes critérios da seguinte forma:

- Características básicas: qualidade do conselho editorial; qualidade das regras de submissão de originais; distribuição de autoria; registro o ISSN; arbitragem por pares; pontualidade e circulação efetiva da publicação do periódico; periodicidade;

- Apresentação formal: capa e folha de rosto (título, numeração do fascículo, data de publicação, local de publicação, entidade editora); contracapa (endereço, corpo editorial, periodicidade, informações sobre assinatura, direitos autorais, plágio, etc.); instruções aos autores; identificação da revista as páginas o texto; sumário; legenda bibliográfica; normalização; indexação;

- Tipologia do conteúdo e autoria: apresentação dos artigos; endogenia; fatores de impacto; 
- Aspectos de gestão e política editorial: layout; impressão ou publicação eletrônica; publicidade; financiamento; forma de distribuição; formato de apresentação.

Ainda, Trzesniak (2006) trabalha com quatro dimensões da qualidade dos periódicos:

- Técnico-normativa: observa-se a obediência a critérios internacionalmente aceitos;

- Finalidade do produto: como e quão bem o periódico cumpre sua finalidade, favorecida por indicadores indiretos (um corpo editorial científico altamente qualificado, seja diversificado institucional e geograficamente; consultores ad hoc com boa qualificação e com diversidade geográfica e institucional; respaldo científico institucional qualificado, sério e atuante; regulamento que contemple explicitamente e favoreça a perenidade da publicação; mecanismo de sucessão de editor em que os aspectos técnico-científicos predominem amplamente sobre quaisquer outros);

- Qualidade do processo produtivo: associada à execução dos procedimentos editoriais de modo sistemático, completo, eficiente, eficaz e transparente;

- Qualidade de mercado: qualidade que o usuário, atribui ao produto, envolvendo a busca por indexação e contagem de citações.

No fluxo da Comunicação Científica, a indexação de um periódico numa base de dados é extremamente importante pois, muitas vezes, sua qualidade é associada à fonte de informação em que o periódico está incluído. Uma vez que a inclusão depende do cumprimento dos critérios de seleção pré-estabelecidos e, a análise e observância destes oferece insumos para o aprimoramento deste processo. 


\section{NORMALIZAÇÃO}

Um dos elementos que norteiam a qualidade de um periódico científico é a sua normalização técnica, extensiva aos artigos que comporão o fascículo (CURTY; BOCCATO, 2005). Ela permite maior clareza na compreensão de um objeto (NASCIMENTO, 2014) e, ainda, avaliza a segurança das informações e a credibilidade na apresentação, resguardase de duplicidade e facilita a padronização. Nos periódicos, a normalização se aplica a sumário, resumos, palavras-chave, legenda bibliográfica, título abreviado, citações, referências bibliográficas, entre outros.

A normalização, no campo da informação científica, é absolutamente indispensável à cooperação entre as unidades de informação, pois facilita as operações documentais e diminui o custo e tempo necessários para realizá-las, viabilizando o intercâmbio e a recuperação de informações (CURTY; BOCCATO, 2005). A normalização é, ainda, primordial no sistema de transferência da informação científica e o rigor na aplicação das normas torna-se fundamental, uma vez que os sistemas automatizados dependem da perfeita sintonia dos dados com as normas, para que sejam interpretados eletronicamente (FERREIRA; KRZYZANOWSKI, 2003). Além disso, repercute na disseminação dos periódicos, uma vez que é critério para ser aceito nas principais bases de dados e responsável direta pela qualidade dos estudos bibliométricos, refletindo-se na avaliação da produção científica (LÓPEZ-CÓZAR, 1997).

Rodrigues, Lima e Oliveira-Garcia (1998) sugerem a normalização como metodologia capaz de uniformizar o processo de comunicação, relacionando o uso destas com a qualidade da comunicação científica. Ainda, a normalização visa à padronização e simplificação no processo de elaboração de qualquer trabalho científico (CURTY; BOCCATO, 2005).

Para Rodrigues, Lima e Oliveira-Garcia (1998), em estudos que mostram a qualidade formal como elemento decisivo para aceitação ou rejeição de artigos para publicação em diversas áreas de conhecimento, a normalização tem sido apontada, o que comprova a sua relevância na comunicação científica.

Fachin, Hillescheim e Rados (2005) afirmam que, quando padronizados e normalizados, os periódicos científicos, 
[...] asseguram aspectos como: informações atualizadas, conhecimento de pontos de vista distintos sobre um mesmo tema, aprofundamento de pesquisas e investigações e como elemento fundamental na preservação do conhecimento, sua difusão relativamente rápida e o estabelecimento da prioridade científica, por atuar mais como veículo de reconhecimento científico de seus autores e editores. (FACHIN; HILLESHEIM; RADOS, 2005).

A normalização se revela, então, como um elemento fundamental no aperfeiçoamento da produção, análise e utilização dos periódicos científicos (DEVIS et al., 2004). A normalização é, ainda, basilar para o avanço da notoriedade, reconhecimento e aprovação dos periódicos no meio científico.

Para que seja viável a avaliação do cumprimento às normas, o periódico deve explicitar as normas adotadas para apresentação e estruturação de textos, referências bibliográficas e descritores. Santos (2010) verificou que 35,6\% dos periódicos de Ciências Humanas e Sociais indexados no SciELO não indicam o tipo de normalização que os autores devem adotar, o que evidencia pouca preocupação a respeito, ainda que estejam em uma base que dispõe de indicadores bibliométricos a partir da correta citação das fontes referenciadas no artigo.

Rodrigues, Lima e Oliveira-Garcia (1998) defendem que

[...] se o fim da Ciência é produzir um conhecimento público, no sentido de conhecimento publicado, [...] é indispensável que os conteúdos dessa Ciência, desde sua geração, sejam transferidos [...] com qualidade formal tal que permita sua rápida manipulação em sistemas de recuperação. [...] todo o esforço a mais na entrada do processo [...] redunda em uma esperada economia na saída. (RODRIGUES; LIMA; OLIVEIRA-GARCIA, 1988, p. 155).

Gonçalves, Ramos e Castro (2006) afirmam que muitos periódicos ainda têm dificuldade em cumprir orientações triviais com relação aos padrões pretendidos de qualidade. Essa dificuldade não se deve unicamente a empecilhos econômicos ou institucionais, mas por falta de Ciência dos critérios utilizados para avaliação e seu valor na melhoria da qualidade dos periódicos. Mesmo havendo normas técnicas e 
internacionais, ao que tudo indica é necessária uma maior divulgação quanto a sua importância.

No Brasil, a normalização é publicada pela Associação Brasileira de Normas Técnicas (ABNT) e, para eles, normalização é uma "atividade que estabelece, em relação a problemas existentes ou potenciais, prescrições destinadas à utilização comum e repetitiva com vistas à obtenção do grau ótimo de ordem em um dado contexto" (ABNT, 2016).

A ABNT possui algumas normas que se referem a aspectos formais / extrínsecos dos periódicos, conforme abaixo:

- NBR 6021:2003 - Apresentação de periódicos

- NBR 6022:2003 - Apresentação de artigos em periódicos

- NBR 6023:2002 - Referências bibliográficas

- NBR 6024:2012 - Numeração de seções

- NBR 6027:2012 - Sumário

- $\quad$ NBR 6028:2003 - Resumo

- NBR 6032:1989 - Abreviação dos títulos de periódicos

- NBR 6034:2004 - Preparação de índice de publicações

- NBR 10520: 2002 - Citações

- NBR 10525:1988 - ISSN

- NBR 12225:2004 - Apresentação da lombada

Outra norma nacional bastante utilizada é a do IBGE (Instituto Brasileiro de Geografia e Estatística), padrão recomendado pela ABNT NBR 14724 para apresentação gráfica de tabelas e seus valores.

Alguns exemplos de normas internacionais:

- APA - American Psychological Association

- ISO - International Organization for Standardization

- ICMJE - International Committee of Medical Journal Editors "Vancouver Style"

- Harvard Law Review Association - "The Bluebook" 
A descrição é o elemento-chave da organização da informação, além de ser fundamental na recuperação da mesma. 0 produto dessa descrição é a individualização de um item e a correta identificação das suas propriedades e características. Sem a descrição e, consequentemente, sem a identificação única de um item de informação, não é possível realizar boas referenciações e, consequentemente, análises bibliométricas (CAFÉ; BRÄSCHER, 2008).

Ao observar por um panorama mais ampliado, percebe-se que a normalização perpassa todos os aspectos da gestão editorial, podendo inclusive, fornecer indicadores relevantes acerca do cuidado, transparência, boas práticas e qualidade na gestão de procedimentos e processos editoriais (SANTOS, 2017).

A fim de minimizar os erros de normalização, o SciELO tem recomendado fortemente a publicação de artigos em formato XML (eXtensible Markup Language, ou Linguagem de Marcação Extendida) é uma metalinguagem de marcação recomendada pela W3C, criada para ser auto-descritiva, transportar e armazenar dados, com foco no conteúdo. Sua utilização permite identificar claramente os elementos bibliográficos que compõe o documento, verificar a estrutura e coerência do artigo, e assegurar que cumpre com as especificações e normas (SANTOS, 2017). Este formato, ainda, garante maior flexibilidade, neutralidade e compatibilidade com sistemas ou formatos futuros, e tem a capacidade de preservação digital do conteúdo a longo prazo, facilitando a interoperabilidade entre distintos sistemas e bases da dados.

Não é bastante que esses padrões estejam definidos para atingir os objetivos de recuperação da informação e de geração de indicadores sobre a comunicação científica. É primordial e urgente que eles sejam empregados efetivamente nas fontes de informação, fazendo-se necessária a firme atuação, colaboração e sensibilização da comunidade científica para a correta aplicação da normalização em todas as instâncias da comunicação científica.

\subsection{Referências Bibliográficas}

A noção de continuidade é fundamental para a Ciência (GARVEY, 1979) e a literatura científica é derivativa, ou seja, cada trabalho é baseado em anteriores, tanto 
para embasamento, como para refutação. Inicialmente, as referências às obras de outrem eram inseridas no decorrer do texto, comumente de uma maneira desestruturada, bibliograficamente falando. Em seguida, as referências eram colocadas nas notas de rodapé e, depois, migraram para o final dos artigos (MEADOWS, 1999).

Referências bibliográficas são um "conjunto padronizado dos elementos descritivos, retirados de um documento, que permite sua identificação individual" (ABNT, 2002a, p. 2), ou seja, são os elementos que permitem o acesso à informação e ao seu conteúdo, e os erros existentes na sua elaboração dificultam a legibilidade no processo de comunicação científica. (CORREIA, 2010). Para Curty e Boccato (2005):

A elaboração de um texto de forma bem estruturada, com suas citações e referências seguindo regras estabelecidas por uma norma, confere a ele um caráter de cientificidade e confiabilidade, fundamental para a seriedade do trabalho proposto. (CURTY; BOCCATO, 2005, p. 95).

Segundo Figueiredo e Cunha (1967, p. 16), o trabalho bibliográfico possui quatro etapas: pesquisa, transcrição, descrição e arranjo dos documentos. As referências bibliográficas inserem-se nos níveis da transcrição e da descrição, pois elas informam os dados, através dos elementos descritivos, o que permite a identificação dos documentos, no todo ou em parte.

Quando a localização e identificação de uma referência é realizada de forma correta e coerente na a etapa de construção do ciclo informacional possibilita a eficiência do processo de comunicação e uso desta informação (CORREIA, 2010), porque as referências bibliográficas são o ponto de partida para a localização da informação. A referência bibliográfica mal elaborada acarreta sérios prejuízos a quem precisa da informação; sem uma identificação correta não é possível encontrá-la

Correia (2010), ao discorrer sobre as referências bibliográficas, conclui que os qualitativos observados pela academia são:

1) Localização e recuperação da informação, através da correta referenciação;

2) Representação do conhecimento através da informação em um tipo de suporte informacional;

3) Compartilhamento da informação; 
4) Parâmetro para a avaliação da qualidade dos trabalhos científicos;

5) Elemento importante para a sociedade da informação (capital intelectual);

6) Elemento essencial para a constituição do trabalho científico (embasamento teórico);

7) Elemento que garante a preservação dos direitos autorais dos trabalhos científicos.

Como ressalta Mugnaini (2006),

o uso de referências bibliográficas para análises bibliométricas impõe a transformação de dados bibliográficos em dados bibliométricos. Dessa forma, a padronização da informação é uma exigência, já que se deve garantir a homogeneidade das informações a serem compatibilizadas [...] as referências bibliográficas dos artigos são estruturadas, permitindo a identificação de uma citação de um título de revista, cuja grafia é armazenada na forma como foi escrita pelo autor, exigindo, por conseguinte, um trabalho de padronização a fim de evitar perda de dados, já que uma revista tem uma citação a seu favor na medida em que a escrita de seu título é perfeitamente reconhecida (MUGNAINI, 2006, p. 100-101).

Um dado interessante relatado em seu estudo mostra que, após a padronização do título, determinada revista que ocupava a primeira posição no ranking passou a ocupar o sexto lugar. Além disso, o autor analisa estes e outros aspectos resultantes do processo de indexação de diferentes bases (SciELO e Web of Science) que repercutem diretamente nos indicadores bibliométricos do periódico, e consequentemente em classificações da comunidade científica, como já se mencionou em relação ao Qualis (MUGNAINI; EFRAINGARCÍA, 2009).

Um recurso que vem sendo utilizado e encorajado pela comunidade científica é o DOI (Digital Object Identifier), código identificador único, baseado na norma ISO 26324, aplicado a objetos que se encontrem disponíveis via web. Outros Sistemas de identificadores persistentes mais conhecidos:

- Identificadores de Autoria

○ Researcher ID 
○ Scopus ID

○ ORCID-Open Researcher and Contributor ID

- Identificadores de Instituições

○ ISNI -International Standard Name Identifier

- Identificadores de Fomento

- CrossRef Funding Data

A normalização de referências se mostra tão fundamental no fluxo da comunicação científica, que algumas bases de dados estão criando guias próprios para auxiliar na construção e identificação dos dados de uma referência, a exemplo da PMC Citation Tagging, da Pubmed.

Tal problemática circunda claramente os objetivos desta pesquisa, e aponta para aspectos essenciais sobre a citação, os indicadores dela derivados, e finalmente, as fontes que os viabilizam.

\subsection{Citações}

Entende-se por citação em documentos a menção, no texto, de uma informação extraída de outra fonte, para esclarecimento do assunto em discussão ou para ilustrar ou sustentar o que se afirma (ABNT, 2002b).

De acordo com Sayão (1996, p. 314), ao buscar informações para fundamentar sua pesquisa, o cientista “[...] está querendo validar as suas dúvidas, traduzindo-as por questões autenticadas por seus pares, por questões presentes na memória coletiva de sua tribo". Logo, percebe-se que uma das etapas fundamentais da pesquisa científica remete à memória coletiva comum da área e aos seus antecessores.

Para Meadows (1999), uma das maneiras de avaliar a qualidade de uma publicação é aferir o grau de interesse de outros pesquisadores pela pesquisa, que pode ser realizado através da análise das citações, ou seja, examinar a quantidade de citações de uma pesquisa na bibliografia sequente. É o caso do Fator de Impacto, divulgado anualmente pelo Journal Citation Reports (JCR), que "mede para os periódicos 
selecionados a relação entre as citações recebidas no ano e o número de artigos publicados nos dois anos anteriores" (PACKER; MENEGHINI, 2006, p. 247).

Segundo Foresti (1989), as referências, ou citações, “[...] evidenciam elos entre os indivíduos, instituições e áreas de pesquisa porque mostram a relação de uma publicação com outra" (FORESTI, 1989, p. 3). Por isso, a análise de citação examina os vínculos entre os documentos citantes e os citados.

Araújo (2009) apresenta oito categorias a partir da adaptação de diferentes categorizações aplicando-as à Ciência da Informação, distribuídas da seguinte forma:

- Citação conceitual: traz a definição de algum conceito trabalhado no artigo;

- Citação metodológica: apresenta os passos ou procedimentos para a execução de alguma atividade ou pesquisa;

- Citação exemplificativa: traz outros casos, realidades ou estudos para demonstrar algum ponto ou questão;

- Citação confirmativa: dá suporte e/ou legitimidade a alguma ideia ou afirmação;

- Citação negativa/crítica: utilizada para contrapor alguma ideia ou afirmação;

- Citação de sustentação: usada para embasar ou dar suporte a alguma ideia, com dados ou outras ideias;

- Citação panorâmica/de revisão: objetiva dar um panorama de quem mais estudou determinada questão;

- Citação orgânica/de compreensão: necessária para a compreensão do que está sendo afirmado.

A prática de citação de artigos científicos é influenciada por uma série de fatores, não sendo possível o estabelecimento de uma relação direta e irrefutável entre citações e mérito científico. De fato, estudos indicam que nem sempre o artigo mais citado de um autor representa seu melhor trabalho, em sua própria opinião (NASSI-CALÒ, 2016). 


\subsubsection{Análises de citações}

Para Merton (1979), muitos estudos fazem uso das citações, pois são consideradas como principal fonte de informação a respeito do desempenho de pesquisadores.

A análise de citações permite a identificação e descrição de vários padrões na produção do conhecimento científico, como: autores mais citados, mais produtivos, fator de impacto dos periódicos, proveniência geográfica, origem institucional dos autores mais prestigiados em certo campo de pesquisa, tipo de documento mais utilizado, obsolescência da literatura, periódicos mais citados, entre outras finalidades (ARAÚJO, 2006).

Muitas vezes, alguns dados sobre citações em bases de dados são incorretos, devido, de acordo com Pinto e Andrade (1999), aos seguintes fatores (exemplificados na figura 3):

- nome do autor estar errado;

- nome do periódico ter sido abreviado ou escrito de maneira incorreta;

- erro no número do volume do periódico;

- erro no número da página do periódico;

- erro no ano de publicação do periódico;

- autores citados fora da ordem.

\begin{tabular}{lclllll}
\hline \multicolumn{1}{c}{ causa } & N Cit. & \multicolumn{1}{c}{ Autor } & \multicolumn{1}{c}{ Perídico } & volume & página & ano \\
\hline O nome do autor esta grafado errado. & 01 & AARSAMA TJ & J AM CHEM SOC & 104 & 6278 & 1982 \\
& 19 & AARTSMA TJ & J AM CHEM SOC & 104 & 6278 & 1982 \\
\hline O nome da revista foi abreviado & 01 & HOFFMAN MR & ENV SCI TECHNOL & 29 & 1215 & 1995 \\
ou escrito de maneira incorreta. & 03 & HOFFMAN MR & ENVIRON SCI TECHNOL & 29 & 1215 & 1995 \\
\hline Erro no número do volume da revista & 67 & MARCUS RA & ANGEW CHEM INT EDIT & 32 & 1111 & 1993 \\
& 01 & MARCUS RA & ANGEW CHEM INT EDIT & 30 & 1111 & 1993 \\
\hline Erro no número da página da revista & 42 & CHANDY KM & ACM T PROG LANG SYS & 06 & 6232 & 1986 \\
& 01 & CHANDY KM & ACM T PROG LANG SYS & 06 & 632 & 1986 \\
\hline Erro no ano de publicaçào da revista & 18 & HOPFIELD JJ & IEEE T CIRCUITS SYST & 33 & 533 & 1986 \\
& 01 & HOPFIELD JJ & IEEE T CIRCUITS SYST & 33 & 533 & 1988 \\
\hline Autores citados fora da ordem & 40 & ..BUCHWALD SL & J AM CHEM SOC & 116 & 8952 & 1994 \\
& 01 & BUCHWALD SL & J AM CHEM SOC & 116 & 8952 & 1994 \\
\hline
\end{tabular}

Figura 3 - Erros mais comuns em referências

Fonte: (PINTO; ANDRADE, 1999) 
Outra razão para erros nas citações e referências é que estas são, muitas vezes, apenas copiadas de um artigo, a partir da lista de referências, para outro. Muitas destas referências não foram lidas pelos autores citantes, de acordo com uma análise de como erros de citações se propagam através da literatura. Simkin e Roychowdhury (2005), ao analisarem 4.300 citações a um mesmo artigo de 1973, identificaram erros idênticos e concluíram que quase $80 \%$ dos autores não havia lido o documento em questão antes de citá-lo.

A falta de consulta à fonte original, além de facilitar a propagação de ideias contrastantes, é um costume considerado, por alguns, como uma espécie de má conduta, má prática de pesquisa e uma questão de negligência (BALL, 2002).

Ghai, Saxena e Makkar (2007) consideram potencialmente mais prejudiciais os erros em que o nome de um periódico é substituído por outro. De acordo com os autores, número de erros encontrados é inversamente relacionado à diligência do autor e ao tempo gasto por ele na correção da bibliografia.

Outro argumento que justifica os erros de citação diz respeito à familiaridade do idioma e do tamanho das sequências de nome, que influenciam na exatidão da digitação. Kotiaho, Tomkins e Simmons (1999) pediram a 36 alunos de graduação em zoologia para digitar sequências de nomes em inglês e em finlandês. Todos os indivíduos eram falantes nativos de inglês com nenhum conhecimento de finlandês. A taxa de erro em nomes desconhecidos foi significativamente maior que a taxa de erro nos nomes conhecidos.

Café e Bräscher (2008) analisaram 59 teses e dissertações que discorriam sobre bibliometria, quanto à existência de dificuldades relativas à ausência de padronização na descrição bibliográfica. Destas, 30 apontaram algum tipo de problema quanto à descrição física ou de conteúdo das fontes utilizadas para coleta de dados.

Rostaing (1996, p. 28) aponta as seguintes questões relacionadas ao tema:

a) Quanto à avaliação de revistas, o maior problema relaciona-se ao uso de uma diversidade de abreviações no título;

b) Quanto à avaliação de pesquisadores (apud MCROBERTS, 1989):

- somente o primeiro autor do artigo citado é considerado;

- risco de homonimía;

- risco de auto-citação; 
- erros ortográficos.

Raja e Cooper (2006) afirmam que os erros de citação refletem mal os autores e o periódico, além da possiblidade de repercutir falhas subjacentes em outras áreas da pesquisa publicada. Ao analisarem todas as referências (2724, de 254 artigos) citadas no Emergency Medical Journal (EMJ), principal revista médica de emergência no Reino Unido, encontraram erros em 19\% das citações e, em 8\% dos casos, os erros foram importantes e diminuíram acentuadamente a qualidade da referência. Ao verificar os artigos de periódicos incorretos ( $\mathrm{n}=404)$, quatro artigos estavam tão mal incorretos que não puderam ser encontrados, apesar da extensa pesquisa. Uma referência não foi citada no texto. As 399 referências de artigos de periódicos restantes foram divididas com base nos seis elementos bibliográficos, e 83 artigos continham erros em dois ou mais elementos. Então, chegaram aos seguintes exemplos principais de referência de baixa qualidade: citação tão ruim que achar a referência muito difícil ou impossível, referência não citada no texto, primeiro autor marcadamente errado ou omitido da referência, título do periódico escrito errado, erros em quatro (ou mais) dos seis elementos bibliográficos, capítulos de livros referenciados sem números de página ou autores.

Mugnaini (2006), apoiando-se na opinião de diversos autores, chama a atenção para o fato de, especialmente no Brasil, muitos estudos se restringirem aos dados fornecidos pelo ISI (Information Sciences Institute) em função de "grande parte do esforço de realização das análises bibliométricas centrar-se na padronização dos dados, quase sempre obtidos de bases de dados bibliográficas onde a falta de uniformidade é extrema".

Analisando as citações realizadas entre 6 periódicos de Enfermagem indexados na SciELO e na WoS, Paula e Mugnaini (2016), chegaram ao resultado de que 65\% não seguia o padrão estabelecido pelas bases na grafia do título do periódico na referência bibliográfica, sugerindo que não passaram por normalização. Os autores consideram esta porcentagem alta, ainda mais porque todos os periódicos têm suas instruções bem claras e possuem bibliotecários na equipe editorial.

Digiampietri e Mugnaini (2016) relatam um caso brasileiro similar: a abreviação "J PEDIAT" é utilizada tantos em citações ao Jornal de Pediatria (brasileiro) como ao Journal of Pediatrics (norte-americano). A ambiguidade pode ser desfeita ao se considerar 
ano e volume, caso as revistas que são citadas homonimamente tenham o ano inicial diferente.

O quadro abaixo permite diferenciar claramente que se trata de duas revistas. Como pode-se observar, praticamente todos os volumes da revista brasileira (Figura 4) são citados, formando assim uma reta contínua, o que não ocorre para a revista americana. Além disso, como a revista brasileira é indexada na SciELO, pode-se recorrer aos dados completos da revista para "casar" ano-volume citado com ano-volume dos dados fonte da mesma na base. Porém o mesmo não pode ser feito com a revista americana.

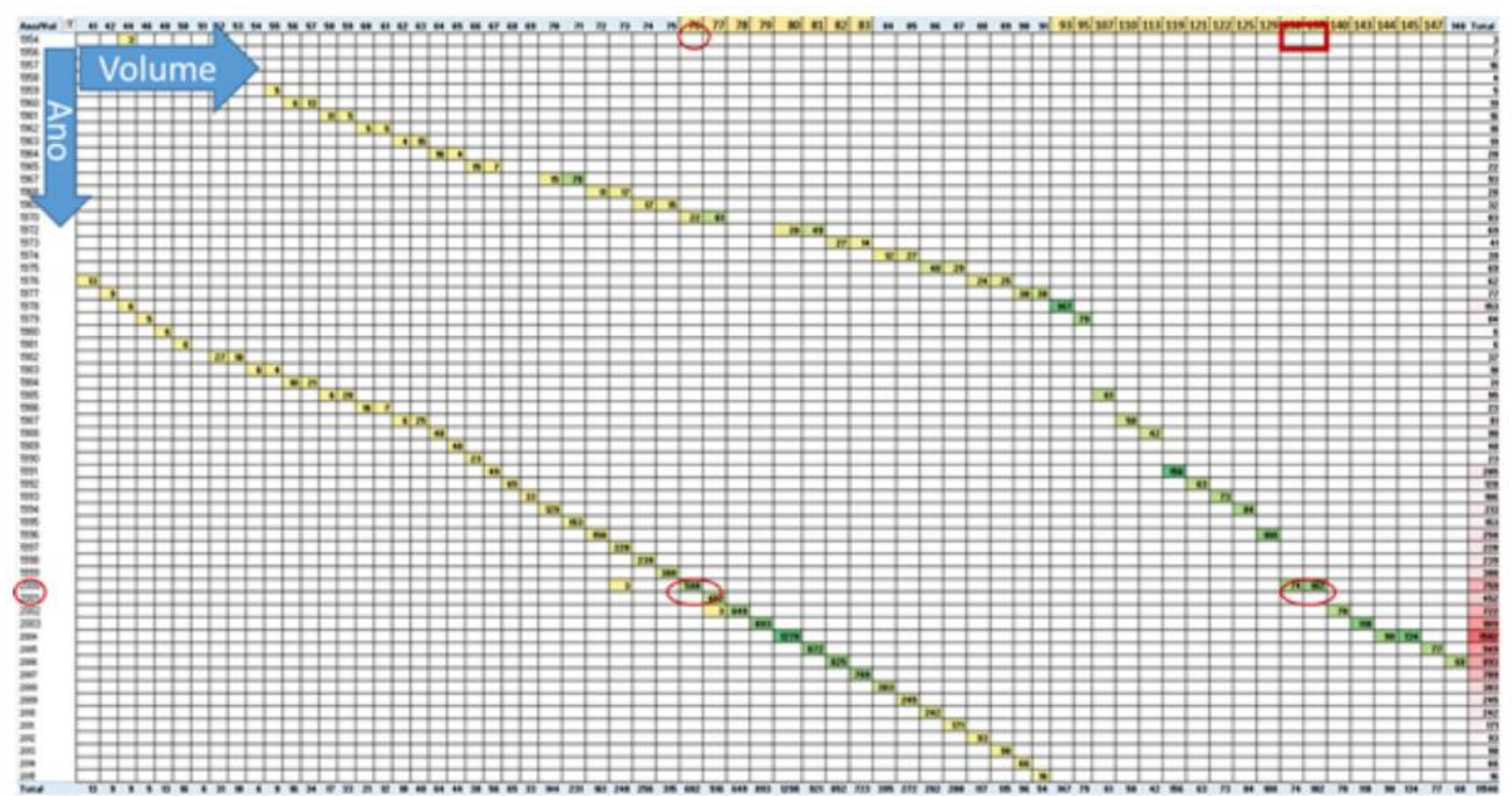

Figura 4 - Distribuição das citações à forma "J PEDIAT" em artigos da base SciELO segundo ano e volume citados

Fonte: (MUGNAINI, 2016²)

Para se entender a aplicação da correção, toma-se como exemplo dois títulos do SciELO Brasil que ambos foram corrigidos automaticamente, considerando-se o ano e volume citados. Na coleção brasileira do SciELO encontram-se Estudos de Psicologia (Campinas) - ISSN 0103-166X - e Estudos de Psicologia (Natal) - ISSN 1413-294X. Das 11.811 citações que a forma "ESTUDOS DE PSICOLOGIA" recebeu, a maioria diz respeito à revista de Natal (8.754 citações), e o restante (3.057) correspondente à campineira. Já a Gaceta Sanitária (SciELO Espanha, ISSN 0187-7496, citado 12.431 vezes), não existe outro título SciELO sendo confundido, porém existe um título mexicano homônimo (ISSN 0213- 
9111). A correção é então resolvida considerando ano e volume, ainda que o título mexicano não tenha sido citado pelos artigos brasileiros.

\subsection{Indicadores Bibliométricos}

Segundo Mugnaini (2006, p. 316), "para se entender a evolução da Ciência como forma de expressão do conhecimento humano produzido são utilizadas técnicas de medição", aplicadas em estudos métricos que são realizados para estabelecimento ou fortalecimento de indicadores que permitem traçar um perfil do mundo científico, tanto em âmbito nacional como internacional.

A bibliometria - conjunto de leis e princípios aplicados a métodos estatísticos e matemáticos que visam o mapeamento da produtividade científica de periódicos, autores e representação da informação (CAFÉ; BRÄSCHER, 2008; MUGNAINI, 2013), apresenta três leis básicas, lidam com levantamento e enumeração de documentos científicos que possuem propriedades similares. A grosso modo, elas podem ser resumidas da seguinte forma: a Lei de Bradford visa tomar conhecimento acerca do núcleo de periódicos produzidos em determinado tema. A Lei de Lotka objetiva indicar as maiores contribuições de pesquisadores em determinadas áreas do conhecimento e a Lei de Zipf pontua a frequência de aparecimento de certas palavras nos textos científicos, de maneira a estipular sua representatividade neste contexto.

Urbizagástegui-Alvorado (1984); Guedes e Borschiver (2005) e Araújo (2006) complementam alguns outros estudos e conceitos relacionados à bibliometria, dentre os quais vale destacar aqueles baseados na análise de citações: Teoria Epidêmica de Goffman; Frente de pesquisa e colégios invisíveis; obsolescência, vida média e idade da literatura; Fator de Impacto; acoplamento bibliográfico e cocitação; Lei de Pareto ou Princípio dos 80/20.

Os indicadores de citação são os de maior utilização e os mais discutidos da bibliometria. Na literatura, tornam-se foco dos trabalhos após 1990, muito provavelmente em consequência das bases de dados que disponibilizam esses dados (MUGNAINI, 2013). O que recebeu maior evidência foi o Fator de Impacto, criado em 1955 por Eugene Garfield, fundador do Information Sciences Institute - ISI, atual Thomson Reuters, com o objetivo de definir os periódicos mais lidos e citados que já figuravam nas 
bases bibliográficas disponibilizadas pelo ISI, e facilitar o acesso à bibliografia citada nos artigos.

Pouco depois, Price (1965) lançou o pressuposto de que, em determinada área científica, artigos de periódicos citados com maior frequência são também mais relevantes do que artigos menos citados.

O Fator de Impacto foi bastante aplicado por bibliotecas como um parâmetro de seleção para aquisição de periódicos e, atualmente, a maioria dos documentos de área do Qualis pauta-se nele para verificação da inclusão internacional dos periódicos. Examinando o conteúdo dos documentos de área do Qualis, Mugnaini e Sales (2011) averiguaram que 37 áreas de avaliação (80,4\% do total) se utilizam do Fator de Impacto.

O Fator de Impacto de um periódico é calculado pela divisão do número de citações a um dado artigo, publicado nos últimos dois anos, pelo total de artigos publicados no mesmo tempo. Somente os periódicos indexados no ISI são considerados para o cálculo do Fator de Impacto.

Apesar de ser o indicador mais utilizado, muitos autores enumeram limitações associadas a esse indicador. De acordo com Mugnaini (2006, 2013), o cálculo do Fator de Impacto numa determinada base cinge o desígnio desse indicador àquela população. Neste caso, a Thomson Reuters apresenta um quadro em que a predominância de periódicos americanos perfaz quase metade da base. Já autores como Sancho (1990); Moed (2002) e Saha, Saint e Christaki (2003), defendem que o Fator de Impacto reflete o impacto científico e a reputação dos periódicos, mas não qualidade.

Pinto e Andrade (1999) enumeram quatro aspectos a serem observados na aplicação do Fator de Impacto:

1. O número de periódicos é diferente em cada área do conhecimento; por isso, as áreas com mais periódicos têm probabilidade de serem mais citadas;

2. O número de referências por artigo também muda de área para área;

3. Algumas pesquisas são de caráter mais regional do que outras;

4. Artigos com erros conceituais ou de interpretação dos resultados são muitos citados por serem contestados cientificamente. 
O surgimento da internet e a digitalização das informações não suprimiram a atividade de transformação de informação bibliográfica em bibliométrica. A primeira, como no manuscrito do autor, com seus códigos, abreviações e erros; e a segunda, requer meticulosa padronização para preservação da qualidade da análise quantitativa (FARIA, 2001; MUGNAINI; JANNUZZI; QUONIAM, 2004). Padrões de organização da informação são essenciais em pesquisas bibliométricas para que documentos relevantes que possuam características similares possam ser recuperados e se atinja confiabilidade na análise dos dados, pois revelarão uma distribuição mais próxima da realidade e, consequentemente, a verificação adequada (CAFÉ; BRÄSCHER, 2008).

Este fato é confirmado por Glänzel e Moed (2002), quando mencionam alguns fatores que afetam o valor do Fator de Impacto, como por exemplo, a falta de normalização das práticas de referência; a não discriminação de artigos de revisão; a frequente utilização do Fator de Impacto isolado de seu contexto, etc.

A qualidade da normalização das citações e referências, além da descrição bibliográfica dos metadados, afeta diretamente a recuperação para efeito de pesquisa bibliométrica. Isto porque a Lei de Bradford utiliza a recuperação por título dos artigos e periódicos e a Lei de Lotka trabalha com a recuperação dos nomes de autores.

Muitas inciativas estão sendo criadas e ganhando a fim de auxiliar na normalização e persistência dos dados para avaliação, como exemplo do ORCID na desambiguação de pesquisadores, o Ringgold na normalização de instituições de pesquisa, e o FundRef na normalização de instituições de fomento à pesquisa.

Diversos países preocupam-se com a melhor avaliação das revistas nacionais não indexadas na WoS, sendo necessário um esforço de padronização de informações das referências bibliográficas para se poder realizar análise de citação. 0 desafio está em associar a referência bibliográfica de um artigo (citante) ao documento fonte (citado). Para isso informações da referência, como sobrenome do(s) autor(es), título da revista, volume e ano, precisarão haver sido escritos corretamente pelo autor citante, para que coincida com as informações do registro bibliográfico do artigo citado. Um estudo realizado sobre as citações recebidas na WoS por revistas croatas revelou que a informação com mais incidência de erro (37\%) foi o título da revista (ANDREIS; JOKIC, 2008). Este tipo de problema afeta diretamente o cálculo do Fator de Impacto do Journal Citation Reports, prejudicando a avaliação da revista, como ocorreu com duas revistas que 
tinham suas citações confundidas - Educational Research e Educational Researcher -, e que foram computadas em favor de uma delas (Educational Researcher) por quase 20 anos (LANGE, 2002).

Outro aspecto bastante considerado em análises bibliométricas é a obsolescência. Segundo Garfield (1998), os editores de periódicos têm reclamado que o período considerado para o cálculo do Fator de Impacto prejudica os títulos das áreas cujos avanços científicos são incorporados mais lentamente pela comunidade. Logo em seguida, Meadows (1999, p. 97), destaca que “[...] uma característica marcante de publicações importantes é não só o fato de serem altamente citadas, mas serem citadas durante um período de tempo mais longo do que outras publicações".

Ao estabelecer como deveria ser calculado o Fator de Impacto, Garfield (1972) observou que de 21 a 25\% das referências correspondem a trabalhos publicados nos três últimos anos. No entanto, esta proporção depende da área em que os trabalhos são publicados, pois cada área apresenta uma taxa diferenciada de obsolescência, definida por Sancho (1990) como a diminuição da informação no decorrer do tempo. Estas discrepâncias constituem objeto de exaustiva discussão no meio editorial.

\subsection{SciELO}

Por muito tempo, somente os dados sobrevindos das bases de dados do Institute of Scientific Informations (ISI) e dos indicadores do Journal Citation Reports (JCR), eram capazes de oferecer uma noção do impacto das publicações na comunidade científica. Atualmente, outras bases de dados têm surgido e disputado o espaço de produção de informações para medida de impacto das publicações científicas (MUGNAINI; STREHL, 2008), como é o caso do projeto SciELO (Scientific Electronic Library Online), iniciada em 1997, objetivando aumentar a difusão da produção científica nacional e criar mecanismos de avaliação complementares aos do ISI (MENEGHINI, 2003).

Um aspecto importante da metodologia SciELO é a aplicação de critérios de avaliação, tanto para ingresso quanto para permanência dos periódicos. A avaliação para a indexação ocorre em quatro etapas: (1) pré-etapa de escopo, pontualidade e duração; (2) avaliação de formato e endogenia; (3) avaliação de mérito científico; (4) avaliação 
pelos membros do comitê consultivo SciELO Brasil. Já os critérios para avaliação de desempenho para permanência são os seguintes: pontualidade de envio dos arquivos; indicador de uso do periódico; indicador de impacto; parecer do processo de exclusão de títulos; recursos; e readmissão (SANTOS, 2010).

No período de 2001 a fevereiro de 2010, mais de 1.400 pedidos de avaliação foram submetidos, resultando em índice médio de aprovação de 18,8\% (LAPIDO, 2009).

No Brasil, o projeto SciELO consolidou-se como marca de boa qualidade e rigor editorial. Em abril de 2007, uma investigação realizada por Ortellado (2008) demonstrou que entre as publicações brasileiras avaliadas como "Internacional A" pelo sistema Qualis da Capes, 58\% delas estavam no SciELO.

Além disso, o SciELO procura manter-se sempre atualizado às demandas da ciência global e se torna um grande incentivados de melhoria da qualidade dos periódicos brasileiros e latino-americanos. Com relação ao tema desta pesquisa, o SciELO tem discutido bastante sobre persistência e normalização de dados que alimentam o processo de avaliação dos artigos. De acordo com Mendonça (2017):

A persistência é essencial para assegurar que os dados ingressados no processo de avaliação sejam devidamente registrados e disponíveis ao final. Já a normalização é essencial para assegurar que os dados sigam padrões, sejam consistentes entre os diferentes artigos e periódicos de modo a assegurar a sua funcionalidade e interoperabilidade com os sistemas de informação. (MENDONÇA, 2017, s.p.).

O Módulo de Bibliometria SciELO foi o primeiro índice de citação do país, projetado inicialmente para oferecer indicadores semelhantes aos do JCR (MUGNAINI; EFRAIN-GARCÍA, 2009). Atualmente disponibiliza, em acesso aberto, indicadores de publicação, coleção e citação. Dentro dos indicadores de publicação, é possível verificar números da rede SciELO por ano de publicação, periódico, assunto ou país de afiliação do autor; país de afiliação do autor por ano de publicação, periódico, assunto ou país de publicação da revista; e número de co-autores por periódico e assunto. Já os indicadores da coleção apresentam os periódicos por ano de publicação, assunto e indicadores gerais. Os indicadores de citação podem ser apresentados por ano de citação por idade do documento citado ou tipo de documento citado; periódico citante por idade do documento citado ou tipo de documento citado; assunto do periódico citante por idade do documento 
citado, tipo de documento citado ou periódico SciELO citado; país de afiliação do autor citante por idade do documento citado, tipo de documento citado ou periódico SciELO citado.

Ao analisar todas as instâncias de avaliação dentro do fluxo da Comunicação Científica, é possível observar que tantos aspectos extrínsecos quanto os extrínsecos têm sua importância e um reflete no outro. Além disso, a normalização está presente em todas as etapas e pode ser determinante para conferir crédito, reconhecimento, gerar indicadores e auxiliar na continuidade e manutenção do fluxo de um conhecimento. 


\section{METODOLOGIA}

Esta pesquisa apresenta caráter descritivo, que de acordo com Gil (2002, p. 42) é a "[...] pesquisa que tem como objetivo primordial a descrição das características de determinada população ou fenômeno ou, então, o estabelecimento de relações entre variáveis", uma vez que descreve as características da normalização e suas relações com a análise quantitativa de citações.

Ao mesmo tempo também se caracteriza como uma pesquisa exploratória, definida por Severino (2007, p. 123) como aquela pesquisa que “[...] busca apenas levantar informações sobre um determinado objeto, delimitando assim um campo de trabalho, mapeando as condições de manifestação desse objeto". Esta modalidade de pesquisa foi definida por possibilitar um maior aprofundamento no tema a ser estudado.

É imprescindível buscar o subsídio teórico e, por isso, esta pesquisa também é bibliográfica, que se caracteriza por ser “[...] aquela que se realiza a partir do registro disponível, decorrente de pesquisas anteriores, em documentos impressos, como livros, artigos, teses" (SEVERINO, 2007, p. 122), entre outras fontes.

Para buscar uma melhor compreensão do problema que caracteriza a pesquisa, foram analisadas as citações feitas por 127 periódicos nacionais indexados na SciELO e WoS, realizadas no período de 2011 a 2015.

Todos os dados foram concedidos pela SciELO, e a coleta final foi realizada em junho de 2018. No entanto, testes foram realizados desde 2016, em colaboração no com um projeto FAPESP1 ${ }^{1}$, realizando-se, a cada nova correção, a conferência por ano e volume, conforme descrito anteriormente na seção "análise de citações". Estes dados foram organizados numa tabela Excel e os resultados foram gerados através da função tabela dinâmica do software.

Para verificar a normalização das citações feitas aos próprios periódicos da amostra, foram utilizadas as formas oficiais de grafia dos títulos registradas por diferentes bases de dados (SciELO e WoS). Com os dados disponíveis, serão analisadas as seguintes variáveis:

\footnotetext{
1 MUGNAINI, R. Avaliação de produção científica no Brasil: estudo da comunicação científica nas diversas áreas e desenvolvimento de infraestrutura institucional. 2016. Processo 12/00255-6. Disponível em: <http://www.bv.fapesp.br/pt/auxilios/48066/avaliacao-de-producao-cientifica-no-brasilestudo-da-comunicacao-cientifica-nas-diversas-areas-e-de/>. Acesso em: 5 Jun. 2017.
} 
- Quantidade de citações total;

- Quantidade de citação por ano citante;

- Quantidade de citações não reconhecidas pelo sistema indexador;

- Tipos de documentos citados (periódicos, livros, capítulos de livros, teses, anais e outros²);

- Citações dentro da janela de dois anos do cálculo do Fator de Impacto;

- Autocitação;

- Citações normalizadas;

- Índice de Price (porcentagem de referências com menos de 5 anos);

- Área do periódico.

Além destas, também foram consideradas as informações referentes ao sistema de citação utilizado, indicação de título abreviado, menção de presença de bibliotecário na equipe editorial, norma utilizada para elaboração de referências, determinação da idade ou quantidade de referências por artigo e recomendação de abreviação do título de periódicos foram colhidas nas páginas de cada periódico dentro do SciELO entre janeiro e junho de 2018.

Atualmente ${ }^{3}$, o SciELO Brasil possui 366 periódicos listados, classificados por área temática, dos quais 292 são correntes e 27 encontram-se classificados em mais de uma área. Dos 74 periódicos não-correntes, 34 tiveram a indexação interrompida, 38 mudaram de título e 2 terminaram (Tabela 1).

Tabela 1 - Quantidade de periódicos brasileiros indexados no SciELO por grande área - São Paulo - janeiro 2019

\begin{tabular}{lcc}
\hline \multicolumn{1}{c}{ Grande Área } & Correntes & Não-correntes \\
\hline Ciências Agrárias & 39 & 9 \\
Ciências Biológicas & 28 & 15 \\
Ciências da Saúde & 93 & 25 \\
Ciências Exatas e da Terra & 10 & 11 \\
Ciências Humanas & 87 & 12 \\
Ciências Sociais Aplicadas & 39 & 7 \\
Engenharias & 21 & 5 \\
Linguística, Letras e Artes & 15 & 1 \\
\hline
\end{tabular}

\footnotetext{
${ }^{2}$ Incluem todos os demais tipos de documentos não contemplados.

${ }^{3}$ Dados atualizados em 10/01/2019.
} 


\section{RESULTADOS}

A seguir, serão apresentados os resultados, primeiramente separados por Grande Área, que estão classificadas por ordem alfabética. Inicia-se com uma descrição dos periódicos da amostra, seguido da caracterização do perfil de citação, com base no total de referências de cada periódico, a fim de avaliar: (1) a importância dos tipos de documento em cada áreas, oferecendo assim uma estimativa da importância relativa do periódico para o processo de comunicação científica; (2) diferenciar as citações a periódicos, segundo indexação ou não no SciELO, e dentre os periódicos SciELO, se fazem parte da amostra em análise (ou seja, periódicos indexados também no SciELO). Procedeu-se ainda a análise das páginas do conjunto de periódicos de cada área, a fim de verificar a clareza das instruções aos autores no que diz respeito da apresentação das citações e à formulação das referências bibliográficas, além de observar a existência de profissionais bibliotecários ou revisores de referências no corpo editorial.

Na segunda parte do capítulo será apresentada uma comparação entre as áreas, a fim de examinar o percentual de citações às formas padronizadas de grafia do título dos periódicos, conforme proposto nos objetivos.

\subsection{Caracterização dos periódicos da amostra segundo área}

\subsubsection{Ciências Agrárias}

De acordo com a CAPES, a área de Ciências Agrárias se divide nas seguintes subáreas: Agronomia, Recursos Florestais e Engenharia Florestal, Engenharia Agrícola, Zootecnia, Recursos Pesqueiros e Engenharia de Pesca, Medicina Veterinária e Ciência e Tecnologia de Alimentos.

No SciELO, são 39 títulos correntes e 9 não-correntes, dos quais 26 foram indexados na WoS no período analisado, conforme segue:

1. Acta Scientiarum. Agronomy

2. Arquivo Brasileiro de Medicina Veterinária e Zootecnia 
3. Bragantia

4. Cerne

5. Ciência e Agrotecnologia

6. Ciência Florestal

7. Ciência Rural

8. Crop Breeding and Applied Biotechnology (também classificado como Ciências Biológicas)

9. Engenharia Agrícola

10. Food Science and Technology

11. Horticultura Brasileira

12. Journal of Seed Science

13. Pesquisa Agropecuária Brasileira

14. Pesquisa Veterinária Brasileira

15. Planta Daninha

16. Revista Árvore

17. Revista Brasileira de Ciência Avícola

18. Revista Brasileira de Ciência Do Solo

19. Revista Brasileira de Engenharia Agrícola e Ambiental

20. Revista Brasileira de Fruticultura

21. Revista Brasileira de Zootecnia

22. Revista Caatinga

23. Revista Ciência Agronômica

24. Scientia Agricola

25. Theoretical and Experimental Plant Physiology

26. Tropical Plant Pathology

Analisando a página de cada título no SciELO, tem-se:

- Todos os periódicos utilizam o sistema autor-data nas citações;

- 23 indicam o título abreviado;

- 5 mencionam a presença de bibliotecário no corpo editorial;

- 6 indicam a presença de revisores de normalização / referências, mas sem especificar se são bibliotecários; 
- 9 utilizam as normas da ABNT para elaboração de referências;

- 1 utiliza as normas da APA para elaboração de referências;

- 1 utiliza as normas Vancouver (ICMJE) para elaboração de referências;

- 14 não especificam a norma utilizada, mas dão exemplos;

- 1 não especifica a norma utilizada, e não dá exemplos;

- 9 determinam a idade das referências;

- 5 limitam a quantidade de referências por artigo;

- 8 determinam a porcentagem de referências de periódicos;

- 3 recomendam a não-abreviação dos títulos dos periódicos nas referências;

- 1 recomenda a abreviação dos títulos dos periódicos nas referências, com indicação do padrão a ser seguido.

De acordo com Santos (2015), a produção brasileira da área de Ciências Agrárias, é a 4⿳亠丷a em número de publicações no contexto brasileiro. No período de 2003 a 2012 apresentou um crescimento de $165 \%$ e seu índice de atividade (IA), neste mesmo período, foi o maior (4,16 - 316\% acima do padrão internacional da área) e, de acordo com a mesma autora, registra esforço de publicação acima da média mundial. Em relação ao contexto mundial, a produção brasileira em Ciências Agrárias ocupa o 2ํo lugar, perdendo somente para os Estados Unidos, na lista dos países que mais publicam nessa área (SANTOS, 2015). Conforme levantamento de 2014, realizado pela mesma autora, na base Essential Science Indicators, Ciências Agrárias ocupa a 6ª posição na produção nacional e, em nível mundial, é a 17ª área em número absoluto de citações recebidas.

Dos periódicos que indicam a norma para referências bibliográficas, a maioria indica ABNT e sugere-se a hipótese de que isso é devido ao aspecto regional e local desta área, o que acaba atraindo mais artigos nacionais.

Os periódicos de Ciências Agrárias citam, em sua maioria (72,23\%) artigos de periódicos, seguidos pelas citações a livros $(13,46 \%)$ e capítulos de livros $(4,98 \%)$. Ao longo dos anos, pode-se notar que a quantidade de referências a artigos de periódicos se mantém próximo aos 60 mil, apesar de pequenas variações, enquanto a livros diminui gradativamente e tem uma pequena elevação em 2015. Quantos às citações a capítulos de livros, teses e anais, apresentam tendência de diminuição (Tabela 2). 
Tabela 2 - Citações da área de Ciências Agrárias por tipo de documento e por ano

\begin{tabular}{crcccccc} 
& & $\mathbf{2 0 1 1}$ & $\mathbf{2 0 1 2}$ & $\mathbf{2 0 1 3}$ & $\mathbf{2 0 1 4}$ & $\mathbf{2 0 1 5}$ & $\begin{array}{c}\text { Total } \\
\text { Geral }\end{array}$ \\
\hline \multirow{2}{*}{ Periódicos } & citações & 64.513 & 59.239 & 61.304 & 58.540 & 55.542 & $\mathbf{2 9 9 . 1 3 8}$ \\
& $\%$ & 69,36 & 70,48 & 72,88 & 73,97 & 75,25 & 72,23 \\
Livros & citações & 13.388 & 11.625 & 10.789 & 9.894 & 10.054 & $\mathbf{5 5 . 7 5 0}$ \\
& $\%$ & 14,39 & 13,83 & 12,83 & 12,50 & 13,62 & 13,46 \\
Cap. Livros & citações & 5.274 & 4.472 & 4.307 & 3.778 & 2.796 & $\mathbf{2 0 . 6 2 7}$ \\
& $\%$ & 5,67 & 5,32 & 5,12 & 4,77 & 3,79 & 4,98 \\
Outros & citações & 4.120 & 3.804 & 3.696 & 3.881 & 3.436 & $\mathbf{1 8 . 9 3 7}$ \\
& $\%$ & 4,43 & 4,53 & 4,39 & 4,90 & 4,66 & 4,57 \\
Teses & citações & 2.649 & 2.549 & 2.156 & 1.532 & 1.085 & $\mathbf{9 . 9 7 1}$ \\
& $\%$ & 2,85 & 3,03 & 2,56 & 1,94 & 1,47 & 2,41 \\
\multirow{2}{*}{ Anais } & citações & 3.066 & 2.362 & 1.861 & 1.514 & 899 & $\mathbf{9 . 7 0 2}$ \\
& $\%$ & 3,30 & 2,81 & 2,21 & 1,91 & 1,22 & 2,34 \\
\multirow{2}{*}{ Total } & citações & $\mathbf{9 3 . 0 1 0}$ & $\mathbf{8 4 . 0 5 1}$ & $\mathbf{8 4 . 1 1 3}$ & $\mathbf{7 9 . 1 3 9}$ & $\mathbf{7 3 . 8 1 2}$ & $\mathbf{4 1 4 . 1 2 5}$ \\
& $\%$ & $\mathbf{1 0 0}$ & $\mathbf{1 0 0}$ & $\mathbf{1 0 0}$ & $\mathbf{1 0 0}$ & $\mathbf{1 0 0}$ & $\mathbf{1 0 0}$ \\
\hline
\end{tabular}

Fazendo uso do índice de Price, que é a porcentagem de referências com até 5 anos (Tabela 3), observa-se uma média de utilização de 38\% de referências mais atuais, sendo que os documentos classificados como 'outros' estão, quase em sua totalidade, dentro desta janela de citação. Na área de Ciências Agrárias nota-se que as referências mais atuais são aquelas às teses $(36,96 \%)$, seguidas pelas citações a periódicos $(31,16 \%)$ e anais $(27,78 \%)$. Vale ressaltar que, na análise das instruções aos autores, 9 periódicos (34\%) indicam a idade das referências a serem utilizadas pelos autores.

Tabela 3 - Citações da área de Ciências Agrárias com até 5 anos (índice de Price)

\begin{tabular}{|c|c|c|c|c|c|c|c|}
\hline & & & & & & & \\
\hline & & 2011 & 2012 & 2013 & 2014 & 2015 & $\begin{array}{l}\text { Total } \\
\text { Geral }\end{array}$ \\
\hline \multirow{2}{*}{ Periódicos } & citações & 19.957 & 18.894 & 19.093 & 18.163 & 17.100 & 93.207 \\
\hline & $\%$ & 30,93 & 31,89 & 31,14 & 31,03 & 30,79 & 31,16 \\
\hline \multirow{2}{*}{ Outros } & citações & 4.120 & 3.804 & 3.696 & 3.865 & 3.411 & 18.896 \\
\hline & $\%$ & 100 & 100 & 100 & 99,59 & 99,27 & 99,78 \\
\hline \multirow{2}{*}{ Livros } & citações & 2.385 & 1.839 & 1.752 & 1.660 & 1.614 & 9.250 \\
\hline & $\%$ & 17,81 & 15,82 & 16,24 & 16,78 & 16,05 & 16,59 \\
\hline \multirow{2}{*}{ Teses } & citações & 1.005 & 959 & 860 & 533 & 328 & 3.685 \\
\hline & $\%$ & 37,94 & 37,62 & 39,89 & 34,79 & 30,23 & 36,96 \\
\hline \multirow{2}{*}{ Cap. Livros } & citações & 1.020 & 900 & 709 & 543 & 349 & 3.521 \\
\hline & $\%$ & 19,34 & 20,13 & 16,46 & 14,37 & 12,48 & 17,07 \\
\hline \multirow{2}{*}{ Anais } & citações & 900 & 673 & 513 & 398 & 211 & 2.695 \\
\hline & $\%$ & 29,35 & 28,49 & 27,57 & 26,29 & 23,47 & 27,78 \\
\hline \multicolumn{2}{|c|}{ Total Geral } & 29.387 & 27.069 & 26.623 & 25.162 & 23.013 & 131.254 \\
\hline
\end{tabular}


Na tabela 4, é possível verificar que a maioria das citações a periódicos é realizada a títulos que não estão indexados no SciELO - no entanto, deve-se atentar para o fato de que dentre estes estão importantes títulos estrangeiros, indexados na WoS, além de periódicos não indexados em bases de dados, que podem ser brasileiros ou não -, correspondendo a uma média de $81 \%$ das citações, e esta porcentagem se mantém ao longo do período analisado. Em seguida, estão as citações aos periódicos da amostra $(16,56 \%)$ e, com menor frequência, citações aos periódicos que estão no SciELO, mas não na $\operatorname{WoS}(2,34 \%)$.

É importante destacar que os diferentes níveis percentuais devem ser interpretados com cautela, uma vez que: o maior percentual (81\%) diz respeito a um grande número de periódicos, que podem ser do mundo todo, indexados ou não; em seguida, os 16,56\% são correspondentes aos principais periódicos SciELO, que são os mais antigos, e aqueles que já tem uma visibilidade internacional, reconhecida pela indexação na WoS; e os demais, são periódicos SciELO mais novos, indexados mais recentemente, e que podem não ter sido indexados na WoS por uma questão de tempo, ou por não apresentar característica de internacionalização.

Tabela 4 - Citações a periódicos, por ano, da área de Ciências Agrárias

\begin{tabular}{crcccccc} 
& & $\mathbf{2 0 1 1}$ & $\mathbf{2 0 1 2}$ & $\mathbf{2 0 1 3}$ & $\mathbf{2 0 1 4}$ & $\mathbf{2 0 1 5}$ & $\begin{array}{c}\text { Total } \\
\text { Geral }\end{array}$ \\
\hline Não-SciELO e & citações & 74.647 & 67.785 & 68.626 & 64.057 & 60.748 & $\mathbf{3 3 5 . 8 6 3}$ \\
não-amostra & $\%$ & 80,26 & 80,65 & 81,59 & 80,94 & 82,30 & $\mathbf{8 1 , 1 0}$ \\
SciELO e & citações & 16.448 & 14.417 & 13.354 & 13.086 & 11.282 & $\mathbf{6 8 . 5 8 7}$ \\
amostra & $\%$ & 17,68 & 17,15 & 15,88 & 16,54 & 15,28 & $\mathbf{1 6 , 5 6}$ \\
SciELO e & citações & 1.915 & 1.849 & 2.133 & 1.996 & 1.782 & $\mathbf{9 . 6 7 5}$ \\
não-amosta & $\%$ & 2,06 & 2,20 & 2,54 & 2,52 & 2,41 & 2,34 \\
& citações & $\mathbf{9 3 . 0 1 0}$ & $\mathbf{8 4 . 0 5 1}$ & $\mathbf{8 4 . 1 1 3}$ & $\mathbf{7 9 . 1 3 9}$ & $\mathbf{7 3 . 8 1 2}$ & $\mathbf{4 1 4 . 1 2 5}$ \\
Total & $\%$ & $\mathbf{1 0 0}$ & $\mathbf{1 0 0}$ & $\mathbf{1 0 0}$ & $\mathbf{1 0 0}$ & $\mathbf{1 0 0}$ & $\mathbf{1 0 0}$ \\
\hline
\end{tabular}

\subsubsection{Ciências Biológicas}

De acordo com a CAPES, a área de Ciências Biológicas se divide nas seguintes subáreas: Biologia Geral, Genética, Morfologia, Fisiologia, Bioquímica, Biofísica, Farmacologia, Imunologia, Microbiologia, Parasitologia, Ecologia, Oceanografia, Botânica e Zoologia. 
No SciELO, são 28 títulos correntes e 15 não-correntes, dos quais 17 foram indexados na WoS no período analisado, conforme segue:

1. Acta Botânica Brasilica

2. Biota Neotropica

3. Brazilian Journal of Biology

4. Brazilian Journal of Botany (indexação interrompida no SciELO em 2012)

5. Brazilian Journal of Infectious Diseases (também classificado como Ciências da Saúde)

6. Brazilian Journal of Medical and Biological Research (também classificado como Ciências da Saúde)

7. Brazilian Journal of Microbiology

8. Crop Breeding and Applied Biotechnology (também classificado como Ciências Agrárias)

9. Genetics and Molecular Biology

10. Iheringia. Série Zoologia

11. Memórias do Instituto Oswaldo Cruz (também classificado como Ciências da Saúde)

12. Neotropical Entomology (indexação interrompida no SciELO em 06/2012)

13. Neotropical Ichthyology

14. Revista Brasileira de Entomologia

15. Revista Brasileira de Parasitologia Veterinária

16. Revista do Instituto de Medicina Tropical de São Paulo (também classificado como Ciências da Saúde)

17. Zoologia (Curitiba)

Analisando a página de cada título no SciELO, tem-se:

- 14 utilizam o sistema autor-data nas citações;

- 3 utilizam o sistema numérico nas citações

- 16 indicam o título abreviado;

- 2 mencionam a presença de bibliotecário no corpo editorial; 
- 1 utiliza as normas da ISO 690/2010 para elaboração de referências;

- 4 utilizam as normas Vancouver (ICMJE) para elaboração de referências;

- 12 não especificam a norma utilizada, mas dão exemplos;

- 2 limitam a quantidade de referências por artigo;

- 6 recomendam a abreviação dos títulos dos periódicos nas referências, com indicação do padrão a ser seguido.

A Área de Ciências Biológicas, no contexto brasileiro, é uma das mais sólidas e com resultados de forte impacto social, cultural e econômico (SCHWARTZMAN, 2001). É tradicionalmente ligada ao contexto internacional, uma vez que seus temas não estão, necessariamente, circunscritos a um espaço geográfico, cultural e histórico (SANTOS, 2003; SANTIN, VANZ; STUMPF, 2015). Além disso, a ausência de títulos brasileiros na área de Ciências Biológicas no estrato A1 do Qualis é um indicativo da valorização da internacionalização da produção científica na área (NEUBERT; RODRIGUES; MÜLLER, 2017).

Os periódicos de Ciências Biológicas citam, em sua maioria (83,43\%) artigos de periódicos, seguidos pelas citações a livros (7,51\%) e capítulos de livros (4,62\%). As citações a periódicos apresentaram uma elevação ao equilibrada entre 2011 e 2014 e teve uma queda em 2015. Já as citações a livros apresentam um comportamento contrário, diminuindo entre 2011 a 2014 e com uma elevação em 2015. As citações a capítulos de livros se mantêm com pouca alteração ao longo do período analisado (Tabela 5).

Fazendo uso do índice de Price (Tabela 6), observa-se uma média de utilização de $37 \%$ de referências mais atuais, sendo que os documentos não-identificados estão, quase em sua totalidade, dentro desta janela de citação. Na área de Ciências Biológicas nota-se que as referências mais atuais são aquelas às teses (32,12\%), seguidas pelas citações a periódicos (30,05\%) e anais $(27,96 \%)$. É possível observar, ainda, que ao longo dos anos, a utilização de referências de até 5 anos, no geral, diminui, com exceção dos anais, que teve uma pequena elevação em 2015. 
Tabela 5 - Citações da área de Ciências Biológicas por tipo de documento e por ano

\begin{tabular}{lrcccccc} 
& & $\mathbf{2 0 1 1}$ & $\mathbf{2 0 1 2}$ & $\mathbf{2 0 1 3}$ & $\mathbf{2 0 1 4}$ & $\mathbf{2 0 1 5}$ & $\begin{array}{c}\text { Total } \\
\text { Geral }\end{array}$ \\
\cline { 3 - 8 } Periódicos & citações & 52.703 & 48.771 & 47.570 & 45.890 & 46.107 & $\mathbf{2 4 1 . 0 4 1}$ \\
& $\%$ & 80,21 & 82,94 & 84,48 & 86,00 & 84,24 & 83,43 \\
\multirow{2}{*}{ Livros } & citações & 5.678 & 4.433 & 3.755 & 3.507 & 4.317 & $\mathbf{2 1 . 6 9 0}$ \\
& $\%$ & 8,64 & 7,54 & 6,67 & 6,57 & 7,89 & 7,51 \\
Cap. Livros & citações & 3.583 & 2.725 & 2.647 & 2.171 & 2.224 & $\mathbf{1 3 . 3 5 0}$ \\
& $\%$ & 5,45 & 4,63 & 4,70 & 4,07 & 4,06 & 4,62 \\
\multirow{2}{*}{ Outros } & citações & 2.320 & 2.012 & 1.935 & 1.557 & 1.593 & $\mathbf{9 . 4 1 7}$ \\
& $\%$ & 3,53 & 3,42 & 3,44 & 2,92 & 2,91 & 3,26 \\
Teses & citações & 974 & 583 & 236 & 145 & 285 & $\mathbf{2 . 2 2 3}$ \\
& $\%$ & 1,48 & 0,99 & 0,42 & 0,27 & 0,52 & $\mathbf{0 , 7 7}$ \\
\multirow{2}{*}{ Anais } & citações & 451 & 276 & 164 & 93 & 207 & $\mathbf{1 . 1 9 1}$ \\
& $\%$ & 0,69 & 0,47 & 0,29 & 0,17 & 0,38 & $\mathbf{0 , 4 1}$ \\
\multirow{2}{*}{ Total } & Citações & $\mathbf{6 5 . 7 0 9}$ & $\mathbf{5 8 . 8 0 0}$ & $\mathbf{5 6 . 3 0 7}$ & $\mathbf{5 3 . 3 6 3}$ & $\mathbf{5 4 . 7 3 3}$ & $\mathbf{2 8 8 . 9 1 2}$ \\
& $\%$ & $\mathbf{1 0 0}$ & $\mathbf{1 0 0}$ & $\mathbf{1 0 0}$ & $\mathbf{1 0 0}$ & $\mathbf{1 0 0}$ & $\mathbf{1 0 0}$ \\
\hline
\end{tabular}

Tabela 6 - Citações da área de Ciências Biológicas com até 5 anos (índice de Price)

\begin{tabular}{|c|c|c|c|c|c|c|c|}
\hline & & & & & & & \\
\hline & & 2011 & 2012 & 2013 & 2014 & 2015 & $\begin{array}{l}\text { Total } \\
\text { Geral }\end{array}$ \\
\hline \multirow{2}{*}{ Periódicos } & citações & 16.081 & 15.466 & 13.767 & 13.645 & 13.477 & 72.436 \\
\hline & $\%$ & 30,51 & 31,71 & 28,94 & 29,73 & 29,23 & 30,05 \\
\hline \multirow{2}{*}{ Outros } & citações & 2.320 & 2.012 & 1.930 & 1.556 & 1.588 & 9.406 \\
\hline & $\%$ & 100 & 100 & 99,74 & 99,94 & 99,69 & 99,88 \\
\hline \multirow{2}{*}{ Livros } & citações & 927 & 720 & 534 & 524 & 730 & 3.435 \\
\hline & $\%$ & 16,33 & 16,24 & 14,22 & 14,94 & 16,91 & 15,84 \\
\hline \multirow{2}{*}{ Cap. Livros } & citações & 708 & 550 & 484 & 407 & 276 & 2.425 \\
\hline & $\%$ & $19,76 \%$ & $20,18 \%$ & 18,28 & 18,75 & 12,41 & 18,16 \\
\hline \multirow{2}{*}{ Teses } & citações & 347 & 195 & 71 & 45 & 56 & 714 \\
\hline & $\%$ & 35,63 & 33,45 & 30,08 & 31,03 & 19,65 & 32,12 \\
\hline \multirow{2}{*}{ Anais } & citações & 124 & 82 & 46 & 24 & 57 & 333 \\
\hline & $\%$ & 27,49 & 29,71 & 28,05 & 25,81 & 27,54 & 27,96 \\
\hline \multicolumn{2}{|c|}{ Total Geral } & 20.507 & 19.025 & 16.832 & 16.201 & 16.184 & 88.749 \\
\hline
\end{tabular}

Na tabela 7, é possível verificar que a maioria das citações a periódicos é realizada a títulos que não estão indexados no SciELO, correspondendo a uma média de $90 \%$ das citações, e esta porcentagem se mantém ao longo do período analisado. Em seguida, estão as citações aos periódicos da amostra $(8,17 \%)$ e, com menos frequência, citações aos periódicos que estão no SciELO, mas não na WoS (1,92\%). 
Tabela 7 - Citações a periódicos, por ano, da área de Ciências Biológicas

\begin{tabular}{crccccccc}
\cline { 3 - 8 } & & $\mathbf{2 0 1 1}$ & $\mathbf{2 0 1 2}$ & $\mathbf{2 0 1 3}$ & $\mathbf{2 0 1 4}$ & $\mathbf{2 0 1 5}$ & $\begin{array}{c}\text { Total } \\
\text { Geral }\end{array}$ \\
\hline Não-SciELO e & citações & 58.785 & 52.929 & 50.222 & 48.248 & 49.567 & $\mathbf{2 5 9 . 7 5 1}$ \\
não-amostra & $\%$ & 89,46 & 90,02 & 89,19 & 90,41 & 90,56 & 89,91 \\
SciELO e & citações & 5.589 & 4.776 & 4.945 & 4.150 & 4.153 & $\mathbf{2 3 . 6 1 3}$ \\
amostra & $\%$ & 8,51 & 8,12 & 8,78 & 7,78 & 7,59 & $\mathbf{8 , 1 7}$ \\
SciELO e & citações & 1.335 & 1.095 & 1.140 & 965 & 1.013 & $\mathbf{5 . 5 4 8}$ \\
não-amosta & $\%$ & 2,03 & 1,86 & 2,02 & 1,81 & 1,85 & $\mathbf{1 , 9 2}$ \\
& citações & $\mathbf{6 5 . 7 0 9}$ & $\mathbf{5 8 . 8 0 0}$ & $\mathbf{5 6 . 3 0 7}$ & $\mathbf{5 3 . 3 6 3}$ & $\mathbf{5 4 . 7 3 3}$ & $\mathbf{2 8 8 . 9 1 2}$ \\
Total & $\%$ & $\mathbf{1 0 0}$ & $\mathbf{1 0 0}$ & $\mathbf{1 0 0}$ & $\mathbf{1 0 0}$ & $\mathbf{1 0 0}$ & $\mathbf{1 0 0}$ \\
\hline
\end{tabular}

\subsubsection{Ciências da Saúde}

De acordo com a CAPES, a área de Ciências da Saúde se divide nas seguintes subáreas: Medicina, Nutrição, Odontologia, Farmácia, Enfermagem, Saúde Coletiva, Educação Física, Fonoaudiologia, Fisioterapia e Terapia Ocupacional.

No SciELO, são 93 títulos correntes e 25 não-correntes, dos quais 47 foram indexados na WoS no período analisado, conforme segue:

1. ABCD. Arquivos Brasileiros de Cirurgia Digestiva (São Paulo)

2. Acta Cirúrgica Brasileira

3. Acta Ortopédica Brasileira

4. Acta Paulista de Enfermagem

5. Anais Brasileiros de Dermatologia

6. Archives of Clinical Psychiatry (São Paulo)

7. Archives of Endocrinology and Metabolism

8. Arquivos Brasileiros de Cardiologia

9. Arquivos Brasileiros de Endocrinologia \& Metabologia (encerrada em 2014)

10. Arquivos Brasileiros de Oftalmologia

11. Arquivos de Neuro-Psiquiatria

12. Brazilian Journal of Cardiovascular Surgery

13. Brazilian Journal of Infectious Diseases (também classificado como Ciências Biológicas) 
14. Brazilian Journal of Medical and Biological Research (também classificado como Ciências Biológicas)

15. Brazilian Journal of Otorhinolaryngology

16. Brazilian Journal of Pharmaceutical Sciences

17. Brazilian Journal of Physical Therapy (indexação interrompida no SciELO em 06/2017)

18. Brazilian Oral Research

19. Cadernos de Saúde Publica

20. Ciência \& Saúde Coletiva

21. Clinics

22. Einstein (São Paulo)

23. História, Ciências, Saúde-Manguinhos

24. International Braz J Urol

25. Jornal Brasileiro de Pneumologia

26. Jornal de Pediatria

27. Journal of Applied Oral Science

28. Memorias do Instituto Oswaldo Cruz (também classificado como Ciências Biológicas)

29. Motriz: Revista de Educação Física

30. Revista Brasileira de Anestesiologia

31. Revista Brasileira de Enfermagem

32. Revista Brasileira de Farmacognosia

33. Revista Brasileira de Ginecologia e Obstetrícia

34. Revista Brasileira de Medicina do Esporte

35. Revista Brasileira de Oftalmologia

36. Revista Brasileira de Psiquiatria

37. Revista Brasileira de Reumatologia

38. Revista da Associação Médica Brasileira

39. Revista da Escola de Enfermagem Da USP

40. Revista da Sociedade Brasileira de Medicina Tropical

41. Revista de Nutrição

42. Revista de Saúde Pública 
43. Revista do Instituto de Medicina Tropical de São Paulo (também classificado como Ciências Biológicas)

44. Revista Latino-Americana de Enfermagem

45. São Paulo Medical Journal

46. Saúde e Sociedade

47. Texto \& Contexto - Enfermagem

Analisando a página de cada título no SciELO, tem-se:

- 5 periódicos utilizam o sistema autor-data nas citações;

- 42 periódicos utilizam o sistema numérico nas citações;

- 43 indicam o título abreviado;

- 8 mencionam a presença de bibliotecário no corpo editorial;

- 4 indicam a presença de revisores de normalização / referências, mas sem especificar se são bibliotecários;

- 2 utilizam as normas da ABNT para elaboração de referências;

- 1 utiliza as normas da AMA para elaboração de referências;

- 32 utilizam as normas Vancouver (ICMJE) para elaboração de referências;

- 11 não especificam a norma utilizada, mas dão exemplos;

- 1 não especifica a norma utilizada, e não dá exemplos;

- 8 determinam a idade das referências;

- 28 limitam a quantidade de referências por artigo;

- 1 determina a porcentagem de referências de periódicos;

- 1 recomenda a não-abreviação dos títulos dos periódicos nas referências;

- 20 recomendam a abreviação dos títulos dos periódicos nas referências, com indicação do padrão a ser seguido.

Os periódicos de Ciências da Saúde citam, em sua maioria (83,89\%) artigos de periódicos, seguidos pelas citações a livros (8,75\%) e capítulos de livros (2,80\%). As 
citações a periódicos têm aumentado gradativamente e a livro, diminuído. Já as citações a capítulos de livros vêm diminuindo, com uma pequena elevação em 2013 (Tabela 8).

Tabela 8 - Citações da área de Ciências da Saúde por tipo de documento e por ano

\begin{tabular}{crcccccc} 
& & $\mathbf{2 0 1 1}$ & $\mathbf{2 0 1 2}$ & $\mathbf{2 0 1 3}$ & $\mathbf{2 0 1 4}$ & $\mathbf{2 0 1 5}$ & $\begin{array}{c}\text { Total } \\
\text { Geral }\end{array}$ \\
\hline \multirow{2}{*}{ Periódicos } & citações & 140.340 & 134.744 & 139.183 & 132.626 & 133.361 & $\mathbf{6 8 0 . 2 5 4}$ \\
& $\%$ & 82,34 & 83,70 & 84,05 & 84,57 & 84,90 & 83,89 \\
Livros & citações & 15.891 & 14.297 & 13.916 & 13.536 & 13.340 & $\mathbf{7 0 . 9 8 0}$ \\
& $\%$ & 9,32 & 8,88 & 8,40 & 8,63 & 8,49 & $\mathbf{8 , 7 5}$ \\
Outros & citações & 6.496 & 5.722 & 6.452 & 5.991 & 5.391 & $\mathbf{3 0 . 0 5 2}$ \\
& $\%$ & 3,81 & 3,55 & 3,90 & 3,82 & 3,43 & 3,71 \\
Cap. Livros & citações & 5.530 & 4.398 & 4.759 & 4.234 & 3.786 & $\mathbf{2 2 . 7 0 7}$ \\
& $\%$ & 3,24 & 2,73 & 2,87 & 2,70 & 2,41 & 2,80 \\
Teses & citações & 1.378 & 1.205 & 785 & 105 & 667 & $\mathbf{4 . 1 4 0}$ \\
& $\%$ & 0,81 & 0,75 & 0,47 & 0,07 & 0,42 & $\mathbf{0 , 5 1}$ \\
Anais & citações & 798 & 610 & 495 & 325 & 531 & $\mathbf{2 . 7 5 9}$ \\
& $\%$ & 0,47 & 0,38 & 0,30 & 0,21 & 0,34 & $\mathbf{0 , 3 4}$ \\
Total & citações & $\mathbf{1 7 0 . 4 3 3}$ & $\mathbf{1 6 0 . 9 7 6}$ & $\mathbf{1 6 5 . 5 9 0}$ & $\mathbf{1 5 6 . 8 1 7}$ & $\mathbf{1 5 7 . 0 7 6}$ & $\mathbf{8 1 0 . 8 9 2}$ \\
& $\%$ & $\mathbf{1 0 0}$ & $\mathbf{1 0 0}$ & $\mathbf{1 0 0}$ & $\mathbf{1 0 0}$ & $\mathbf{1 0 0}$ & $\mathbf{1 0 0}$ \\
\hline
\end{tabular}

Fazendo uso do índice de Price (Tabela 9), observa-se uma média de utilização de $44 \%$ de referências mais atuais, sendo que os documentos não-identificados estão, quase em sua totalidade, dentro desta janela de citação. Nota-se que as referências mais atuais são aquelas a periódicos (38,44\%), seguidas pelas citações a teses $(38,26 \%)$ e anais $(36,21 \%)$. Vale ressaltar que, na análise das instruções aos autores, 8 periódicos (17\%) indicam a idade das referências a serem utilizadas pelos autores. É possível observar, ainda, que ao longo dos anos, as citações a documentos de até 5 anos, no caso de periódicos, apesar de uma ligeira queda em 2013, normalmente vêm crescendo, assim como citações a livros e capítulos de livros. Já as citações a teses, cresceu entre 2011 e 2012, e depois diminui no período de 2012 a 2015.

Na tabela 10, é possível verificar que a maioria das citações a periódicos é realizada a títulos que não estão indexados no SciELO, correspondendo a uma média de 86\% das citações, e esta porcentagem vêm crescendo ao longo do período analisado. Em seguida, estão as citações aos periódicos da amostra, com uma média de 10\%, que diminui ao passar dos anos e, com menos frequência, citações aos periódicos que estão no SciELO, mas não na WoS, que cresceu no período analisado. 
Tabela 9 - Citações da área de Ciências da Saúde com até 5 anos (índice de Price)

\begin{tabular}{|c|c|c|c|c|c|c|c|}
\hline & & & & & & & \\
\hline & & 2011 & 2012 & 2013 & 2014 & 2015 & $\begin{array}{l}\text { Total } \\
\text { Geral }\end{array}$ \\
\hline \multirow{2}{*}{ Periódicos } & citações & 53.790 & 52.264 & 52.083 & 51.054 & 52.320 & 261.511 \\
\hline & $\%$ & 38,33 & 38,79 & 37,42 & 38,49 & 39,23 & 38,44 \\
\hline \multirow{2}{*}{ Outros } & citações & 6.496 & 5.721 & 6.394 & 5.830 & 5.314 & 29.755 \\
\hline & $\%$ & 100 & 99,98 & 99,10 & 97,31 & 98,57 & 99,01 \\
\hline \multirow{2}{*}{ Livros } & citações & 3.900 & 3.699 & 3.621 & 3.920 & 3.998 & 19.138 \\
\hline & $\%$ & 24,54 & 25,87 & 26,02 & 28,96 & 29,97 & 26,96 \\
\hline \multirow{2}{*}{ Cap. Livros } & citações & 1.405 & 1.111 & 1.230 & 1.102 & 985 & 5.833 \\
\hline & $\%$ & 25,41 & 25,26 & 25,85 & 26,03 & 26,02 & 25,69 \\
\hline \multirow{2}{*}{ Teses } & citações & 533 & 496 & 298 & 34 & 223 & 1.584 \\
\hline & $\%$ & 38,68 & 41,16 & 37,96 & 32,38 & 33,43 & 38,26 \\
\hline \multirow{2}{*}{ Anais } & citações & 292 & 222 & 203 & 111 & 171 & 999 \\
\hline & $\%$ & 36,59 & 36,39 & 41,01 & 34,15 & 32,20 & 36,21 \\
\hline \multicolumn{2}{|c|}{ Total Geral } & 66.416 & 63.513 & 63.829 & 62.051 & 63.011 & 318.820 \\
\hline
\end{tabular}

Tabela 10 - Citações a periódicos, por ano, da área de Ciências da Saúde

\begin{tabular}{crcccccc} 
& & $\mathbf{2 0 1 1}$ & $\mathbf{2 0 1 2}$ & $\mathbf{2 0 1 3}$ & $\mathbf{2 0 1 4}$ & $\mathbf{2 0 1 5}$ & $\begin{array}{c}\text { Total } \\
\text { Geral }\end{array}$ \\
\hline Não-SciELO e & citações & 147.143 & 138.329 & 142.848 & 135.512 & 136.910 & $\mathbf{7 0 0 . 7 4 2}$ \\
não-amostra & \% & 86,33 & 85,93 & 86,27 & 86,41 & 87,16 & $\mathbf{8 6 , 4 2}$ \\
SciELO e & citações & 18.497 & 17.939 & 17.752 & 16.148 & 14.989 & $\mathbf{8 5 . 3 2 5}$ \\
amostra & $\boldsymbol{\%}$ & 10,85 & 11,14 & 10,72 & 10,30 & 9,54 & $\mathbf{1 0 , 5 2}$ \\
SciELO e & citações & 4.793 & 4.708 & 4.990 & 5.157 & 5.177 & $\mathbf{2 4 . 8 2 5}$ \\
não-amosta & $\mathbf{\%}$ & 2,81 & 2,92 & 3,01 & 3,29 & 3,30 & 3,06 \\
Total & citações & $\mathbf{1 7 0 . 4 3 3}$ & $\mathbf{1 6 0 . 9 7 6}$ & $\mathbf{1 6 5 . 5 9 0}$ & $\mathbf{1 5 6 . 8 1 7}$ & $\mathbf{1 5 7 . 0 7 6}$ & $\mathbf{8 1 0 . 8 9 2}$ \\
& $\%$ & $\mathbf{1 0 0}$ & $\mathbf{1 0 0}$ & $\mathbf{1 0 0}$ & $\mathbf{1 0 0}$ & $\mathbf{1 0 0}$ & $\mathbf{1 0 0}$ \\
\hline
\end{tabular}

\subsubsection{Ciências Exatas e da Terra}

De acordo com a CAPES, a área de Ciências Exatas e da Terra se divide nas seguintes subáreas: Matemática, Probabilidade e Estatística, Ciência da Computação, Astronomia, Física, Química e Geociências.

No SciELO, são 10 títulos correntes e 11 não-correntes, dos quais 8 foram indexados na WoS no período analisado, conforme segue:

1. Boletim de Ciências Geodésicas

2. Brazilian Journal of Geology

3. Brazilian Journal of Oceanography 
4. Computational \& Applied Mathematics (indexação interrompida no SciELO em 12/2012)

5. Eclética Química (indexação interrompida no SciELO em 06/2012)

6. Journal of The Brazilian Chemical Society

7. Journal of The Brazilian Society of Mechanical Sciences and Engineering (indexação interrompida no SciELO em 12/2012)

8. Química Nova

Analisando a página de cada título no SciELO, tem-se:

- 4 periódicos utilizam o sistema autor-data nas citações;

- 4 periódicos utilizam o sistema numérico nas citações;

- 7 indicam o título abreviado;

- 1 utiliza as normas da ABNT para elaboração de referências;

- 7 não especificam a norma utilizada, mas dão exemplos;

- 3 recomendam a abreviação dos títulos dos periódicos nas referências, com indicação do padrão a ser seguido.

Os periódicos de Ciências Exatas e da Terra citam, em sua maioria (95,74\%) artigos de periódicos, seguidos pelas citações a livros $(2,15 \%)$ e anais $(0,81 \%)$. Observase que as citações a periódicos cresceram entre 2011 e 2013, e depois diminui nos anos de 2014 e 2015, enquanto citações a livros e capítulos de livros aumenta, em especial no último ano do período em análise (Tabela 11).

Fazendo uso do índice de Price (Tabela 12), observa-se uma média de utilização de $40 \%$ de referências mais atuais, sendo que os documentos não-identificados estão, quase em sua totalidade, dentro desta janela de citação. Nota-se que as referências mais atuais são aquelas a teses (41,38\%), seguidas pelas citações a periódicos (36,82\%) e anais $(31,71 \%)$. Com exceção das citações a capítulos de livros, nota-se que todos os tipos documentais tiveram uma queda em 2015, principalmente as citações a teses e anais, que diminuíram quase pela metade. É possível observar, ainda, que ao longo dos anos, as citações a documentos de até 5 anos, no caso de periódicos, aumentaram de 2011 a 2013, e diminuíram no período de 2014 e 2015. 
Tabela 11 - Citações da área de Ciências Exatas e da Terra por tipo de documento e por ano

\begin{tabular}{crcccccc} 
& & $\mathbf{2 0 1 1}$ & $\mathbf{2 0 1 2}$ & $\mathbf{2 0 1 3}$ & $\mathbf{2 0 1 4}$ & $\mathbf{2 0 1 5}$ & $\begin{array}{c}\text { Total } \\
\text { Geral }\end{array}$ \\
\cline { 3 - 8 } Periódicos & citações & 23.139 & 24.549 & 17.556 & 20.783 & 8.648 & $\mathbf{9 4 . 6 7 5}$ \\
& $\%$ & 82,92 & 81,89 & 83,01 & 78,02 & 33,25 & 71,90 \\
\multirow{2}{*}{ Outros } & citações & 1.600 & 1.760 & 1.317 & 2.809 & 14.246 & $\mathbf{2 1 . 7 3 2}$ \\
& $\%$ & 5,73 & 5,87 & 6,23 & 10,55 & 54,78 & $\mathbf{1 6 , 5 0}$ \\
\multirow{2}{*}{ Livros } & citações & 2.227 & 2.668 & 1.715 & 2.122 & 2.191 & $\mathbf{1 0 . 9 2 3}$ \\
& $\%$ & 7,98 & 8,90 & 8,11 & 7,97 & 8,42 & $\mathbf{8 , 3 0}$ \\
\multirow{2}{*}{ Anais } & citações & 395 & 464 & 216 & 373 & 425 & $\mathbf{1 . 8 7 3}$ \\
& $\%$ & 1,42 & 1,55 & 1,02 & 1,40 & 1,63 & $\mathbf{1 , 4 2}$ \\
\multirow{2}{*}{ Teses } & citações & 312 & 356 & 200 & 234 & 140 & $\mathbf{1 . 2 4 2}$ \\
& $\%$ & 1,12 & 1,19 & 0,95 & 0,88 & 0,54 & $\mathbf{0 , 9 4}$ \\
\multirow{2}{*}{ Cap. Livros } & citações & 233 & 181 & 145 & 316 & 357 & $\mathbf{1 . 2 3 2}$ \\
& $\%$ & 0,83 & 0,60 & 0,69 & 1,19 & 1,37 & $\mathbf{0 , 9 4}$ \\
\multirow{2}{*}{ Total } & citações & $\mathbf{1 5 . 8 2 0}$ & $\mathbf{2 7 . 9 0 6}$ & $\mathbf{2 9 . 9 7 8}$ & $\mathbf{2 1 . 1 4 9}$ & $\mathbf{2 6 . 6 3 7}$ & $\mathbf{1 2 1 . 4 9 0}$ \\
& $\%$ & $\mathbf{1 0 0}$ & $\mathbf{1 0 0}$ & $\mathbf{1 0 0}$ & $\mathbf{1 0 0}$ & $\mathbf{1 0 0}$ & $\mathbf{1 0 0}$ \\
\hline
\end{tabular}

Tabela 12 - Citações da área de Ciências Exatas e da Terra com até 5 anos (índice de Price)

\begin{tabular}{|c|c|c|c|c|c|c|c|}
\hline & & & & & & & \\
\hline & & 2011 & 2012 & 2013 & 2014 & 2015 & $\begin{array}{l}\text { Total } \\
\text { Geral }\end{array}$ \\
\hline \multirow{2}{*}{ Periódicos } & citações & 8.710 & 9.303 & 6.753 & 7.605 & 2.488 & 34.859 \\
\hline & $\%$ & 37,64 & 37,90 & 38,47 & 36,59 & 28,77 & 36,82 \\
\hline \multirow{2}{*}{ Outros } & citações & 1.600 & 1.760 & 1.317 & 2.806 & 14.242 & 21.725 \\
\hline & $\%$ & 100 & 100 & 100 & 99,89 & 99,97 & 99,97 \\
\hline \multirow{2}{*}{ Livros } & citações & 404 & 456 & 294 & 351 & 339 & 1.844 \\
\hline & $\%$ & 18,14 & 17,09 & 17,14 & 16,54 & 15,47 & 16,88 \\
\hline \multirow{2}{*}{ Anais } & citações & 157 & 160 & 79 & 124 & 74 & 594 \\
\hline & $\%$ & 39,75 & 34,48 & 36,57 & 33,24 & 17,41 & 31,71 \\
\hline \multirow{2}{*}{ Teses } & citações & 155 & 146 & 82 & 95 & 36 & 514 \\
\hline & $\%$ & 49,68 & 41,01 & 41,00 & 40,60 & 25,71 & 41,38 \\
\hline \multirow{2}{*}{ Cap. Livros } & citações & 52 & 44 & 27 & 39 & 45 & 207 \\
\hline & $\%$ & 22,32 & 24,31 & 18,62 & 12,34 & 12,61 & 16,80 \\
\hline \multicolumn{2}{|c|}{ Total Geral } & 11.078 & 11.869 & 8.552 & 11.020 & 17.224 & $\mathbf{5 9 . 7 4 3}$ \\
\hline
\end{tabular}

Na tabela 13, é possível verificar que a maioria das citações a periódicos é realizada a títulos que não estão indexados no SciELO, correspondendo a uma média de 94\% das citações, e esta porcentagem vêm crescendo ao longo do período analisado, atingindo quase a totalidade das citações em 2015. Em seguida, estão as citações aos periódicos da amostra $(5,11 \%)$ que diminui ao passar dos anos, principalmente no ano de 2015 e, com menos frequência, citações aos periódicos que estão no SciELO, mas não na WoS (0,51\%), que também, após um período estável, caiu no último ano. 
Tabela 13 - Citações a periódicos, por ano, da área de Ciências Exatas e da Terra

\begin{tabular}{crcccccc}
\cline { 3 - 8 } & & $\mathbf{2 0 1 1}$ & $\mathbf{2 0 1 2}$ & $\mathbf{2 0 1 3}$ & $\mathbf{2 0 1 4}$ & $\mathbf{2 0 1 5}$ & $\begin{array}{c}\text { Total } \\
\text { Geral }\end{array}$ \\
\hline Não-SciELO e & citações & 26.213 & 27.865 & 19.606 & 25.089 & 25.492 & $\mathbf{1 2 4 . 2 6 5}$ \\
não-amostra & $\%$ & 93,93 & 92,95 & 92,70 & 94,19 & 98,02 & 94,37 \\
SciELO e & citações & 1.566 & 1.937 & 1.417 & 1.380 & 434 & $\mathbf{6 . 7 3 4}$ \\
amostra & $\%$ & 5,61 & 6,46 & 6,70 & 5,18 & 1,67 & 5,11 \\
SciELO e & citações & 127 & 176 & 126 & 168 & 81 & $\mathbf{6 7 8}$ \\
não-amosta & $\%$ & 0,46 & 0,59 & 0,60 & 0,63 & 0,31 & $\mathbf{0 , 5 1}$ \\
& citações & $\mathbf{2 7 . 9 0 6}$ & $\mathbf{2 9 . 9 7 8}$ & $\mathbf{2 1 . 1 4 9}$ & $\mathbf{2 6 . 6 3 7}$ & $\mathbf{2 6 . 0 0 7}$ & $\mathbf{1 3 1 . 6 7 7}$ \\
Total & $\%$ & $\mathbf{1 0 0}$ & $\mathbf{1 0 0}$ & $\mathbf{1 0 0}$ & $\mathbf{1 0 0}$ & $\mathbf{1 0 0}$ & $\mathbf{1 0 0}$ \\
\hline
\end{tabular}

\subsubsection{Ciências Humanas}

De acordo com a CAPES, a área de Ciências Humanas se divide nas seguintes subáreas: Filosofia, Teologia, Sociologia, Antropologia, Arqueologia, História, Geografia, Psicologia, Educação e Ciência Política.

No SciELO, são 87 títulos correntes e 12 não-correntes, dos quais 17 foram indexados na WoS no período analisado, conforme segue:

1. Bolema: Boletim de Educação Matemática

2. Dados

3. Educar em Revista

4. História, Ciências, Saúde-Manguinhos

5. Kriterion: Revista De Filosofia

6. Mana

7. Manuscrito

8. Psicologia: Reflexão e Crítica

9. Revista Brasileira de Ensino de Física

10. Revista Brasileira de História

11. Revista Brasileira de Política Internacional

12. Revista Latinoamericana de Psicopatologia Fundamental

13. Saúde e Sociedade

14. Tempo

15. Tempo Social

16. Topoi (Rio de Janeiro) 
Analisando a página de cada título no SciELO, tem-se:

- 15 periódicos utilizam o sistema autor-data nas citações;

- 2 periódicos utilizam o sistema numérico nas citações;

- 15 indicam o título abreviado;

- 1 menciona a presença de bibliotecário no corpo editorial;

- 1 indica a presença de revisores de normalização / referências, mas sem especificar se são bibliotecários;

- 8 utilizam as normas da ABNT para elaboração de referências;

- 2 utilizam as normas da APA para elaboração de referências;

- 7 não especificam a norma utilizada, mas dão exemplos;

- 1 limita a quantidade de referências por artigo.

Os periódicos de Ciências Humanas citam de maneira quase equivalente, livros $(37,91 \%)$ e periódicos $(37,05 \%)$. Percebe-se que as citações a periódicos crescem até 2014 e têm uma queda em 2015. Já as referências à livros cai entre 2012 e 2014 e volta a aumentar em 2015. É possível observar que citações a materiais como teses, anais e outros tipos de documentos cresceram no último ano (Tabela 14).

Fazendo uso do índice de Price (Tabela 15), observa-se uma média de utilização de 39\% de referências mais atuais, sendo que os documentos não-identificados estão, quase em sua totalidade, dentro desta janela de citação. Nota-se que as referências mais atuais são aquelas a anais (40,45\%), seguidas pelas citações a teses $(37,37 \%)$ e periódicos (26,65\%). É possível observar, ainda, que ao longo dos anos, as citações a documentos de até 5 anos, no caso de periódicos e capítulos de livros, aumentam com o passar dos anos, tendo uma pequena queda em 2015. As citações a livros tiveram uma pequena elevação em 2013 e se mantiveram sem grandes alterações em 2014 e 2015. As citações a teses diminuíram do período analisado e as citações a anais aumentaram, observando-se uma elevação significativa no último ano. 
Tabela 14 - Citações da área de Ciências Humanas por tipo de documento e por ano

\begin{tabular}{crcccccc} 
& & $\mathbf{2 0 1 1}$ & $\mathbf{2 0 1 2}$ & $\mathbf{2 0 1 3}$ & $\mathbf{2 0 1 4}$ & $\mathbf{2 0 1 5}$ & $\begin{array}{c}\text { Total } \\
\text { Geral }\end{array}$ \\
\cline { 3 - 8 } Livros & citações & 8.227 & 8.541 & 8.979 & 10.122 & 10.587 & $\mathbf{4 6 . 4 5 6}$ \\
& $\%$ & 39,67 & 36,81 & 37,24 & 37,66 & 38,35 & 37,91 \\
Periódicos & citações & 7.507 & 8.400 & 9.389 & 10.355 & 9.750 & $\mathbf{4 5 . 4 0 1}$ \\
& $\%$ & 36,20 & 36,20 & 38,94 & 38,53 & 35,32 & 37,05 \\
Cap. Livros & citações & 2.709 & 2.761 & 2.728 & 3.340 & 2.924 & $\mathbf{1 4 . 4 6 2}$ \\
& $\%$ & 13,06 & 11,90 & 11,31 & 12,43 & 10,59 & $\mathbf{1 1 , 8 0}$ \\
\multirow{2}{*}{ Outros } & citações & 1.555 & 2.296 & 1.854 & 2.329 & 3.209 & $\mathbf{1 1 . 2 4 3}$ \\
& $\%$ & 7,50 & 9,90 & 7,69 & 8,67 & 11,62 & 9,18 \\
\multirow{2}{*}{ Teses } & citações & 500 & 801 & 809 & 438 & 773 & $\mathbf{3 . 3 2 1}$ \\
& $\%$ & 2,41 & 3,45 & 3,36 & 1,63 & 2,80 & 2,71 \\
\multirow{2}{*}{ Anais } & citações & 241 & 404 & 353 & 291 & 365 & $\mathbf{1 . 6 5 4}$ \\
& $\%$ & 1,16 & 1,74 & 1,46 & 1,08 & 1,32 & $\mathbf{1 , 3 5}$ \\
\multirow{2}{*}{ Total } & citações & $\mathbf{2 0 . 7 3 9}$ & $\mathbf{2 3 . 2 0 3}$ & $\mathbf{2 4 . 1 1 2}$ & $\mathbf{2 6 . 8 7 5}$ & $\mathbf{2 7 . 6 0 8}$ & $\mathbf{1 2 2 . 5 3 7}$ \\
& $\%$ & $\mathbf{1 0 0}$ & $\mathbf{1 0 0}$ & $\mathbf{1 0 0}$ & $\mathbf{1 0 0}$ & $\mathbf{1 0 0}$ & $\mathbf{1 0 0}$ \\
\hline
\end{tabular}

Tabela 15 - Citações da área de Ciências Humanas com até 5 anos (índice de Price)

\begin{tabular}{|c|c|c|c|c|c|c|c|}
\hline & & & & & & & \\
\hline & & 2011 & 2012 & 2013 & 2014 & 2015 & $\begin{array}{l}\text { Total } \\
\text { Geral }\end{array}$ \\
\hline \multirow{2}{*}{ Periódicos } & citações & 1.902 & 2.161 & 2.475 & 2.867 & 2.694 & 12.099 \\
\hline & $\%$ & 25,34 & 25,73 & 26,36 & 27,69 & 27,63 & 26,65 \\
\hline \multirow{2}{*}{ Outros } & citações & 1.550 & 2.263 & 1.826 & 2.266 & 3.183 & 11.088 \\
\hline & $\%$ & 99,68 & 98,56 & 98,49 & 97,29 & 99,19 & 98,62 \\
\hline \multirow{2}{*}{ Livros } & citações & 1.204 & 1.277 & 1.424 & 1.571 & 1.607 & 7.083 \\
\hline & $\%$ & 14,63 & 14,95 & 15,86 & 15,52 & 15,18 & 15,25 \\
\hline \multirow{2}{*}{ Cap. Livros } & citações & 531 & 520 & 545 & 759 & 627 & 2.982 \\
\hline & $\%$ & 19,60 & 18,83 & 19,98 & 22,72 & 21,44 & 20,62 \\
\hline \multirow{2}{*}{ Teses } & citações & 209 & 309 & 311 & 161 & 251 & 1.241 \\
\hline & $\%$ & 41,80 & 38,58 & 38,44 & 36,76 & 32,47 & 37,37 \\
\hline \multirow{2}{*}{ Anais } & citações & 86 & 160 & 140 & 110 & 173 & 669 \\
\hline & $\%$ & 35,68 & 39,60 & 39,66 & 37,80 & 47,40 & 40,45 \\
\hline \multicolumn{2}{|c|}{ Total Geral } & 5.482 & 6.690 & 6.721 & 7.734 & 8.535 & 35.162 \\
\hline
\end{tabular}

Na tabela 16, é possível verificar que a maioria das citações a periódicos é realizada a títulos que não estão indexados no SciELO, correspondendo a uma média de 93\% das citações, e esta porcentagem diminui nos anos de 2012 e 2013, mas cresceu em 2014 e 2015. Já as citações aos periódicos da amostra e periódicos que estão no SciELO, mas não na WoS, é bastante equilibrada e com pouca variação ao longo dos anos. 
Tabela 16 - Citações a periódicos, por ano, da área de Ciências Humanas

\begin{tabular}{crcccccc}
\cline { 3 - 8 } & & $\mathbf{2 0 1 1}$ & $\mathbf{2 0 1 2}$ & $\mathbf{2 0 1 3}$ & $\mathbf{2 0 1 4}$ & $\mathbf{2 0 1 5}$ & $\begin{array}{c}\text { Total } \\
\text { Geral }\end{array}$ \\
\hline Não-SciELO e & citações & 19.454 & 21.569 & 22.317 & 25.112 & 25.716 & $\mathbf{1 1 4 . 1 6 8}$ \\
não-amostra & $\%$ & 93,8 & 92,96 & 92,56 & 93,44 & 93,15 & 93,17 \\
SciELO e & citações & 696 & 863 & 951 & 881 & 849 & $\mathbf{4 . 2 4 0}$ \\
amostra & $\%$ & 3,36 & 3,72 & 3,94 & 3,28 & 3,08 & 3,46 \\
SciELO e & citações & 589 & 771 & 844 & 882 & 1.043 & $\mathbf{4 . 1 2 9}$ \\
não-amosta & $\%$ & 2,84 & 3,32 & 3,50 & 3,28 & 3,78 & 3,37 \\
& citações & $\mathbf{2 0 . 7 3 9}$ & $\mathbf{2 3 . 2 0 3}$ & $\mathbf{2 4 . 1 1 2}$ & $\mathbf{2 6 . 8 7 5}$ & $\mathbf{2 7 . 6 0 8}$ & $\mathbf{1 2 2 . 5 3 7}$ \\
Total & $\%$ & $\mathbf{1 0 0}$ & $\mathbf{1 0 0}$ & $\mathbf{1 0 0}$ & $\mathbf{1 0 0}$ & $\mathbf{1 0 0}$ & $\mathbf{1 0 0}$ \\
\hline
\end{tabular}

\subsubsection{Ciências Sociais Aplicadas}

De acordo com a CAPES, a área de Ciências Sociais Aplicadas se divide nas seguintes subáreas: Direito, Administração, Turismo, Economia, Arquitetura e Urbanismo, Desenho Industrial, Planejamento Urbano e Regional, Demografia, Ciência da Informação, Museologia, Comunicação e Serviço Social.

No SciELO, são 39 títulos correntes e 7 não-correntes, dos quais 5 foram indexados na WoS no período analisado, conforme segue:

1. Perspectivas em Ciência da Informação

2. Revista Brasileira de Gestão de Negócios

3. Revista de Administração de Empresas

4. Revista Direito GV

5. Transinformação

Analisando a página de cada título no SciELO, tem-se:

- todos utilizam o sistema autor-data nas citações;

- 4 indicam o título abreviado;

- 1 menciona a presença de bibliotecário no corpo editorial;

- 1 indica a presença de revisores de normalização / referências, mas sem especificar se são bibliotecários;

- 3 utilizam as normas da ABNT para elaboração de referências;

- 2 utilizam as normas da APA para elaboração de referências; 
- 1 limita a quantidade de referências por artigo.

Os periódicos de Ciências Sociais Aplicadas citam, em sua maioria (51,13\%) artigos de periódicos, seguidos pelas citações a livros (26,37\%) e capítulos de livros (6,95\%). As citações a periódicos cresceram a cada ano no período analisado, enquanto as citações a livros e capítulos de livros diminui com o passar dos anos (Tabela 17).

Tabela 17 - Citações da área de Ciências Sociais Aplicadas por tipo de documento e por ano

\begin{tabular}{crcccccc} 
& & $\mathbf{2 0 1 1}$ & $\mathbf{2 0 1 2}$ & $\mathbf{2 0 1 3}$ & $\mathbf{2 0 1 4}$ & $\mathbf{2 0 1 5}$ & $\begin{array}{c}\text { Total } \\
\text { Geral }\end{array}$ \\
\cline { 3 - 8 } Periódicos & citações & 1.705 & 1.949 & 2.651 & 4.048 & 4.316 & $\mathbf{1 4 . 6 6 9}$ \\
& $\%$ & 42,44 & 44,49 & 48,31 & 55,65 & 57,29 & 51,13 \\
Livros & citações & 1.272 & 1.212 & 1.512 & 1.747 & 1.824 & $\mathbf{7 . 5 6 7}$ \\
& $\%$ & 31,67 & 27,66 & 27,56 & 24,02 & 24,21 & 26,37 \\
\multirow{2}{*}{ Outros } & citações & 444 & 564 & 641 & 646 & 566 & $\mathbf{2 . 8 6 1}$ \\
& $\%$ & 11,05 & 12,87 & 11,68 & 8,88 & 7,51 & 9,97 \\
\multirow{2}{*}{ Cap. Livros } & citações & 318 & 333 & 398 & 472 & 474 & $\mathbf{1 . 9 9 5}$ \\
& $\%$ & 7,92 & 7,60 & 7,25 & 6,49 & 6,29 & 6,95 \\
\multirow{2}{*}{ Anais } & citações & 158 & 168 & 202 & 255 & 250 & $\mathbf{1 . 0 3 3}$ \\
& $\%$ & 3,93 & 3,83 & 3,68 & 3,51 & 3,32 & 3,60 \\
\multirow{2}{*}{ Teses } & citações & 120 & 155 & 83 & 106 & 103 & $\mathbf{5 6 7}$ \\
& $\%$ & 2,99 & 3,54 & 1,51 & 1,46 & 1,37 & $\mathbf{1 , 9 8}$ \\
\multirow{2}{*}{ Total } & citações & $\mathbf{4 . 0 1 7}$ & $\mathbf{4 . 3 8 1}$ & $\mathbf{5 . 4 8 7}$ & $\mathbf{7 . 2 7 4}$ & $\mathbf{7 . 5 3 3}$ & $\mathbf{2 8 . 6 9 2}$ \\
& $\%$ & $\mathbf{1 0 0}$ & $\mathbf{1 0 0}$ & $\mathbf{1 0 0}$ & $\mathbf{1 0 0}$ & $\mathbf{1 0 0}$ & $\mathbf{1 0 0}$ \\
\hline
\end{tabular}

Fazendo uso do índice de Price (Tabela 18), observa-se uma média de utilização de $43 \%$ de referências mais atuais, sendo que os documentos não-identificados estão, quase em sua totalidade, dentro desta janela de citação. Nota-se que as referências mais atuais são aquelas a anais (44,53\%), seguidas pelas citações a teses $(42,33 \%)$ e periódicos $(28,34 \%)$. É possível observar, ainda, que as citações variam bastante ao longo dos anos e, em todos os tipos documentais houve uma queda nas citações no ano de 2014 e voltaram a aumentar em 2015, com exceção das citações a teses.

Na tabela 19, é possível verificar que a maioria das citações a periódicos é realizada a títulos que não estão indexados no SciELO, correspondendo a uma média de 94\% das citações, e esta porcentagem aumenta com o passar dos anos. Já as citações aos periódicos da amostra (2,25\%) e periódicos que estão no SciELO, mas não na WoS $(2,82 \%)$, são equilibradas entre elas, mas com variações ao longo dos anos. 
Tabela 18 - Citações da área de Ciências Sociais Aplicadas com até 5 anos (índice de Price)

\begin{tabular}{|c|c|c|c|c|c|c|c|}
\hline & & & & & & & \\
\hline & & 2011 & 2012 & 2013 & 2014 & 2015 & $\begin{array}{l}\text { Total } \\
\text { Geral }\end{array}$ \\
\hline \multirow{2}{*}{ Periódicos } & citações & 460 & 642 & 816 & 898 & 1.341 & 4.157 \\
\hline & $\%$ & 26,98 & 32,94 & 30,78 & 22,18 & 31,07 & 28,34 \\
\hline \multirow{2}{*}{ Outros } & citações & 444 & 564 & 641 & 641 & 559 & 2.849 \\
\hline & $\%$ & 100 & 100 & 100 & 99,23 & 98,76 & 99,58 \\
\hline \multirow{2}{*}{ Livros } & citações & 277 & 261 & 340 & 333 & 377 & 1.588 \\
\hline & $\%$ & 21,78 & 21,53 & 22,49 & 19,06 & 20,67 & 20,99 \\
\hline \multirow{2}{*}{ Cap. Livros } & citações & 95 & 92 & 112 & 58 & 117 & 474 \\
\hline & $\%$ & 29,87 & 27,63 & 28,14 & 12,29 & 24,68 & 23,76 \\
\hline \multirow{2}{*}{ Anais } & citações & 81 & 75 & 86 & 98 & 120 & 460 \\
\hline & $\%$ & 51,27 & 44,64 & 42,57 & 38,43 & 48,00 & 44,53 \\
\hline \multirow{2}{*}{ Teses } & citações & 49 & 70 & 46 & 43 & 32 & 240 \\
\hline & $\%$ & 40,83 & 45,16 & 55,42 & 40,57 & 31,07 & 42,33 \\
\hline \multicolumn{2}{|c|}{ Total Geral } & 1.406 & 1.704 & 2.041 & 2.071 & 2.546 & 9.768 \\
\hline
\end{tabular}

Tabela 19 - Citações a periódicos, por ano, da área de Ciências Sociais Aplicadas

\begin{tabular}{crcccccc}
\cline { 3 - 7 } & & $\mathbf{2 0 1 1}$ & $\mathbf{2 0 1 2}$ & $\mathbf{2 0 1 3}$ & $\mathbf{2 0 1 4}$ & $\mathbf{2 0 1 5}$ & $\begin{array}{c}\text { Total } \\
\text { Geral }\end{array}$ \\
\hline Não-SciELO e & citações & 3.746 & 4.134 & 5.183 & 6.958 & 7.216 & $\mathbf{2 7 . 2 3 7}$ \\
não-amostra & $\%$ & 93,25 & 94,36 & 94,46 & 95,66 & 95,79 & 94,93 \\
SciELO e & citações & 133 & 142 & 179 & 198 & 158 & $\mathbf{8 1 0}$ \\
não-amosta & $\%$ & 3,31 & 3,24 & 3,26 & 2,72 & 2,10 & 2,82 \\
SciELO e & citações & 138 & 105 & 125 & 118 & 159 & $\mathbf{6 4 5}$ \\
amostra & $\%$ & 3,44 & 2,39 & 2,28 & 1,62 & 2,11 & 2,25 \\
& citações & $\mathbf{4 . 0 1 7}$ & $\mathbf{4 . 3 8 1}$ & $\mathbf{5 . 4 8 7}$ & $\mathbf{7 . 2 7 4}$ & $\mathbf{7 . 5 3 3}$ & $\mathbf{2 8 . 6 9 2}$ \\
Total & $\%$ & $\mathbf{1 0 0}$ & $\mathbf{1 0 0}$ & $\mathbf{1 0 0}$ & $\mathbf{1 0 0}$ & $\mathbf{1 0 0}$ & $\mathbf{1 0 0}$ \\
\hline
\end{tabular}

\subsubsection{Engenharias}

De acordo com a CAPES, a área de Engenharias se divide nas seguintes subáreas: Engenharia Civil, Sanitária, de Transportes, de Minas, de Materiais e Metalúrgica, Química, Nuclear, Mecânica, de Produção, Naval e Oceânica, Aeroespacial, Elétrica e Biomédica.

No SciELO, são 21 títulos correntes e 5 não-correntes, dos quais 10 foram indexados na WoS no período analisado, conforme segue:

1. Brazilian Journal of Chemical Engineering

2. Engenharia Sanitária e Ambiental 
3. Journal of Aerospace Technology and Management

4. Journal of The Brazilian Society of Mechanical Sciences and Engineering (também classificado como Ciências Exatas e da Terra; indexação interrompida em 12/2012)

5. Latin American Journal of Solids and Structures

6. Materia (Rio de Janeiro)

7. Materials Research

8. Polímeros

9. Rem: Revista Escola de Minas

10. Soldagem \& Inspeção

Analisando a página de cada título no SciELO, tem-se:

- 7 periódicos utilizam o sistema autor-data nas citações;

- 3 periódicos utilizam o sistema numérico nas citações;

- Todos indicam o título abreviado;

- 3 utilizam as normas da ABNT para elaboração de referências;

- 1 utiliza as normas Vancouver (ICMJE) para elaboração de referências;

- 6 não especificam a norma utilizada, mas dão exemplos;

- 1 recomenda a abreviação dos títulos dos periódicos nas referências, com indicação do padrão a ser seguido.

Os periódicos de Engenharias citam, em sua maioria (74,01\%) artigos de periódicos, seguidos pelas citações a livros $(9,21 \%)$ e outros documentos $(8,66 \%)$. Percebe-se que as citações a periódicos crescem até 2014 e têm uma pequena queda em 2015. Já as referências à livros, teses e anais caem até 2014 e voltam a aumentar em 2015 (Tabela 20).

Fazendo uso do índice de Price (Tabela 21), observa-se uma média de utilização de $40 \%$ de referências mais atuais, sendo que os documentos não-identificados estão, quase em sua totalidade, dentro desta janela de citação. Nota-se que as referências mais atuais são aquelas a teses (36,17\%), seguidas pelas citações a periódicos $(34,76 \%)$ e anais (33,68\%). É possível observar, ainda, que ao longo dos anos, as citações a artigos de 
periódicos de até 5 anos vêm diminuindo, apesar de uma breve elevação em 2014. Este comportamento também é observado nas citações a teses a anais. Já as citações a livros e capítulos de livros permanecem equilibradas, com pouca variação no decorrer do período analisado.

Tabela 20 - Citações da área de Engenharias por tipo de documento e por ano

\begin{tabular}{|c|c|c|c|c|c|c|c|}
\hline & & & & & & & \\
\hline & & 2011 & 2012 & 2013 & 2014 & 2015 & $\begin{array}{l}\text { Total } \\
\text { Geral }\end{array}$ \\
\hline \multirow{2}{*}{ Periódicos } & citações & 8.516 & 11.109 & 13.076 & 16.927 & 18.274 & 67.902 \\
\hline & $\%$ & 69,05 & 71,23 & 73,99 & 76,58 & 76,00 & 74,01 \\
\hline \multirow{2}{*}{ Livros } & citações & 1.291 & 1.405 & 1.530 & 1.761 & 2.461 & 8.448 \\
\hline & $\%$ & 10,47 & 9,01 & 8,66 & 7,97 & 10,23 & 9,21 \\
\hline \multirow{2}{*}{ Outros } & citações & 1.307 & 1.642 & 1.694 & 1.903 & 1.399 & 7.945 \\
\hline & $\%$ & 10,60 & 10,53 & 9,59 & 8,61 & 5,82 & 8,66 \\
\hline \multirow{2}{*}{ Anais } & citações & 583 & 774 & 629 & 686 & 956 & 3.628 \\
\hline & $\%$ & 4,73 & 4,96 & 3,56 & 3,10 & 3,98 & 3,95 \\
\hline \multirow{2}{*}{ Teses } & citações & 386 & 454 & 412 & 467 & 617 & 2.336 \\
\hline & $\%$ & 3,13 & 2,91 & 2,33 & 2,11 & 2,57 & 2,55 \\
\hline \multirow{2}{*}{ Cap. Livros } & citações & 250 & 212 & 331 & 360 & 339 & 1.492 \\
\hline & $\%$ & 2,03 & 1,36 & 1,87 & 1,63 & 1,41 & 1,63 \\
\hline \multirow{2}{*}{ Total } & citações & 12.333 & 15.596 & 17.672 & 22.104 & 24.046 & 91.751 \\
\hline & $\%$ & 100 & 100 & 100 & 100 & 100 & 100 \\
\hline
\end{tabular}

Tabela 21 - Citações da área de Engenharias com até 5 anos (índice de Price)

\begin{tabular}{|c|c|c|c|c|c|c|c|}
\hline & & & & & & & \\
\hline & & 2011 & 2012 & 2013 & 2014 & 2015 & $\begin{array}{l}\text { Total } \\
\text { Geral }\end{array}$ \\
\hline \multirow{2}{*}{ Periódicos } & citações & 3.129 & 3.938 & 4.449 & 5.971 & 6.119 & 23.606 \\
\hline & $\%$ & 36,74 & 35,45 & 34,02 & 35,28 & 33,48 & 34,76 \\
\hline \multirow{2}{*}{ Outros } & citações & 1.307 & 1.642 & 1.694 & 1.903 & 1.395 & 7.941 \\
\hline & $\%$ & 100 & 100 & 100 & 100 & 99,71 & 99,95 \\
\hline \multirow{2}{*}{ Livros } & citações & 191 & 220 & 219 & 276 & 388 & 1.294 \\
\hline & $\%$ & 14,79 & 15,66 & 14,31 & 15,67 & 15,77 & 15,32 \\
\hline \multirow{2}{*}{ Anais } & citações & 234 & 275 & 212 & 233 & 268 & 1.222 \\
\hline & $\%$ & 40,14 & 35,53 & 33,70 & 33,97 & 28,03 & 33,68 \\
\hline \multirow{2}{*}{ Teses } & citações & 164 & 178 & 145 & 151 & 207 & 845 \\
\hline & $\%$ & 42,49 & 39,21 & 35,19 & 32,33 & 33,55 & 36,17 \\
\hline \multirow{2}{*}{ Cap. Livros } & citações & 57 & 46 & 73 & 74 & 73 & 323 \\
\hline & $\%$ & 22,80 & 21,70 & 22,05 & 20,56 & 21,53 & 21,65 \\
\hline \multicolumn{2}{|c|}{ Total Geral } & 5.082 & 6.299 & 6.792 & 8.608 & 8.450 & 35.231 \\
\hline
\end{tabular}

Na tabela 22, é possível verificar que a grande maioria das citações a periódicos é realizada a títulos que não estão indexados no SciELO, correspondendo a uma média de 
98\% das citações. Já as citações aos periódicos da amostra correspondem a 1,69\%, e citações a periódicos que estão no SciELO, mas não na WoS, é bem pequena $(0,22 \%)$. As citações aos periódicos dos três extratos variam bastante no decorrer dos anos.

Tabela 22 - Citações a periódicos, por ano, da área de Engenharias

\begin{tabular}{crcccccc}
\cline { 3 - 7 } & & $\mathbf{2 0 1 1}$ & $\mathbf{2 0 1 2}$ & $\mathbf{2 0 1 3}$ & $\mathbf{2 0 1 4}$ & $\mathbf{2 0 1 5}$ & $\begin{array}{c}\text { Total } \\
\text { Geral }\end{array}$ \\
\hline Não-SciELO e & citações & 12.036 & 15.089 & 17.248 & 54.905 & 23.377 & $\mathbf{1 2 2 . 6 5 5}$ \\
não-amostra & $\%$ & 97,59 & 96,75 & 97,60 & 99,11 & 97,22 & 98,09 \\
SciELO e & citações & 249 & 440 & 389 & 440 & 593 & $\mathbf{2 . 1 1 1}$ \\
amostra & $\%$ & 2,02 & 2,82 & 2,20 & 0,79 & 2,47 & $\mathbf{1 , 6 9}$ \\
SciELO e & citações & 48 & 67 & 35 & 53 & 76 & $\mathbf{2 7 9}$ \\
não-amosta & $\%$ & 0,39 & 0,43 & 0,20 & 0,10 & 0,32 & $\mathbf{0 , 2 2}$ \\
& citações & $\mathbf{1 2 . 3 3 3}$ & $\mathbf{1 5 . 5 9 6}$ & $\mathbf{1 7 . 6 7 2}$ & $\mathbf{5 5 . 3 9 8}$ & $\mathbf{2 4 . 0 4 6}$ & $\mathbf{1 2 5 . 0 4 5}$ \\
Total & $\%$ & $\mathbf{1 0 0}$ & $\mathbf{1 0 0}$ & $\mathbf{1 0 0}$ & $\mathbf{1 0 0}$ & $\mathbf{1 0 0}$ & $\mathbf{1 0 0}$ \\
\hline
\end{tabular}

\subsubsection{Linguística, Letras e Artes}

No SciELO, são 15 títulos correntes e 1 não-corrente na área de Linguística, Letras e Artes, dos quais 1 foi indexado na WoS no período analisado, conforme segue:

1. Estudos de Literatura Brasileira Contemporânea

Analisando a página do título em questão no SciELO, é apresentado o título abreviado, indicado a utilização do sistema autor-data para citações, mas as diretrizes referentes à normalização dos artigos encontram-se no site externo da revista, que não especifica a norma seguida e apresenta somente a estrutura de uma referência, sem exemplos.

O periódico analisado cita, em sua maioria livros (61,73\%), seguidos pelas citações a capítulos de livros (18,38\%) e periódicos (9,92\%). Observa-se que as citações, independente do tipo documental, variam ao longo dos anos do período analisado (Tabela 23). 
Tabela 23 - Citações da área de Linguística, Letras e Artes por tipo de documento e por ano

\begin{tabular}{crcccccc} 
& & $\mathbf{2 0 1 1}$ & $\mathbf{2 0 1 2}$ & $\mathbf{2 0 1 3}$ & $\mathbf{2 0 1 4}$ & $\mathbf{2 0 1 5}$ & $\begin{array}{c}\text { Total } \\
\text { Geral }\end{array}$ \\
\hline \multirow{2}{*}{ Livros } & citações & 167 & 645 & 566 & 616 & 693 & $\mathbf{2 . 6 8 7}$ \\
& $\%$ & 54,22 & 66,36 & 62,40 & 54,56 & 66,83 & $\mathbf{6 1 , 7 3}$ \\
Cap. Livros & citações & 49 & 201 & 165 & 203 & 182 & $\mathbf{8 0 0}$ \\
& $\%$ & 15,91 & 20,68 & 18,19 & 17,98 & 17,55 & $\mathbf{1 8 , 3 8}$ \\
\multirow{2}{*}{ Periódicos } & citações & 24 & 78 & 96 & 141 & 93 & $\mathbf{4 3 2}$ \\
& $\%$ & 7,7 & 8,02 & 10,58 & 12,49 & 8,97 & 9,92 \\
\multirow{2}{*}{ Outros } & citações & 68 & 36 & 61 & 146 & 48 & $\mathbf{3 5 9}$ \\
& $\%$ & 22,08 & 3,70 & 6,73 & 12,93 & 4,63 & $\mathbf{8 , 2 5}$ \\
\multirow{2}{*}{ Teses } & citações & & 8 & 14 & 13 & 15 & $\mathbf{5 0}$ \\
& $\%$ & & 0,82 & 1,54 & 1,15 & 1,45 & $\mathbf{1 , 1 5}$ \\
\multirow{2}{*}{ Anais } & citações & & 4 & 5 & 10 & 6 & $\mathbf{2 5}$ \\
\multirow{2}{*}{ Total } & citações & $\mathbf{3 0 8}$ & $\mathbf{9 7 2}$ & $\mathbf{9 0 7}$ & $\mathbf{1 . 1 2 9}$ & $\mathbf{1 . 0 3 7}$ & $\mathbf{4 . 3 5 3}$ \\
& $\%$ & $\mathbf{1 0 0}$ & $\mathbf{1 0 0}$ & $\mathbf{1 0 0}$ & $\mathbf{1 0 0}$ & $\mathbf{1 0 0}$ & $\mathbf{1 0 0}$ \\
\hline
\end{tabular}

Fazendo uso do índice de Price (Tabela 24), observa-se uma média de utilização de $44 \%$ de referências mais atuais, sendo que os documentos não-identificados estão, quase em sua totalidade, dentro desta janela de citação. Nota-se que as referências mais atuais são aquelas a teses (54\%), seguidas pelas citações a anais (44\%) e periódicos (30,09\%). É possível observar, ainda, que ao longo dos anos, as citações a periódicos, livros e anais teve um crescimento no último ano, enquanto a citação a teses teve uma queda.

Tabela 24 - Citações da área de Linguística, Letras e Artes com até 5 anos (índice de Price)

\begin{tabular}{|c|c|c|c|c|c|c|c|}
\hline & & & & & & & \\
\hline & & 2011 & 2012 & 2013 & 2014 & 2015 & $\begin{array}{l}\text { Total } \\
\text { Geral }\end{array}$ \\
\hline \multirow{2}{*}{ Livros } & citações & 32 & 121 & 110 & 99 & 127 & 489 \\
\hline & $\%$ & 19,16 & 18,76 & 19,43 & 16,07 & 18,33 & 18,20 \\
\hline \multirow{2}{*}{ Outros } & citações & 68 & 36 & 61 & 146 & 41 & 352 \\
\hline & $\%$ & 100 & 100 & 100 & 100 & 85,42 & 98,05 \\
\hline \multirow{2}{*}{ Cap. Livros } & citações & 14 & 41 & 43 & 41 & 28 & 167 \\
\hline & $\%$ & 28,57 & 20,40 & 26,06 & 20,20 & 15,38 & 20,88 \\
\hline \multirow{2}{*}{ Periódicos } & citações & 9 & 27 & 24 & 37 & 33 & 130 \\
\hline & $\%$ & 37,50 & 34,62 & 25,00 & 26,24 & 35,48 & 30,09 \\
\hline \multirow{2}{*}{ Teses } & citações & & 5 & 8 & 9 & 5 & 27 \\
\hline & $\%$ & & 62,50 & 57,14 & 69,23 & 33,33 & 54,00 \\
\hline \multirow{2}{*}{ Anais } & citações & & 3 & 3 & 1 & 4 & 11 \\
\hline & $\%$ & & 75,00 & 60,00 & 10,00 & 66,67 & 44,00 \\
\hline \multicolumn{2}{|c|}{ Total Geral } & 123 & 233 & 249 & 333 & 238 & 1.176 \\
\hline
\end{tabular}


Na tabela 25, é possível verificar que a grande maioria das citações a periódicos é realizada a títulos que não estão indexados no SciELO, correspondendo a quase totalidade das citações $(99,43 \%)$. Estas citações mostram-se equilibradas no decorrer dos anos, com uma pequena queda em 2014. Já as citações aos periódicos da amostra (0,16\%) e aos periódicos que estão no SciELO, mas não na WoS $(0,41 \%)$, é bem pequena, ambas com um pequeno crescimento em 2014, mas mantendo-se equilibrada nos demais anos.

Tabela 25 - Citações a periódicos, por ano, da área de Linguística, Letras e Artes

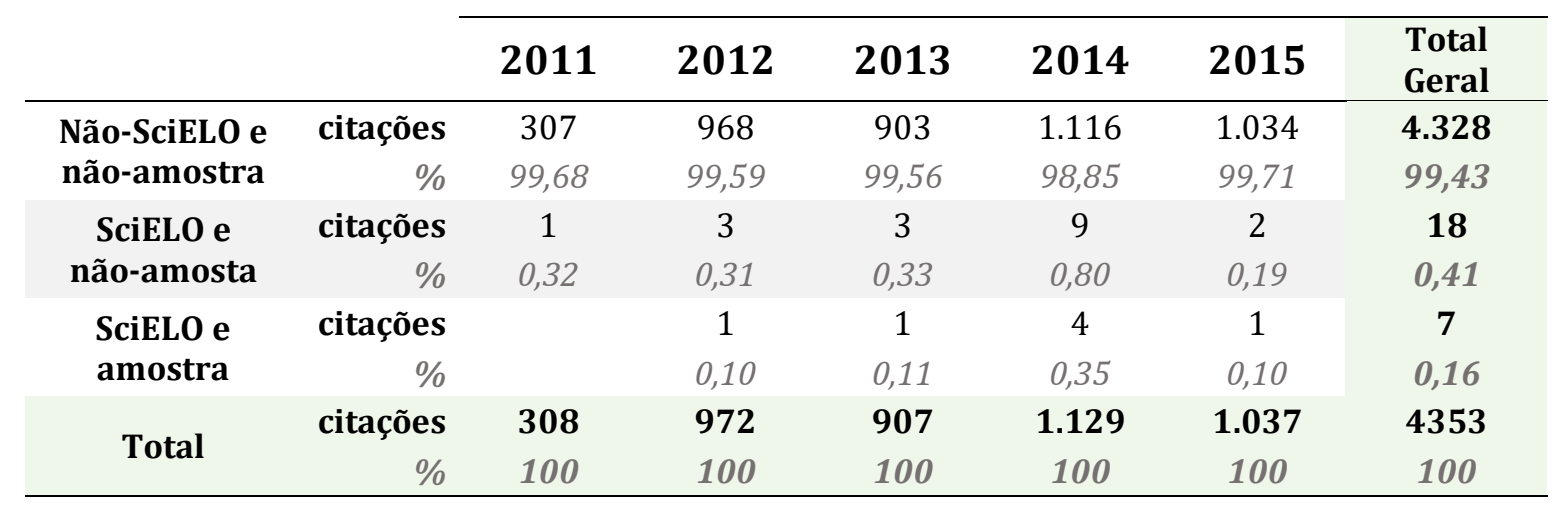

\subsubsection{Multidisciplinar}

De acordo com a CAPES, a área Multidisciplinar se divide nas seguintes subáreas: Interdisciplinar, Ensino, Materiais, Biotecnologia e Ciências Ambientais.

Não existe esta divisão por assunto no SciELO, mas consideraram-se os títulos que estão classificados em mais de duas áreas, conforme segue:

1. Acta Amazônica (classificado em Ciências Agrárias, Biológicas, da Saúde e Exatas e da Terra)

2. Anais da Academia Brasileira de Ciências (classificado em Ciências Agrárias, Biológicas, da Saúde e Exatas e da Terra, Humanas e Engenharias)

3. Brazilian Archives of Biology and Technology (classificado em Ciências Agrárias, Biológicas, da Saúde e Engenharias) 
4. Journal of Venomous Animals and Toxins Including Tropical Diseases classificado em Ciências Agrárias, Biológicas e da Saúde)

Analisando a página de cada título no SciELO, tem-se:

- 2 periódicos utilizam o sistema autor-data nas citações;

- 2 periódicos utilizam o sistema numérico nas citações;

- Todos indicam o título abreviado;

- 1 utiliza as normas Vancouver (ICMJE) para elaboração de referências;

- 3 não especificam a norma utilizada, mas dão exemplos;

- 1 determina a idade das referências;

- 1 limita a quantidade de referências por artigo;

- 1 determina a porcentagem de referências de periódicos;

- 1 recomenda a não-abreviação dos títulos dos periódicos nas referências;

- 2 recomendam a abreviação dos títulos dos periódicos nas referências, com indicação do padrão a ser seguido.

Os periódicos classificados como Multidisciplinar citam, em sua maioria (82,71\%) artigos de periódicos, seguidos pelas citações a livros (7,20\%) e capítulos de livros $(4,37 \%)$. As citações a periódicos crescem ao longo dos anos, enquanto citações as livros, capítulos de livros, teses e outros tipos de documentos, diminuem. Já as citações a anais, apesar de diminuírem de 2011 a 2014, apresentaram uma elevação no último ano (Tabela 26).

Fazendo uso do índice de Price (Tabela 27), observa-se uma média de utilização de 35\% de referências mais atuais, sendo que as citações a documentos não-identificados estão, em sua totalidade, dentro desta janela de citação. Nota-se que as referências mais atuais são aquelas a teses $(30,61 \%)$, seguidas pelas citações a anais $(25,17 \%)$ e periódicos (27,09\%). É possível observar, ainda, que ao longo dos anos, com exceção das citações a capítulos de livros, as citações a periódicos, livros, teses e anais apresentam bastante variações. As citações a periódicos diminuíram entre 2011 e 2013 e voltaram a aumentar 
a partir de 2014. Já as citações a livros dobram em 2014, enquanto as citações a teses caem quase pela metade em 2015.

Tabela 26 - Citações da área Multidisciplinar por tipo de documento e por ano

\begin{tabular}{crcccccc} 
& & $\mathbf{2 0 1 1}$ & $\mathbf{2 0 1 2}$ & $\mathbf{2 0 1 3}$ & $\mathbf{2 0 1 4}$ & $\mathbf{2 0 1 5}$ & $\begin{array}{c}\text { Total } \\
\text { Geral }\end{array}$ \\
\cline { 3 - 8 } Periódicos & citações & 11.389 & 9.538 & 10.341 & 13.193 & 14.895 & $\mathbf{5 9 . 3 5 6}$ \\
& $\%$ & 79,08 & 79,78 & 83,46 & 84,76 & 85,37 & 82,71 \\
\multirow{2}{*}{ Livros } & citações & 1.156 & 947 & 843 & 1.021 & 1.198 & $\mathbf{5 . 1 6 5}$ \\
& $\%$ & 8,03 & 7,92 & 6,80 & 6,56 & 6,87 & 7,20 \\
\multirow{2}{*}{ Cap. Livros } & citações & 766 & 600 & 502 & 733 & 538 & $\mathbf{3 . 1 3 9}$ \\
& $\%$ & 5,32 & 5,02 & 4,05 & 4,71 & 3,08 & 4,37 \\
\multirow{2}{*}{ Outros } & citações & 636 & 554 & 524 & 513 & 654 & $\mathbf{2 . 8 8 1}$ \\
& $\%$ & 4,42 & 4,63 & 4,23 & 3,30 & 3,75 & 4,01 \\
\multirow{2}{*}{ Teses } & citações & 227 & 166 & 129 & 65 & 37 & $\mathbf{6 2 4}$ \\
& $\%$ & 1,58 & 1,39 & 1,04 & 0,42 & 0,21 & $\mathbf{0 , 8 7}$ \\
\multirow{2}{*}{ Anais } & citações & 227 & 151 & 51 & 41 & 126 & $\mathbf{5 9 6}$ \\
& $\%$ & 1,58 & 1,26 & 0,41 & 0,26 & 0,72 & $\mathbf{0 , 8 3}$ \\
\multirow{2}{*}{ Total } & citações & $\mathbf{1 4 . 4 0 1}$ & $\mathbf{1 1 . 9 5 6}$ & $\mathbf{1 2 . 3 9 0}$ & $\mathbf{1 5 . 5 6 6}$ & $\mathbf{1 7 . 4 4 8}$ & $\mathbf{7 1 . 7 6 1}$ \\
& $\%$ & $\mathbf{1 0 0}$ & $\mathbf{1 0 0}$ & $\mathbf{1 0 0}$ & $\mathbf{1 0 0}$ & $\mathbf{1 0 0}$ & $\mathbf{1 0 0}$ \\
\hline
\end{tabular}

Tabela 27 - Citações da área Multidisciplinar com até 5 anos (índice de Price)

\begin{tabular}{|c|c|c|c|c|c|c|c|}
\hline & & & & & & & \\
\hline & & 2011 & 2012 & 2013 & 2014 & 2015 & $\begin{array}{l}\text { Total } \\
\text { Geral }\end{array}$ \\
\hline \multirow{2}{*}{ Periódicos } & citações & 3.142 & 2.494 & 2.590 & 3.456 & 4.395 & 16.077 \\
\hline & $\%$ & 27,59 & 26,15 & 25,05 & 26,20 & 29,51 & 27,09 \\
\hline \multirow{2}{*}{ Outros } & citações & 636 & 554 & 524 & 513 & 654 & 2.881 \\
\hline & $\%$ & 100 & 100 & 100 & 100 & 100 & 100 \\
\hline \multirow{2}{*}{ Livros } & citações & 141 & 115 & 85 & 206 & 189 & 736 \\
\hline & $\%$ & 12,20 & 12,14 & 10,08 & 20,18 & 15,78 & 14,25 \\
\hline \multirow{2}{*}{ Cap. Livros } & citações & 113 & 75 & 79 & 102 & 73 & 442 \\
\hline & $\%$ & 14,75 & 12,50 & 15,74 & 13,92 & 13,57 & 14,08 \\
\hline \multirow{2}{*}{ Teses } & citações & 74 & 48 & 40 & 22 & 7 & 191 \\
\hline & $\%$ & 32,60 & 28,92 & 31,01 & 33,85 & 18,92 & 30,61 \\
\hline \multirow{2}{*}{ Anais } & citações & 57 & 39 & 20 & 9 & 25 & 150 \\
\hline & $\%$ & 25,11 & 25,83 & 39,22 & 21,95 & 19,84 & 25,17 \\
\hline \multicolumn{2}{|c|}{ Total Geral } & 4.163 & 3.325 & 3.338 & 4.308 & 5.343 & 20.477 \\
\hline
\end{tabular}

Na tabela 28, é possível verificar que a grande maioria das citações a periódicos é realizada a títulos que não estão indexados no SciELO nem na WoS, correspondendo a quase totalidade das citações $(91,01 \%)$, e apresentam um crescimento ao longo dos anos. Já as citações aos periódicos da amostra correspondem a 7,36\%, que diminui no decorrer 
dos anos analisados. As citações a periódicos que estão no SciELO, mas não na WoS é de $1,62 \%$, que também diminui com o passar dos anos.

Tabela 28 - Citações a periódicos, por ano, da área Multidisciplinar

\begin{tabular}{ccccccc} 
& $\mathbf{2 0 1 1}$ & $\mathbf{2 0 1 2}$ & $\mathbf{2 0 1 3}$ & $\mathbf{2 0 1 4}$ & $\mathbf{2 0 1 5}$ & $\begin{array}{c}\text { Total } \\
\text { Geral }\end{array}$ \\
\hline Não-SciELO e & 13.101 & 10.711 & 11.111 & 14.172 & 16.216 & $\mathbf{6 5 . 3 1 1}$ \\
não-amostra & $90,97 \%$ & $89,59 \%$ & $89,68 \%$ & $91,04 \%$ & $92,94 \%$ & $91,01 \%$ \\
SciELO e & 1.062 & 1.035 & 1.057 & 1.131 & 1.000 & $\mathbf{5 . 2 8 5}$ \\
amostra & $7,37 \%$ & $8,66 \%$ & $8,53 \%$ & $7,27 \%$ & $5,73 \%$ & $7,36 \%$ \\
SciELO e & 238 & 210 & 222 & 263 & 232 & $\mathbf{1 . 1 6 5}$ \\
não-amosta & $1,65 \%$ & $1,76 \%$ & $1,79 \%$ & $1,69 \%$ & $1,33 \%$ & $\mathbf{1 , 6 2 \%}$ \\
Total & $\mathbf{1 4 . 4 0 1}$ & $\mathbf{1 1 . 9 5 6}$ & $\mathbf{1 2 . 3 9 0}$ & $\mathbf{1 5 . 5 6 6}$ & $\mathbf{1 7 . 4 4 8}$ & $\mathbf{7 1 . 7 6 1}$ \\
& $\mathbf{1 0 0 \%}$ & $\mathbf{1 0 0} \%$ & $\mathbf{1 0 0} \%$ & $\mathbf{1 0 0} \%$ & $\mathbf{1 0 0} \%$ & $\mathbf{1 0 0} \%$ \\
\hline
\end{tabular}

\subsection{Comparação entre áreas}

A seguir, utilizando os resultados apresentados na seção anterior, buscará fazer uma análise geral e comparativa entre as áreas. Primeiro serão consideradas as informações retiradas das páginas de cada periódico e, em seguida, as informações sobre citações.

\subsubsection{Informações gerais}

Analisando-se as informações disponíveis na página de cada periódico, podemos observar que a maioria (91\%) informa qual o título abreviado oficial que deve ser utilizado nas citações aos mesmos. Em relação à revisão das normas, 17 periódicos indicam a presença de bibliotecários na equipe editorial e 12 informam que possuem revisores, mas sem indicar se são bibliotecários. Os periódicos que indicam bibliotecários na equipe são das áreas de Ciências Agrárias, Biológicas, da Saúde, Humanas e Sociais Aplicadas (Tabela 29). 
Tabela 29 - Periódicos que indicam título abreviado oficial e a presença de bibliotecários e revisores em sua equipe editorial -2018

\begin{tabular}{ccccc}
\hline Grande Área & $\mathbf{N}$ & Título Abreviado & Bibliotecário & Revisor \\
\hline Ciências Agrárias & $\mathbf{2 6}$ & $\mathbf{2 3}(88 \%)$ & $\mathbf{5}(19 \%)$ & $\mathbf{6}(23 \%)$ \\
Ciências Biológicas & $\mathbf{1 7}$ & $\mathbf{1 6}(94 \%)$ & $\mathbf{2}(11 \%)$ & $\mathbf{0}$ \\
Ciências da Saúde & $\mathbf{4 7}$ & $\mathbf{4 3}(91 \%)$ & $\mathbf{8}(17 \%)$ & $\mathbf{4}(8 \%)$ \\
Ciências Exatas e da Terra & $\mathbf{8}$ & $\mathbf{7}(87 \%)$ & $\mathbf{0}$ & $\mathbf{0}$ \\
Ciências Humanas & $\mathbf{1 7}$ & $\mathbf{1 5}(88 \%)$ & $\mathbf{1}(5 \%)$ & $\mathbf{1}(5 \%)$ \\
Ciências Soc. Aplicadas & $\mathbf{5}$ & $\mathbf{4}(80 \%)$ & $\mathbf{1}(20 \%)$ & $\mathbf{1}(20 \%)$ \\
Engenharias & $\mathbf{1 0}$ & $\mathbf{1 0}(100 \%)$ & $\mathbf{0}$ & $\mathbf{0}$ \\
Linguística, Letras e Artes & $\mathbf{1}$ & $\mathbf{1}(100 \%)$ & $\mathbf{0}$ & $\mathbf{0}$ \\
Multidisciplinar & $\mathbf{4}$ & $\mathbf{4}(100 \%)$ & $\mathbf{0}$ & $\mathbf{0}$ \\
Total Geral & $\mathbf{1 3 5}$ & $\mathbf{1 2 3}(\mathbf{9 1 \% )}$ & $\mathbf{1 7}(12 \%)$ & $\mathbf{1 2}(8 \%)$ \\
\hline
\end{tabular}

Segundo os Critérios, política e procedimentos para a admissão e a permanência de periódicos científicos na Coleção SciELO Brasil,

\begin{abstract}
"Os periódicos devem especificar nas instruções aos autores as normas que seguem para a estruturação e apresentação dos textos e para a apresentação e formatação das citações e das referências bibliográficas. [...] Para as citações e referências bibliográficas recomenda-se a adoção fiel de normas estabelecidas formalmente como padrões nacional e/ou internacional e mais utilizadas internacionalmente na área temática do periódico. A adoção precisa de normas bibliográficas é essencial para viabilizar o processo de marcação e geração estruturada dos textos em XML." (SciELO, 2017, p. 18-19).
\end{abstract}

No entanto, quase metade (47\%) dos periódicos analisados não especifica a norma utilizada, principalmente as áreas de Ciências Exatas e da Terras e Linguística, Letras e Artes. Ao contrário, todos os periódicos de Ciências Sociais e Aplicadas indicam a norma seguida para elaboração de referências bibliográficas. Dos periódicos que especificam as normas utilizadas, 25\% utilizam a Vancouver, especialmente os periódicos de Ciências da Saúde. Por outro lado, as normas da ABNT prevalecem entre os periódicos de Ciências Agrárias, Humanas e Sociais Aplicadas, devido ao forte aspecto regional e local destas áreas (Tabela 30).

Nota-se que as áreas que utilizam mais as normas ABNT e APA, também seguem o padrão autor-data de citação, enquanto as que utilizam a Vancouver, recomendam o uso de citações numéricas (Tabela 31). 
Tabela 30 - Indicação da norma para elaboração das referências bibliográficas - 2018

\begin{tabular}{cccccc}
\hline Grande Área & N & ABNT & APA & Vancouver & Não especifica \\
\hline Ciências Agrárias & $\mathbf{2 6}$ & $\mathbf{9}(34 \%)$ & $\mathbf{1}(3 \%)$ & $\mathbf{1}(3 \%)$ & $\mathbf{1 5}(57 \%)$ \\
Ciências Biológicas & $\mathbf{1 7}$ & $\mathbf{0}$ & $\mathbf{4}(23 \%)$ & $\mathbf{0}$ & $\mathbf{1 3}(76 \%)$ \\
Ciências da Saúde & $\mathbf{4 7}$ & $\mathbf{2}(4 \%)$ & $\mathbf{1}(2 \%)$ & $\mathbf{3 2}(68 \%)$ & $\mathbf{1 2}(25 \%)$ \\
Ciências Exatas e da Terra & $\mathbf{8}$ & $\mathbf{1}(12 \%)$ & $\mathbf{0}$ & $\mathbf{0}$ & $\mathbf{7}(87 \%)$ \\
Ciências Humanas & $\mathbf{1 7}$ & $\mathbf{8}(47 \%)$ & $\mathbf{2}(11 \%)$ & $\mathbf{0}$ & $\mathbf{7}(41 \%)$ \\
Ciências Soc. Aplicadas & $\mathbf{5}$ & $\mathbf{3}(60 \%)$ & $\mathbf{2}(40 \%)$ & $\mathbf{0}$ & $\mathbf{0}$ \\
Engenharias & $\mathbf{1 0}$ & $\mathbf{3}(30 \%)$ & $\mathbf{0}$ & $\mathbf{1}(10 \%)$ & $\mathbf{6}(60 \%)$ \\
Linguística, Letras e Artes & $\mathbf{1}$ & $\mathbf{0}$ & $\mathbf{0}$ & $\mathbf{0}$ & $\mathbf{1}(100 \%)$ \\
Multidisciplinar & $\mathbf{4}$ & $\mathbf{0}$ & $\mathbf{0}$ & $\mathbf{1}(25 \%)$ & $\mathbf{3}(75 \%)$ \\
Total Geral & $\mathbf{1 3 5}$ & $\mathbf{2 6}(19 \%)$ & $\mathbf{1 0}(7 \%)$ & $\mathbf{3 5}(25 \%)$ & $\mathbf{6 4}(47 \%)$ \\
\hline
\end{tabular}

Tabela 31 - Indicação de padrão para citação - 2018

\begin{tabular}{cccc}
\hline Grande Área & $\mathbf{N}$ & Autor-Data & Numérico \\
\hline Ciências Agrárias & 26 & $\mathbf{2 6}(100 \%)$ & $\mathbf{0}$ \\
Ciências Biológicas & 17 & $\mathbf{1 4}(82 \%)$ & $\mathbf{3}(18 \%)$ \\
Ciências da Saúde & 47 & $\mathbf{5}(10 \%)$ & $\mathbf{4 2}(90 \%)$ \\
Ciências Exatas e da Terra & 8 & $\mathbf{4}(50 \%)$ & $\mathbf{4}(50 \%)$ \\
Ciências Humanas & 17 & $\mathbf{1 5}(88 \%)$ & $\mathbf{2}(12 \%)$ \\
Ciências Soc. Aplicadas & 5 & $\mathbf{5}(100 \%)$ & $\mathbf{0}$ \\
Engenharias & 10 & $\mathbf{7}(70 \%)$ & $\mathbf{3}(30 \%)$ \\
Linguística, Letras e Artes & 1 & $\mathbf{1}(100 \%)$ & $\mathbf{0}$ \\
Multidisciplinar & 4 & $\mathbf{2}(50 \%)$ & $\mathbf{2}(50 \%)$ \\
Total Geral & $\mathbf{1 3 5}$ & $\mathbf{7 9}(58 \%)$ & $\mathbf{5 6}(42 \%)$ \\
\hline
\end{tabular}

Pelas informações de cada periódico, foi possível observar que algumas têm recomendações quanto às referências bibliográficas. Estas sugestões dizem respeito à quantidade de referências por artigo, utilização de título abreviado dos periódicos ou, ainda, exigem uma determinada porcentagem de referências à artigos de periódicos. Conforme tabela 32, a área Multidisciplinar e de Ciências da Saúde são as com mais periódicos com recomendações quanto às referências bibliográficas.

Tabela 32 - Recomendações quanto às referências bibliográficas - 2018

\begin{tabular}{ccccc}
\hline Grande Área & $\mathbf{N}$ & Quantidade & Abreviação & \% Periódicos \\
\hline Ciências Agrárias & 26 & $\mathbf{5}(19 \%)$ & $\mathbf{4}(15 \%)$ & $\mathbf{8}(30 \%)$ \\
Ciências Biológicas & 17 & $\mathbf{2}(11 \%)$ & $\mathbf{6}(35 \%)$ & $\mathbf{0}$ \\
Ciências da Saúde & 47 & $\mathbf{2 8}(57 \%)$ & $\mathbf{2 1}(44 \%)$ & $\mathbf{1}(2 \%)$ \\
Ciências Exatas e da Terra & 8 & $\mathbf{0}$ & $\mathbf{3}(37 \%)$ & $\mathbf{0}$ \\
Ciências Humanas & 17 & $\mathbf{1}(5 \%)$ & $\mathbf{0}$ & $\mathbf{0}$ \\
Ciências Soc. Aplicadas & 5 & $\mathbf{1}(20 \%)$ & $\mathbf{0}$ & $\mathbf{0}$ \\
Engenharias & 10 & $\mathbf{0}$ & $\mathbf{1}(10 \%)$ & $\mathbf{0}$ \\
Linguística, Letras e Artes & 1 & $\mathbf{0}$ & $\mathbf{0}$ & $\mathbf{0}$ \\
Multidisciplinar & 4 & $\mathbf{1}(25 \%)$ & $\mathbf{3}(75 \%)$ & $\mathbf{1}(25 \%)$ \\
Total Geral & $\mathbf{1 3 5}$ & $\mathbf{3 8}(28 \%)$ & $\mathbf{3 8}(28 \%)$ & $\mathbf{1 0}(7 \%)$ \\
\hline
\end{tabular}




\subsubsection{Citações}

Quanto ao tipo documental das citações analisadas, observa-se que todas as áreas, com exceção de Ciências Humanas e Linguística, Letras e Artes, citam mais periódicos, enquanto estes dois últimos, fazem mais citações a livros (Tabela 33).

Tabela 33 - Percentual quanto ao tipo documental citado - 2011-2015

\begin{tabular}{ccccccc}
\hline Grande Área & \% Periódicos & \% Livro & $\begin{array}{c}\text { \% Cap. } \\
\text { Livro }\end{array}$ & \% Teses & \% Anais & \% Outros \\
\hline Ciências Agrárias & $\underline{\mathbf{7 2 , 2 3}}$ & 13,46 & 4,98 & 2,41 & 2,34 & 4,57 \\
Ciências Biológicas & $\underline{\mathbf{8 3 , 4 3}}$ & 7,51 & 4,62 & 0,77 & 0,41 & 3,26 \\
Ciências da Saúde & $\underline{\mathbf{8 3 , \mathbf { 8 9 }}}$ & 8,75 & 2,80 & 0,51 & 0,34 & 3,71 \\
C. Exatas e da Terra & $\underline{\mathbf{7 1 , 9 0}}$ & 8,30 & 0,94 & 0,94 & 1,42 & 16,50 \\
Ciências Humanas & $\mathbf{3 7 , 0 5}$ & $\underline{\mathbf{3 7 , 9 1}}$ & 11,80 & 2,71 & 1,35 & 9,18 \\
C. Sociais Aplicadas & $\underline{\mathbf{5 1 , 1 3}}$ & 26,37 & 6,95 & 1,98 & 3,60 & 9,97 \\
Engenharias & $\underline{\mathbf{7 4 , 0 1}}$ & 9,21 & 1,63 & 2,55 & 3,95 & 8,66 \\
Ling., Letras e Artes & $\mathbf{9 , 9 2}$ & $\underline{\mathbf{6 1 , 7 3}}$ & 18,38 & 1,15 & 0,57 & 8,25 \\
Multidisciplinar & $\underline{\mathbf{8 2 , 7 1}}$ & $\mathbf{7 , 2 0}$ & 4,37 & 0,87 & 0,83 & 4,01 \\
\hline
\end{tabular}

Considerando as citações entre os periódicos da amostra, em relação à normalização, é possível observar que os periódicos de Ciências Exatas e da Terra $(91,91 \%)$ e Ciências Humanas $(90,21 \%)$ são os que possuem a maior quantidade de citações normalizadas, enquanto os periódicos de Ciências Sociais Aplicadas (57,83\%) e Ciências da Saúde $(53,01 \%)$ apresentam uma taxa elevada de citações não-normalizadas. Vale ressaltar que dos 47 periódicos da área de Ciências da Saúde, somente 12 indicam bibliotecários ou revisores de referências (25\%) e em Ciências Sociais Aplicadas, 2 (40\%) dos 5 periódicos possuem assistência de bibliotecários e/ou revisores (Tabela 34).

Pelos resultados apresentados é possível observar um padrão em todas as áreas na questão de citarem, em sua maioria, artigos de periódicos, seguidos por citações a livros e capítulos de livros. A única exceção é a área de Linguística, Letras e Artes, que cita, principalmente livros. Já os periódicos de Ciências Exatas e da Terra citam mais anais que capítulos de livros e, os de Engenharias, citam outros documentos em seguida a periódicos e livros. 
Tabela 34 - Citações normalizadas entre os periódicos da amostra - 2011 a 2015

\begin{tabular}{ccc}
\hline Grande Área & Citações & $\mathbf{\%}$ \\
\hline Ciências Exatas e da Terra & 6.734 & 91,91 \\
Ciências Humanas & 4.240 & 90,21 \\
Ciências Agrárias & 68.587 & 85,91 \\
Engenharias & 2.111 & 75,41 \\
Ciências Biológicas & 23.613 & 68,92 \\
Multidisciplinar & 5.285 & 62,80 \\
Ciências Sociais Aplicadas & 645 & 57,83 \\
Ciências da Saúde & 85.325 & 53,01 \\
Total Geral & $\mathbf{1 9 6 . 5 4 0}$ & $\mathbf{6 9 , 0 6}$ \\
\hline
\end{tabular}

Quanto às citações normalizadas dentro da janela de 2 anos considerada para cálculo do Fator de Impacto, verifica-se que, novamente, os periódicos de Ciências Exatas e da Terra $(94,71 \%)$ e Ciências Humanas $(91,56 \%)$ são os que referenciam com menos erros, enquanto os periódicos de Ciências Sociais Aplicadas (53,06\%) e Ciências da Saúde $(53,53 \%)$ apresentam uma taxa elevada de erros de citação, indicando que quase metade das citações que poderiam ser contabilizadas estão sendo perdidas por descuido no momento da normalização (Tabela 35). Nota-se que, assim como na observação da normalização das citações, as áreas assumem a mesma posição, ou seja, quanto mais citações normalizadas, maiores as possibilidades daquelas que estão dentro da janela de 2 anos serem utilizadas para efeito de cálculo do FI.

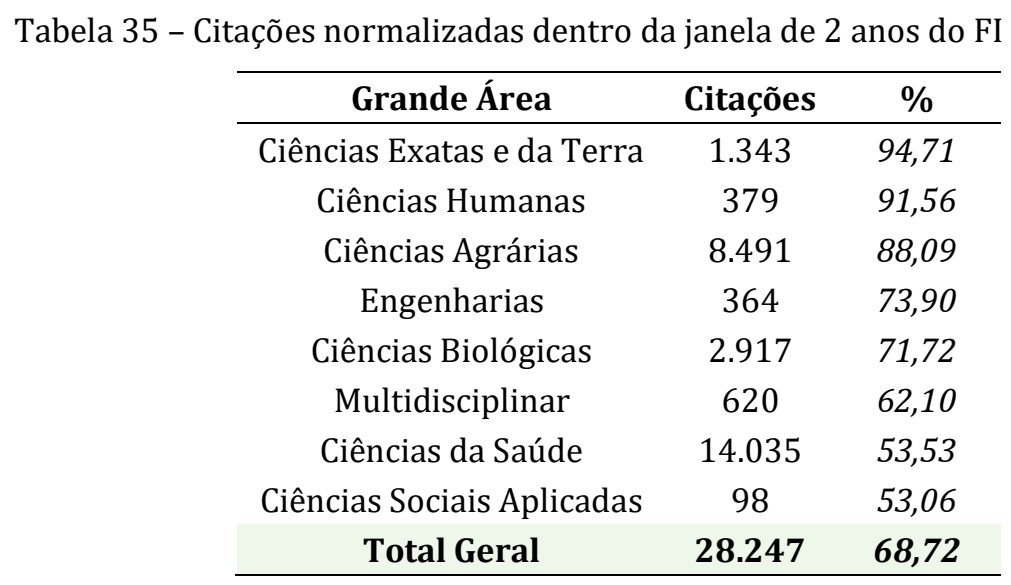

Analisando-se a taxa de autocitação dos periódicos da amostra, Ciências da Saúde (44,63\%) e Agrárias $(33,80 \%)$ são os maiores praticantes. Nota-se que quase metade $(49,62 \%)$ das autocitações na área de Ciências da Saúde não são normalizadas, o que 
aponta um aspecto bastante crítico, uma vez que o periódico não atenta para a normalização quando ele mesmo está sendo citado. Já a taxa de autocitação das áreas de Ciências Sociais Aplicadas, Engenharias, Multidisciplinar e Ciências Humanas ficam abaixo de 2,5\%. No entanto, as autocitações não-normalizadas $(56,21 \%)$ na área de Ciências Sociais Aplicadas ultrapassam as normalizadas (43,79\%). A área com menor taxa de autocitações não-normalizadas é a de Ciências Exatas e da Terra, com somente 2,97\% de erro (Tabela 36). Vale destacar que a área de Ciências da Saúde é a que tem mais menção de bibliotecários e revisores de referências nas equipes editoriais.

Tabela 36 - Autocitação dos periódicos da amostra, de acordo com a normalização - 2011 a 2015

\begin{tabular}{rccccccc}
\cline { 2 - 7 } & \multicolumn{3}{c}{ Normalizadas } & \multicolumn{2}{c}{ Não-normalizadas } & \multicolumn{2}{c}{ Total } \\
\cline { 2 - 7 } & citações & \% & citações & \% & Autocitações & \% \\
\hline Ciências da Saúde & 16.371 & 50,38 & 16.124 & 49,62 & $\mathbf{3 2 . 4 9 5}$ & $\mathbf{4 4 , 6 3}$ \\
Ciências Agrárias & 19.374 & 78,72 & 5.236 & 21,28 & $\mathbf{2 4 . 6 1 0}$ & $\mathbf{3 3 , 8 0}$ \\
Ciências Biológicas & 4.890 & 66,40 & 2.475 & 33,60 & $\mathbf{7 . 3 6 5}$ & $\mathbf{1 0 , 1 2}$ \\
Ciências Exatas e da Terra & 3.751 & 97,03 & 115 & 2,97 & $\mathbf{3 . 8 6 6}$ & $\mathbf{5 , 3 1}$ \\
Ciências Humanas & 1.355 & 86,47 & 212 & 13,53 & $\mathbf{1 . 5 6 7}$ & $\mathbf{2 , 1 5}$ \\
Multidisciplinar & 896 & 60,54 & 584 & 39,46 & $\mathbf{1 . 4 8 0}$ & $\mathbf{2 , 0 3}$ \\
Engenharias & 655 & 65,83 & 340 & 34,17 & $\mathbf{9 9 5}$ & $\mathbf{1 , 3 7}$ \\
Ciências Sociais Aplicadas & 187 & 43,79 & 240 & 56,21 & $\mathbf{4 2 7}$ & $\mathbf{0 , 5 9}$ \\
Total Geral & $\mathbf{4 7 . 4 7 9}$ & $\mathbf{6 5 , 2 1}$ & $\mathbf{2 5 . 3 2 6}$ & $\mathbf{3 4 , 7 9}$ & $\mathbf{7 2 . 8 0 5}$ & $\mathbf{1 0 0}$ \\
\hline
\end{tabular}

Ao verificar a porcentagem de normalização das referências dentro da janela de 5 anos do índice de Price, observa-se que quase metade das citações nas áreas de Engenharias (54,80\%) e Ciências Exatas e da Terra (45,37\%) estão normalizadas. Já as áreas de Ciências Humanas (28,70\%), Multidisciplinar (28,53\%) e Linguística, Letras e Artes $(27,02 \%)$ apresentam um percentual de normalização bastante baixo (Tabela 37).

Analisando-se a origem de indexação das citações a periódicos, todas as áreas utilizam, em sua maioria, periódicos que não estão no SciELO, em especial áreas de Engenharias e Linguística, Letras e Artes. Já a utilização de periódicos que estão no SciELO, as áreas de Ciências Agrárias, Ciências da Saúde e Ciências Biológicas têm destaque, apesar de Ciências Humanas ser a área com maior número de periódicos indexados na base. 
Tabela 37 - Percentual de citações normalizadas a periódicos, com até 5 anos (índice de Price) - 2011 a 2015

\begin{tabular}{rcccc}
\cline { 2 - 5 } & $\begin{array}{c}\text { Não-SciELO e } \\
\text { não-amostra }\end{array}$ & $\begin{array}{c}\text { SciELO e } \\
\text { não-amosta }\end{array}$ & $\begin{array}{c}\text { SciELO e } \\
\text { amostra }\end{array}$ & $\begin{array}{c}\text { Total } \\
\text { Geral }\end{array}$ \\
\hline Engenharias & 54,89 & 49,46 & 50,31 & $\mathbf{5 4 , 8 0}$ \\
Ciências Exatas e da Terra & 45,07 & 32,30 & 52,15 & $\mathbf{4 5 , 3 7}$ \\
Ciências da Saúde & 37,70 & 48,15 & 50,06 & $\mathbf{3 9 , 3 2}$ \\
Ciências Sociais Aplicadas & 33,81 & 33,21 & 44,81 & $\mathbf{3 4 , 0 4}$ \\
Ciências Agrárias & 29,36 & 35,98 & 42,50 & $\mathbf{3 1 , 6 9}$ \\
Ciências Biológicas & 30,03 & 26,01 & 39,44 & $\mathbf{3 0 , 7 2}$ \\
Ciências Humanas & 28,06 & 39,04 & 35,61 & $\mathbf{2 8 , 7 0}$ \\
Multidisciplinar & 27,72 & 22,92 & 39,91 & $\mathbf{2 8 , 5 3}$ \\
Linguística, Letras e Artes & 26,99 & 38,89 & 14,29 & $\mathbf{2 7 , 0 2}$ \\
\hline
\end{tabular}

Com respeito às citações realizadas entre os periódicos da amostra, é possível observar que as áreas com maior índice de normalização são as de Ciências Exatas e da Terra e Ciências Humanas. Vale ressaltar que Ciências Exatas e da Terra é a área com menor quantidade de periódicos indexados no SciELO ( $n=10)$ e, Ciências Humanas ( $n=$ 87), a segunda. Já a área com menor índice de normalização é a de Ciências da Saúde, área com maior número de periódicos indexados no SciELO (n = 92). 


\section{CONCLUSÕES}

0 referencial teórico deste trabalho sustentou a importância da normalização no contexto da comunicação científica. No entanto, apesar do avanço tecnológico e o crescimento das discussões e iniciativas da academia a respeito da qualidade da Ciência, a normalização bibliográfica, ainda constitui, em muitos casos, um empecilho para melhoria da qualidade dos periódicos e reconhecimento dos pesquisadores e suas instituições.

No último ano, a maioria dos eventos sobre comunicação científica, a exemplo da comemoração de 20 anos do SciELO, tem discutido a respeito da Ciência Aberta, préprints e publicações contínuas, mas a revisão da literatura evidencia que a observância e prática de iniciativas a respeito da qualidade extrínseca dos periódicos científicos, incluindo a normalização, ganham tanta importância quanto às características a respeito do conteúdo.

No cenário brasileiro, a indexação no SciELO confere prestígio e é o foco dos esforços de grande número de periódicos mas, apesar da criteriosa seleção para ingresso e permanência na base, além da promoção de muitas iniciativas para melhoria dos periódicos e profissionalização da equipe editorial, percebe-se que ainda há muitos avanços a serem realizados a respeito da normalização das referências bibliográficas.

Pela experiência acadêmica e profissional da autora pode-se afirmar que a atuação de bibliotecários em todos os processos da Comunicação Científica, auxiliaria na melhora destes resultados, sendo importante a recomendação da instrução destes profissionais desde sua formação.

A presente pesquisa é passível de aprimoramentos, reformulações e questionamentos, mas espera-se que o levantamento realizado sirva de subsídio e estímulo para o aprofundamento do tema, contribuindo para a melhoria em todas as instâncias do fluxo da Comunicação Científica. Destaca-se algumas limitações do estudo: 1) a dificuldade que o bibliotecário de um periódico terá de consultar a forma normalizada de escrita do título de outro periódico; 2) a ausência de menção a processos automáticos ou semi-automáticos de normalização utilizados pelas bases de dados, inclusive pela SciELO (mas com a ressalva que estes processos não estão livres de erro); 3 ) aspectos 
qualitativos dos periódicos que poderiam ter sido analisados (por exemplo, com questionários à equipe editorial de cada um), etc.

Por fim, muitas alternativas estão sendo apresentadas para transpôr os empecilhos da falta normalização, como alguns apresentados no texto (identificadores persistentes, guias, aplicativos para automação na geração de referências, novos formatos de publicação de metadados; etc.), mas todas visam a assertividade do presente para o futuro. Todavia, a comunidade científica ainda carece de soluções para a falta de normalização da literatura mais antiga. 


\section{REFERÊNCIAS}

ANDREIS, M.; JOKIC, M. An impact of Croatian journals measured by citation analysis from SCI-expanded database in time span 1975-2001. Scientometrics, v. 75, n. 2, p. 263-288, 2008.

ARAÚJO, C. A. A. Bibliometria: evolução histórica e questões atuais. Em Questão, v. 12, n. 1, p. 11-32, 2006.

ARAÚJO, C. A. A. Estudo bibliométrico sobre a incidência de dez dos principais autores da Ciência da Informação nos periódicos brasileiros entre 2003 e 2007. In: ENCONTRO NACIONAL DE PESQUISA EM CIÊNCIA DA INFORMAÇÃO, 2009, João Pessoa. Anais...João Pessoa: Ideia; Editora Universitária da UFPB, 2009.

ASSOCIAÇÃO BRASILEIRA DE NORMAS TÉCNICAS (ABNT). NBR 6022: Informação e documentação - Artigo em publicação periódica científica impressa - Apresentação. Rio de Janeiro: ABNT, 2003. 5 p.

ASSOCIAÇÃO BRASILEIRA DE NORMAS TÉCNICAS (ABNT). NBR 6023: Informação e documentação - Referências - Elaboração. Rio de Janeiro: ABNT, 2002a. 24 p.

ASSOCIAÇÃO BRASILEIRA DE NORMAS TÉCNICAS (ABNT). NBR 10520: Informação e documentação - Citações em documentos - Apresentação. Rio de Janeiro: ABNT, 2002b. 7 p.

ASSOCIAÇÃO BRASILEIRA DE NORMAS TÉCNICAS (ABNT). Normalização: definição. 2016. Disponível em: <https://goo.gl/v5bxQ3>. Acesso em 25 abr. 2016.

BUDD, J. Publicar em bibliotecologia y ciencia de La informacion: estado atual de la literatura. Revista Interamericana de Bibliotecologia, v. 12, n. 2, p. 71-91, 1989.

BALL, P. Paper trail reveals references go unread by citing authors. Nature, v. 420, p. 594, 2002. News.

BARATA, R. C. B. Dez coisas que você deveria saber sobre o Qualis. Revista Brasileira de Pós-Graduação, v. 13, n. 30, p. 13-40, 2016. doi: 10.21713/2358-2332.2016.v13.947.

BARBALHO, C. R. S. Periódicos científicos em formato eletrônico: elementos para sua avaliação. In: CONGRESSO BRASILEIRO DE CIÊNCIAS DA COMUNICAÇÃO, 28., 2005, Rio de Janeiro. Anais... São Paulo: INTERCOM, 2005. 
BICAS, H. E. A.; ROTHER, E. T.; BRAGA, M. E. R. Ainda sobre indexações. Arquivos Brasileiros de Oftalmologia, v. 65, n. 1, p. 5-6, 2002.

BRAGA, G. M.; OBERHOFER, C. A. Diretrizes para avaliação de periódicos científicos e técnicos brasileiros. Revista Latinoamericana de Documentación, v. 2, n. 1, p. 27-31, 1982.

CAFÉ, L.; BRÄSCHER, M. Organização da informação e bibliometria. Encontros Bibli: Revista Eletrônica de Biblioteconomia e Ciência da Informação, p. 54-75, 2008. doi: 10.5007/1518-2924.2008v13nesp1p54.

CASTRO, R. C. F.; FERREIRA, M. C. G.; VIDILI, A. L. Periódicos latino-americanos: avaliação das características formais e sua relação com a qualidade científica. Ciência da Informação, v. 25, n. 3, p. 357-367, 1996.

CASTRO, R. Indexação de revistas científicas em bases de dados. In: POBLACIÓN, D. A. et al. (Org.). Revistas científicas: dos processos tradicionais às perspectivas alternativas de comunicação. Cotia: Ateliê Editorial, 2011. p. 109-126.

COORDENAÇÃO DE APERFEIÇOAMENTO DE PESSOAL DE NÍVEL SUPERIOR (CAPES). CAPES 60 anos. Revista Comemorativa 2011. Disponível em: <https://goo.gl/TiwLvM>. Acesso em: 19 jun. 2018.

CORREIA, M. C. S. Levantamento das necessidades e requisitos bibliográficos dos pesquisadores da faculdade de Ciência da Informação, com vistas à adoção de um aplicativo para a automação de referências. 2010. 250 f. Dissertação (Mestrado em Ciência da Informação) - Faculdade de Ciência da Informação, Universidade de Brasília, 2010 .

CÔRTES, P. L. Considerações sobre a evolução da ciência e da comunicação científica. In: POBlaCiON, D. A.; WITTER, G. P.; SILVA; J. F. M. (Org.). Comunicação \& Produção Científica. São Paulo: Angellara Editora, 2006. p. 33-56.

CUNHA, L. G. C. Normalização de originais. Ciência da Informação, v. 2, n. 1, p. 59-63, 1973.

CURTY, M. G.; BOCCATO, V. R. C. O artigo científico como forma de comunicação do conhecimento na área de Ciência da Informação. Perspectivas em Ciência da Informação, v. 10, n. 1, p. 94-107, 2005.

DAVYT, A.; VELHO, L. A. A avaliação da ciência e a revisão por pares: passado e presente. Como será o futuro? História, Ciência, Saúde- Manguinhos, v. 7, n. 1, p. 93-116, 2000. 
DEVIS, J.; HERRERA, M. V.; JIMENO, L. A.; VALCÁRCEL, J. V.; DOÑA, A. M. Las revistas científico-técnicas españolas de ciencias da la actividad física y del deporte: adecuación a las normas ISO y grado de normalización. Ciência da Informação, v. 33, n. 1, p. 38-47, 2004.

DIAS, V. Normalização documentária: influência nos trabalhos científicos e técnicos. Resumos e resenhas. 2008. Disponível em: <https://goo.gl/NBomCm>. Acesso em: 23 jun. 2017.

DIGIAMPIETRI, L. A.; MUGNAINI, R. Técnicas para desambiguação de citações: o uso de Regressão a partir do ano e volume. In: ENCONTRO BRASILEIRO DE BIBLIOMETRIA E CIENTOMETRIA, 5., 2016, São Paulo. Anais... São Paulo: USP, 2016.

FACHIN, G. R. B. Modelo de avaliação para periódicos científicos on-line: proposta de indicadores bibliográficos e telemáticos. 2002. 210 f. Dissertação (Mestrado em Engenharia de Produção) - Programa de Pós-Graduação em Engenharia de Produção, Universidade Federal de Santa Catarina, Florianópolis, 2002.

FACHIN, G. R.; HILLESHEIM, A. I. A.; RADOS, G. J. V. Normas e padrões para os periódicos científicos on-line. In: SEMANA DE ENSINO, PESQUISA E EXTENSÃO DA UFSC, 5., 2005, Florianópolis. Anais... Florianópolis: UFSC, 2005.

FARIA, L. I. L. Prospecção tecnológica em materiais: aumento da eficiência do tratamento bibliométrico: aplicação na análise de tratamentos de superfície resistentes ao desgaste. 2001. 202 f. Tese (Doutorado em Ciência e Engenharia de Materiais) Universidade Federal de São Carlos: São Carlos, 2001.

FERREIRA, M. C. G.; KRZYZANOWSKI, R. F. Periódicos científicos: critérios de qualidade. Pesquisa Odontológica Brasileira, v. 17, p. 43-48, 2003. Suplemento 1.

FERREIRA, M. M.; MOREIRA, R. L. (Orgs.). CAPES 50 anos: depoimentos ao CPDOC/FGV. Brasília: FGV/CPDOC/CAPES, 2002. Disponível em: <https://goo.gl/Ad8p67>. Acesso em: 08 jul. 2018.

FERREIRA, S. M. S. P. Critérios de qualidade para as revistas científicas em comunicação. In: FERREIRA, S. M. S. P.; TARGINO, M. G. (Org.). Preparação de revistas científicas: teoria e prática. São Paulo: Reichmann \& Autores, 2005. p. 269-293.

FIGUEIREDO, L. M.; CUNHA, L. G. C. Curso de bibliografia geral, para uso dos alunos das escolas de biblioteconomia. Rio de Janeiro: Distribuidora Record, 1967.

FONSECA, C. Avaliação dos programas de pós-graduação: do ponto de vista de um nativo. Horizontes Antropológicos, v. 7, n. 16, p. 261-275, 2001. 
FORESTI, N. Estudo da contribuição das revistas brasileiras de biblioteconomia e ciência da informação enquanto fonte de referência para a pesquisa. 1989. $209 \mathrm{f}$. Dissertação (Mestrado) - Departamento de Biblioteconomia, Faculdade de Estudos Sociais e Aplicados, Universidade de Brasília, Brasília, DF, 1989.

FROHMANN, B. Deflating information: from science studies to documentation. Toronto: University of Toronto Press, 2000. 320 p. doi: 10.3138/9781442673779.

GALEMBECK, F. Sem avaliações, sem progresso. Ciência e Cultura, v. 42, n. 9, p. 627-628, 1990.

GARFIELD, E. Citation analysis as a tool in journal evaluation. Science, v. 178, n. 4060, p. 471-479, 1972.

GARFIELD, E. Long-term vc. short-term impact: does it matter? The Scientist, v. 12, n. 3, p. 10-13, 1998.

GARVEY, W. D. Communication: the essence of science: facilitating information among librarians, scientists, engeneers and students. Oxford: Pergamon Press, 1979. 332 p.

GHAI, B.; SAXENA, A. K.; MAKKAR, J. K. A guide to reducing citation errors in bibliographies. Emergency Medical Journal, v. 24, n. 3, p. 232-233, 2007. doi: 10.1136/emj.2006.044206.

GIL, A. C. Como elaborar projetos de pesquisa. 4. ed. São Paulo: Atlas, 2002. 175 p.

GLÄNZEL, W.; MOED, H. F. Journal impact measures in bibliometric research. Scientometrics, v. 53, n. 2, p. 171-193, 2002.

GONÇALVES, A.; RAMOS, L. M. S. V. C.; CASTRO, R. C. F. Revistas Científicas: características, funções e critérios de qualidade. In: POBLACION, D. A.; WITTER, G. P.; SILVA; J. F. M. (Org.). Comunicação \& Produção Científica. São Paulo: Angellara Editora, 2006.p. 163-190.

GREENE, L. J. 0 dilema do editor de uma revista biomédica: aceitar ou não aceitar. Ciência da Informação, v. 27, n. 2, p. 230-32, 1998.

GUEDES, V. L. S.; BORSCHIVER, S. Bibliometria: uma ferramenta estatística para a gestão da informação e do conhecimento, em sistemas de informação, de comunicação e de avaliação científica e tecnológica. In: ENCONTRO NACIONAL DE CIÊNCIA DA INFORMAÇÃO, 6., 2005, Salvador. Anais... Guaratinguetá: UNESP, 2005. 18 p.

IOANNIDIS, J. P. A.; BOYACK, K.; WOUTERS, P. F. Citation metrics: a primer on how (not) to normalize. PLoS Biology, v. 14, n. 9, e1002542, 2016. doi: 10.1371/journal.pbio.1002542. 
KAPLAN, N.; STORER, N. Scientific communication. International Enciclopedia of Social Sciences, v. 41, p. 112-117, 1968.

KOTIAHO, J. S.; TOMKINS, J. L.; SIMMONS, L. W. Unfamiliar citations breed mistakes. Nature, v. 400, p. 307, 1999. Correspondence.

KRZYZANOWSKI, R. F.; FERREIRA, M. C. G. Avaliação de periódicos científicos e técnicos brasileiros. Ciência da Informação, v. 27, n. 2, p. 165-175, 1998.

LANGE, L. L. The impact factor as a phantom: Is there a self-fulfilling prophecy effect of impact? Journal of Documentation, v. 58, n. 2, p. 175-184, 2002. doi: 10.1108/00220410210425449.

LAPIDO, F. M. Seleção SciELO Brasil: critérios e procedimentos para a admissão e permanência de periódicos científicos na coleção. In: ENCONTRO INTERNACIONAL DE EDITORES E AUTORES DE PERIÓDICOS CIENTÍFICOS DA ÁREA DE ODONTOLOGIA, 6., 2009, Porto Alegre. Anais... Porto Alegre: PUCRS, 2009.

LE PAIR, E. Formal evaluation methods: their utility and limitations. International Forum on Information and Documentation, v. 20, n. 4, p. 16-24, 1995.

LINDSEY, D. Using citations counts as a measure of quality in science measuring what's measurable rather than what's valid. Scientometrics, v. 15, n. 3-4, p. 189-203, 1989. doi: 10.1007/BF02017198.

LÓPEZ-CÓZAR, E. D. Evaluacióndel grado de ajuste de las revistas españolas de ciencias de lasalud a las normas internacionales de presentación de publicaciones periódicas. Revista Española de Salud Pública, v. 71, n. 6, p. 531-56, 1997.

MEADOWS, A. J. A comunicação científica. Brasília: Briquet de Lemos, 1999.

MENDONÇA, A. Persistência e normalização dos dados dominaram a agenda do III Curso de Atualização SciELO-ScholarOne [online]. SciELO em Perspectiva, 2017 Disponível em: <https://goo.gl/5jgMUi>. Acesso em 14 set. 2017.

MENEGHINI, R. SciELO (Scientific Eletronic Library Online) project and the visibility of “peripheral’ scientific literature. Química Nova, v. 26. n. 2, p. 156-156, 2003.

MERTON, R. K. In: GARFIELD, E. Citation indexing: its theory and application in science, technology, and humanities. Philadelphia: ISI-Press, 1979. p.v-ix.

MERTON, R. K. Sociologia: teoria e estrutura. São Paulo: Mestre Jou, 1970. 758 p. 
MIRANDA, E. C. P. M. Periódicos científicos de Turismo e Hospitalidade no Brasil: padrões de normalização. 2012. 210 f. Dissertação (Mestrado em Hospitalidade) Programa de Mestrado em Hospitalidade, Universidade Anhembi Morumbi, São Paulo, 2012.

MOED, H. F. The impact-factors debate: the ISI's uses and limits. Nature, v. 415, n. 6873, p. 731-732, 2002.

MOREIRA, C. O. F.; HORTALE, V. A.; HARTZ, Z. A. Avaliação da pós-graduação: buscando consenso. Revista Brasileira de Pós-graduação, v. 1, n. 1, p. 26-40, 2004.

MUELLER, S. P. M. O periódico científico. In: CAMPELLO, B. S.; CENDÓN, B. V.; KREMER, J. M. (Orgs.). Fontes de informação para pesquisadores e profissionais. Belo Horizonte: Editora UFMG, 2007. p. 73-95.

MUGNAINI, R. 40 anos de bibliometria no Brasil: da bibliografia estatística à avaliação da produção científica nacional. In: HAYASHI, M. C. P. I.; LETA, J. (Ed.). Bibliometria e cientometria: reflexões teóricas e interfaces. São Carlos: Pedro e João Editores, 2013. p. 37-58.

MUGNAINI, R. Avaliação da produção científica nacional: contextualização e indicadores. In: POBLACIÓN, D. A.; WITTER, G. P.; RAMOS, L. M. S. V. C.; FUNARO, V. M. B. O. (Org.). Revistas científicas: dos processos tradicionais às perspectivas alternativas de comunicação. Cotia: Ateliê Editorial, 2011. p. 43-68.

MUGNAINI, R. Caminhos para adequação da avaliação da produção científica brasileira: impacto nacional versus internacional. São Paulo, 2006. 253 f. Tese (Doutorado em Ciência da Informação) - Escola de Comunicações e Artes, Universidade de São Paulo, São Paulo, 2006.

MUGNAINI, R. Ciclo avaliativo de periódicos no Brasil: caminho virtuoso ou colcha de retalhos? In: ENCONTRO NACIONAL DE PESQUISA EM CIÊNCIA DA INFORMAÇÃO, 16., 2015, João Pessoa. Anais... João Pessoa: UFPB, 2015.

MUGNAINI, R.; EFRAIN-GARCÍA, P. Influências metodológicas na mensuração de impacto: o caso das Memórias do Instituto Oswaldo Cruz e sua "qualificação". Perspectivas em Ciência da Informação, v. 14, n. 3, p. 10, 2009. doi: 10.1590/S1413-99362009000300011.

MUGNAINI, R.; JANNUZZI, P.; QUONIAM, L. Indicadores bibliométricos da produção científica brasileira: uma análise a partir da base Pascal. Ciência da Informação, v. 33, n. 2, p. 123-131, 2004. 
MUGNAINI, R.; PIO, L.; PAULA, A. S. A. A comunicação científica em periódicos no Brasil: índices de citação, indexação e indicadores bibliométricos na avaliação da ciência. In: NETO, A. F.; CARNEIRO, F. F. B.; SANTOS, W. (Orgs.). Comunicação científica em periódicos. Curitiba: Appris, 2019. Capítulo 7. p. 197-231.

MUGNAINI, R.; SALES, D. P. Mapeamento do uso de índices de citação e indicadores bibliométricos na avaliação da produção científica brasileira. In: ENCONTRO NACIONAL DE PESQUISA EM CIÊNCIA DA INFORMAÇÃO, 12., Brasília, 2011. Anais... Brasília: Thesaurus, 2011. v. 12. p. 2361-2372.

MUGNAINI, R.; STREHL, L. Recuperação e impacto da produção científica na era Google: uma análise comparativa entre o Google Acadêmico e a Web of Science. Encontros Bibli: Revista Eletrônica de Biblioteconomia e Ciência da Informação, v. 13, p. 92-105, 2008.

NASCIMENTO, C. C. Revistas científicas: a busca pela qualidade e indicadores bibliométricos. 2014. 196 f. Dissertação (Mestrado em Ciência da Informação) - Programa de Pós-Graduação em Ciência da informação, Escola de Comunicação e Artes, Universidade de São Paulo, São Paulo, 2014.

NASSI-CALÒ, L. É possível normalizar métricas de citação? [online]. SciELO em Perspectiva, 2016 Disponível em: <https://goo.gl/Sg9oNt>. Acesso em: 12 dez. 2017.

NEUBERT, P. S.; RODRIGUES, R. S.; MÜLLER, Y. M. R. Periódicos científicos de ciências biológicas: estudo dos títulos classificados no estrato A1 do Qualis. Reciis, v. 11, n. 3, p. 115, 2017.

NORONHA, D. P.; MARICATO, J. M. Estudos métricos da informação: primeiras aproximações. Encontros Bibli: Revista Eletrônica de Biblioteconomia e Ciência da Informação, p. 116-128, 2008. doi: 10.5007/1518-2924.2008v13nesp1p116.

ORTELLADO, P. As políticas nacionais de acesso à informação científica. Liinc em Revista, v. 4, n. 2, p. 186-195, 2008.

PACKER, A. L.; MENEGHINI, R. Visibilidade da produção científica. In: POBLACIÓN, D. A.; WITTER, G. P.; SILVA, J. F. M. (Org.). Comunicação e produção científica: contexto, indicadores, avaliação. São Paulo: Angellara, 2006. p. 235-259.

PAULA, A. S. A.; MUGNAINI, R. Normalização de referências e suas implicações no impacto de periódicos de Enfermagem In: ENCONTRO BRASILEIRO DE BIBLIOMETRIA E CIENTOMETRIA, 5., 2016, São Paulo. Anais... São Paulo: USP, 2016. p. 1-7.

PINTO, A. C.; ANDRADE, J. B. Fator de Impacto de revistas científicas: qual o significado deste parâmetro? Química Nova, v. 22, n. 3, p. 448-453, 1999. 
PRICE, D. J. S. Networks of scientific papers. Science, v. 149, n. 3683, p. 56-64, 1965.

RAJA, U. Y.; COOPER, J. G. How accurate are the references in Emergency Medical Journal? Emergency Medical Journal, v. 23, n. 8, 2006. doi: 10.1136/emj.2004.022103.

RODRIGUES, M. E. F.; LIMA, M. H. T. F.; OLIVEIRA-GARCIA, M. J. A normalização no contexto da comunicação científica. Perspectivas em Ciência da Informação, v. 3, n. 2, p. 147-156, 1998.

ROSTAING, H. La bibliométrie et ses techniques. Toulouse: Sciences de la Société; Marselle: Centre de Recherche Rétrospective de Marseille, 1996. 131 p.

SAHA, S.; SAINT, S.; CHRISTAKIS, D. A. Impact factor: a valid measure of journal quality? Journal of Medical Library Association, v. 91, n. 1, p. 42-46, 2003.

SALES, D. P. Critérios de avaliação da produção científica em ciências sociais aplicadas: inquirindo as bases de dados. 2013. 115 f. Dissertação (Mestrado em Ciência da Informação) - Escola de Comunicação e Artes, Universidade de São Paulo, São Paulo, 2013.

SANCHO, R. Indicadores bibliométricos utilizados en la evaluación de la ciencia y la tecnología. Revista Española de Documentação Científica, v. 13, n. 3-4, p. 842-865. 1990.

SANTIN, D. M.; VANZ, S. A. S.; STUMPF, I. R. C. Internacionalização da produção científica em Ciências Biológicas da UFRGS: 2000-2011. Transinformação, v. 27, n. 3, p. 209-218, 2015.

SANTOS, C. M. Tradições e contradições da pós-graduação no Brasil. Educação \& Sociedade, v. 24, n. 83, p. 627-641, 2003.

SANTOS, S. M. O desempenho das universidades brasileiras nos rankings internacionais: áreas de destaque da produção científica brasileira. 2015. 344 f. Tese (Doutorado em Ciência da Informação) - Escola de Comunicações e Artes, Universidade de São Paulo, São Paulo, 2015. doi:10.11606/T.27.2015.tde-26052015-122043.

SANTOS, S. M. Perfil dos periódicos científicos de Ciências Sociais e de Humanidades: mapeamento das características extrínsecas. 2010. 176 f. Dissertação (Mestrado em Cultura e Informação) - Escola de Comunicações e Artes, Universidade de São Paulo, São Paulo, 2010. 
SANTOS, S. M. Profissionalização de processos editoriais: normalização de dados. In: CURSO DE EDITORAÇÃo CIENTÍFICA, 25., 2017, São Paulo. Anais... São Paulo: ABEC, 2017.

SAYÃO, F. Bases de dados: a metáfora da memória científica. Ciência da Informação, v. 25, n. 3, p. 314-318, 1996.

SCHWARTZMAN, S. Um espaço para a ciência: a formação da comunidade científica no Brasil. Brasília: Ministério da Ciência e Tecnologia, 2001. Disponível em: <http://livroaberto.ibict.br/handle/1/757>. Acesso em: 14 ago. 2018.

SEVERINO, A. J. Metodologia do trabalho científico. 23. ed. rev. e atual. São Paulo: Cortez, 2007. 304 p.

SILVA, J. F. M.; RAMOS, L. M. S. V. C. R.; NORONHA, D. P. Base de dados. In: POBLACIÓN, D. A.; WITTER, G. P.; SILVA, J. F. M. In: POBLACIÓN, D. A.; WITTER, G. P.; SILVA, J. F. M. (Org.). Comunicação e produção científica: contexto, indicadores, avaliação. São Paulo: Angellara, 2006. p. 263-285.

SILVA, J. F. M.; SANTOS, M.; PRAZERES, A. P. P. Incubadora de revistas científicas. In: POBlACión, D. A.; WITTER, G. P.; RAMOS, L. M. S. V. C.; FUNARO, V. M. B. O. (Org.). Revistas científicas: dos processos tradicionais às perspectivas alternativas de comunicação. Cotia: Ateliê Editorial, 2011. p. 69-90.

SIMKIN, M. V.; ROYCHOWDHURY, V. P. Do copied citations create renowned papers? Annals of Improbable Research, v. 11, n. 1, p. 24-27, 2005.

SOUZA, E. P.; PAULA, M. C. S. QUALIS: a base de qualificação dos periódicos científicos utilizada na avaliação CAPES. INFOCAPES - Boletim Informativo da CAPES, v. 10, n. 2, p. 7-25, 2002.

SPAGNOLO, F.; SOUZA, V. C. O que mudar na avaliação da Capes? Revista Brasileira de Pós-Graduação, v. 1, n. 2, p. 8-34, 2004.

SPINAK, E. Indicadores cienciometricos. Ciência da Informação, v. 27, n. 2, p. 141-148, 1998. doi: 10.18225/ci.inf..v27i2.795.

TAGLER, J. What are the reasons for the current packaging of journals? Library Acquisitions: Practice \& Theory, v. 13, p. 109-113, 1989.

TARGINO, M. G.; GARCIA, J. C. R. O editor e a revista científica: entre "o feijão e o sonho". In: FERREIRA, S. M. S. P.; TARGINO, M. G. (Orgs.). Mais sobre revistas científicas: em foco a gestão. São Paulo: Senac; Cengage Learning, 2008. p. 41-72. 
TRZESNIAK, P. A concepção e a construção da revista científica. In: CURSO DE EDITORAÇÃO CIENTÍFICA, 10., 2001, Petrópolis. Petrópolis: ABEC, 2001. p. 17-23.

TRZESNIAK, P. A estrutura editorial de um periódico científico. In: SABADINI, A. A. Z. P.; SAMPAIO, M. I. C.; KOLLER, S. H. (Orgs.). Publicar em psicologia: um enfoque para a revista científica. São Paulo: Associação Brasileira de Editores Científicos de Psicologia; Instituto de Psicologia da Universidade de São Paulo, 2009. p. 87-102.

TRZESNIAK, P. As dimensões da qualidade dos periódicos científicos e sua presença em um instrumento da área da educação. Revista Brasileira de Educação, v. 11, n. 32, p. 346-361, 2006. doi: 10.1590/S1413-24782006000200013.

UNESCO. Organización de las Naciones Unidas para la Educación, la Ciencia y la Cultura. Hacia las sociedades del conocimiento. Paris: UNESCO, 2005.

URBIZAGÁSTEGUI-ALVARADO, R. U. A bibliometria no Brasil. Ciência da Informação, v. 13, n. 2, p. 91-105, 1984.

VOGEL, M. J. M. Avaliação da pós-graduação brasileira: análise dos quesitos utilizados pela Capes e das críticas da comunidade acadêmica. 2015. Tese (Doutorado em Cultura e Informação) - Escola de Comunicações e Artes, Universidade de São Paulo, São Paulo, 2015. doi: 10.11606/T.27.2015.tde-29062015-150747.

WEISMAN, H. M. Information Systems, services and centers. New York: Becker \& Hayes, 1972.

WEITZEL, S. R. Fluxo da informação científica. In: POBLACIÓN, D. A.; WITTER, G. P.; SILVA, F. J. M. (Org.). Comunicação e produção científica: contexto, indicadores, avaliação. São Paulo: Angellara, 2006. p. 81-114. Capítulo 3.

YAMAMOTO, O. H.; MENANDRO, P. R. M.; KOLLER, S. H.; LOBIANCO, A. C.; HUTZ, C. S.; BUENO, J. L. O.; GUEDES, M. C. Avaliação de periódicos científicos brasileiros da área da psicologia. Ciência da Informação, v. 31, n. 2, p. 163-177, 2002. doi: 10.1590/S010019652002000200017.

ZIMAN, J. Conhecimento público. Belo Horizonte: Itatiaia; São Paulo: Universidade de São Paulo, 1979. 
Apêndice A - Porcentagem de citações normalizadas entre os periódicos da amostra

\begin{tabular}{|c|c|c|c|c|}
\hline Periódicos & Total & PRICE & FI & AUTOCITAÇÃO \\
\hline $\begin{array}{l}\text { ABCD. ARQUIVOS BRASILEIROS DE CIRURGIA DIGESTIVA } \\
\text { (SAO PAULO) }\end{array}$ & $51,07 \%$ & $40,28 \%$ & $32,14 \%$ & $15,66 \%$ \\
\hline ACTA AMAZONICA & $85,22 \%$ & $88,92 \%$ & $90,74 \%$ & $87,29 \%$ \\
\hline ACTA BOTANICA BRASILICA & $97,71 \%$ & $98,55 \%$ & $97,20 \%$ & $99,28 \%$ \\
\hline ACTA CIRURGICA BRASILEIRA & $60,66 \%$ & $58,78 \%$ & $63,37 \%$ & $68,68 \%$ \\
\hline ACTA ORTOPEDICA BRASILEIRA & $55,47 \%$ & $57,94 \%$ & $74,07 \%$ & $0,00 \%$ \\
\hline ACTA PAULISTA DE ENFERMAGEM & $66,96 \%$ & $71,44 \%$ & $75,50 \%$ & $97,77 \%$ \\
\hline ACTA SCIENTIARUM. AGRONOMY & $98,32 \%$ & $98,43 \%$ & $100,00 \%$ & $0,00 \%$ \\
\hline ANAIS BRASILEIROS DE DERMATOLOGIA & $80,98 \%$ & $86,05 \%$ & $90,00 \%$ & $99,06 \%$ \\
\hline ANAIS DA ACADEMIA BRASILEIRA DE CIENCIAS & $73,28 \%$ & $82,18 \%$ & $87,95 \%$ & $99,55 \%$ \\
\hline ARCHIVES OF CLINICAL PSYCHIATRY (SAO PAULO) & $58,33 \%$ & $61,44 \%$ & $65,38 \%$ & $0,00 \%$ \\
\hline ARCHIVES OF ENDOCRINOLOGY AND METABOLISM & $51,01 \%$ & $32,88 \%$ & $43,33 \%$ & $0,00 \%$ \\
\hline $\begin{array}{l}\text { ARQUIVO BRASILEIRO DE MEDICINA VETERINARIA E } \\
\text { ZOOTECNIA }\end{array}$ & $54,90 \%$ & $62,68 \%$ & $71,99 \%$ & $96,21 \%$ \\
\hline ARQUIVOS BRASILEIROS DE CARDIOLOGIA & $86,74 \%$ & $89,29 \%$ & $91,34 \%$ & $98,92 \%$ \\
\hline $\begin{array}{l}\text { ARQUIVOS BRASILEIROS DE ENDOCRINOLOGIA \& } \\
\text { METABOLOGIA }\end{array}$ & $36,57 \%$ & $33,61 \%$ & $23,02 \%$ & $34,98 \%$ \\
\hline ARQUIVOS BRASILEIROS DE OFTALMOLOGIA & $89,41 \%$ & $91,29 \%$ & $88,66 \%$ & $98,56 \%$ \\
\hline ARQUIVOS DE NEURO-PSIQUIATRIA & $17,63 \%$ & $14,95 \%$ & $11,64 \%$ & $0,73 \%$ \\
\hline BIOTA NEOTROPICA & $81,07 \%$ & $87,34 \%$ & $91,54 \%$ & $97,51 \%$ \\
\hline BOLEMA: BOLETIM DE EDUCACAO MATEMATICA & $95,17 \%$ & $94,12 \%$ & $94,87 \%$ & $95,62 \%$ \\
\hline BOLETIM DE CIENCIAS GEODESICAS & $88,46 \%$ & $80,00 \%$ & $71,43 \%$ & $0,00 \%$ \\
\hline BRAGANTIA & $98,85 \%$ & $98,92 \%$ & $99,68 \%$ & $99,34 \%$ \\
\hline BRAZILIAN ARCHIVES OF BIOLOGY AND TECHNOLOGY & $45,88 \%$ & $41,22 \%$ & $49,67 \%$ & $35,99 \%$ \\
\hline BRAZILIAN JOURNAL OF BIOLOGY & $95,49 \%$ & $96,72 \%$ & $96,28 \%$ & $99,30 \%$ \\
\hline BRAZILIAN JOURNAL OF BOTANY & $98,07 \%$ & $97,53 \%$ & $97,87 \%$ & $98,28 \%$ \\
\hline BRAZILIAN JOURNAL OF CARDIOVASCULAR SURGERY & $27,94 \%$ & $22,20 \%$ & $20,08 \%$ & $0,00 \%$ \\
\hline BRAZILIAN JOURNAL OF CHEMICAL ENGINEERING & $93,40 \%$ & $94,94 \%$ & $95,50 \%$ & $97,07 \%$ \\
\hline BRAZILIAN JOURNAL OF GEOLOGY & $61,02 \%$ & $77,78 \%$ & $71,43 \%$ & $73,33 \%$ \\
\hline BRAZILIAN JOURNAL OF INFECTIOUS DISEASES & $52,82 \%$ & $59,38 \%$ & $62,07 \%$ & $96,27 \%$ \\
\hline $\begin{array}{l}\text { BRAZILIAN JOURNAL OF MEDICAL AND BIOLOGICAL } \\
\text { RESEARCH }\end{array}$ & $82,23 \%$ & $83,81 \%$ & $81,82 \%$ & $100,00 \%$ \\
\hline BRAZILIAN JOURNAL OF MICROBIOLOGY & $72,84 \%$ & $78,44 \%$ & $86,08 \%$ & $97,32 \%$ \\
\hline BRAZILIAN JOURNAL OF OCEANOGRAPHY & $88,68 \%$ & $93,43 \%$ & $97,62 \%$ & $91,23 \%$ \\
\hline BRAZILIAN JOURNAL OF OTORHINOLARYNGOLOGY & $22,87 \%$ & $17,41 \%$ & $15,44 \%$ & $0,00 \%$ \\
\hline BRAZILIAN JOURNAL OF PHARMACEUTICAL SCIENCES & $82,17 \%$ & $84,98 \%$ & $87,62 \%$ & $97,39 \%$ \\
\hline BRAZILIAN JOURNAL OF PHYSICAL THERAPY & $60,28 \%$ & $63,57 \%$ & $55,78 \%$ & $71,71 \%$ \\
\hline BRAZILIAN ORAL RESEARCH & $76,38 \%$ & $81,06 \%$ & $82,94 \%$ & $89,51 \%$ \\
\hline CADERNOS DE SAUDE PUBLICA & $67,34 \%$ & $70,78 \%$ & $71,94 \%$ & $99,93 \%$ \\
\hline CERNE & $98,20 \%$ & $97,87 \%$ & $96,00 \%$ & $0,00 \%$ \\
\hline CIENCIA \& SAUDE COLETIVA & $44,11 \%$ & $38,30 \%$ & $29,02 \%$ & $2,16 \%$ \\
\hline CIENCIA E AGROTECNOLOGIA & $95,36 \%$ & $95,95 \%$ & $96,23 \%$ & $98,13 \%$ \\
\hline CIENCIA FLORESTAL & $93,91 \%$ & $93,69 \%$ & $89,13 \%$ & $0,00 \%$ \\
\hline CIENCIA RURAL & $94,96 \%$ & $95,43 \%$ & $97,08 \%$ & $99,33 \%$ \\
\hline CLINICS & $43,40 \%$ & $42,33 \%$ & $29,91 \%$ & $0,00 \%$ \\
\hline COMPUTATIONAL \& APPLIED MATHEMATICS & $100,00 \%$ & $100,00 \%$ & $100,00 \%$ & $100,00 \%$ \\
\hline CROP BREEDING AND APPLIED BIOTECHNOLOGY & $96,51 \%$ & $96,68 \%$ & $96,88 \%$ & $0,00 \%$ \\
\hline DADOS & $78,61 \%$ & $85,94 \%$ & $80,77 \%$ & $69,53 \%$ \\
\hline
\end{tabular}




\begin{tabular}{|c|c|c|c|c|}
\hline ECLETICA QUIMICA & $94,20 \%$ & $93,55 \%$ & $100,00 \%$ & $100,00 \%$ \\
\hline EDUCAR EM REVISTA & $87,97 \%$ & $88,68 \%$ & $100,00 \%$ & $100,00 \%$ \\
\hline EINSTEIN (SAO PAULO) & $59,37 \%$ & $66,78 \%$ & $62,89 \%$ & $97,06 \%$ \\
\hline ENGENHARIA AGRICOLA & $95,50 \%$ & $95,53 \%$ & $96,13 \%$ & $99,31 \%$ \\
\hline ENGENHARIA SANITARIA E AMBIENTAL & $80,68 \%$ & $79,38 \%$ & $67,39 \%$ & $62,71 \%$ \\
\hline $\begin{array}{l}\text { ESTUDOS DE LITERATURA BRASILEIRA } \\
\text { CONTEMPORANEA }\end{array}$ & $85,71 \%$ & $100,00 \%$ & $0,00 \%$ & $0,00 \%$ \\
\hline FOOD SCIENCE AND TECHNOLOGY & $93,68 \%$ & $91,80 \%$ & $88,89 \%$ & $91,28 \%$ \\
\hline GENETICS AND MOLECULAR BIOLOGY & $84,95 \%$ & $87,82 \%$ & $89,29 \%$ & $100,00 \%$ \\
\hline HISTORIA, CIENCIAS, SAUDE-MANGUINHOS & $87,16 \%$ & $85,44 \%$ & $71,88 \%$ & $78,17 \%$ \\
\hline HORTICULTURA BRASILEIRA & $98,20 \%$ & $97,34 \%$ & $98,58 \%$ & $99,68 \%$ \\
\hline IHERINGIA. SERIE ZOOLOGIA & $87,81 \%$ & $82,50 \%$ & $77,39 \%$ & $0,00 \%$ \\
\hline INTERNATIONAL BRAZ J UROL & $77,78 \%$ & $77,17 \%$ & $84,78 \%$ & $88,45 \%$ \\
\hline JORNAL BRASILEIRO DE PNEUMOLOGIA & $79,12 \%$ & $81,20 \%$ & $79,05 \%$ & $97,32 \%$ \\
\hline JORNAL DE PEDIATRIA & $25,69 \%$ & $22,80 \%$ & $20,23 \%$ & $0,00 \%$ \\
\hline $\begin{array}{l}\text { JOURNAL OF AEROSPACE TECHNOLOGY AND } \\
\text { MANAGEMENT }\end{array}$ & $65,22 \%$ & $63,64 \%$ & $100,00 \%$ & $0,00 \%$ \\
\hline JOURNAL OF APPLIED ORAL SCIENCE & $94,86 \%$ & $97,75 \%$ & $97,09 \%$ & $99,56 \%$ \\
\hline JOURNAL OF SEED SCIENCE & $98,10 \%$ & $97,14 \%$ & $98,94 \%$ & $97,78 \%$ \\
\hline JOURNAL OF THE BRAZILIAN CHEMICAL SOCIETY & $93,19 \%$ & $94,24 \%$ & $96,43 \%$ & $97,12 \%$ \\
\hline $\begin{array}{l}\text { JOURNAL OF THE BRAZILIAN SOCIETY OF MECHANICAL } \\
\text { SCIENCES AND ENGINEERING }\end{array}$ & $63,16 \%$ & $61,36 \%$ & $73,33 \%$ & $62,75 \%$ \\
\hline $\begin{array}{l}\text { JOURNAL OF VENOMOUS ANIMALS AND TOXINS } \\
\text { INCLUDING TROPICAL DISEASES }\end{array}$ & $23,53 \%$ & $16,38 \%$ & $10,95 \%$ & $0,00 \%$ \\
\hline KRITERION: REVISTA DE FILOSOFIA & $85,71 \%$ & $100,00 \%$ & $100,00 \%$ & $0,00 \%$ \\
\hline LATIN AMERICAN JOURNAL OF SOLIDS AND STRUCTURES & $44,44 \%$ & $57,14 \%$ & $0,00 \%$ & $16,67 \%$ \\
\hline MANA & $15,69 \%$ & $31,82 \%$ & $57,14 \%$ & $1,18 \%$ \\
\hline MANUSCRITO & $100,00 \%$ & $0,00 \%$ & $0,00 \%$ & $100,00 \%$ \\
\hline MATERIA (RIO DE JANEIRO) & $83,13 \%$ & $89,71 \%$ & $92,00 \%$ & $100,00 \%$ \\
\hline MATERIALS RESEARCH & $80,16 \%$ & $76,53 \%$ & $74,29 \%$ & $25,00 \%$ \\
\hline MEMORIAS DO INSTITUTO OSWALDO CRUZ & $18,05 \%$ & $18,82 \%$ & $16,63 \%$ & $0,00 \%$ \\
\hline MOTRIZ: REVISTA DE EDUCACAO FISICA & $90,14 \%$ & $89,49 \%$ & $92,00 \%$ & $95,83 \%$ \\
\hline NEOTROPICAL ENTOMOLOGY & $68,13 \%$ & $80,00 \%$ & $87,80 \%$ & $100,00 \%$ \\
\hline NEOTROPICAL ICHTHYOLOGY & $77,33 \%$ & $75,47 \%$ & $80,65 \%$ & $79,84 \%$ \\
\hline PERSPECTIVAS EM CIENCIA DA INFORMACAO & $83,04 \%$ & $82,11 \%$ & $84,85 \%$ & $80,71 \%$ \\
\hline PESQUISA AGROPECUARIA BRASILEIRA & $98,68 \%$ & $98,76 \%$ & $99,02 \%$ & $99,88 \%$ \\
\hline PESQUISA VETERINARIA BRASILEIRA & $89,93 \%$ & $93,18 \%$ & $95,61 \%$ & $98,66 \%$ \\
\hline PLANTA DANINHA & $91,06 \%$ & $92,66 \%$ & $94,38 \%$ & $99,83 \%$ \\
\hline POLIMEROS & $56,51 \%$ & $54,19 \%$ & $41,67 \%$ & $1,31 \%$ \\
\hline PSICOLOGIA: REFLEXAO E CRITICA & $94,40 \%$ & $94,78 \%$ & $100,00 \%$ & $96,01 \%$ \\
\hline QUIMICA NOVA & $92,40 \%$ & $93,27 \%$ & $94,49 \%$ & $98,08 \%$ \\
\hline REM: REVISTA ESCOLA DE MINAS & $33,54 \%$ & $31,91 \%$ & $32,26 \%$ & $9,91 \%$ \\
\hline REVISTA ARVORE & $97,29 \%$ & $97,94 \%$ & $97,30 \%$ & $99,00 \%$ \\
\hline REVISTA BRASILEIRA DE ANESTESIOLOGIA & $77,67 \%$ & $78,34 \%$ & $90,74 \%$ & $85,05 \%$ \\
\hline REVISTA BRASILEIRA DE CIENCIA AVICOLA & $79,81 \%$ & $74,07 \%$ & $60,00 \%$ & $41,85 \%$ \\
\hline REVISTA BRASILEIRA DE CIENCIA DO SOLO & $25,07 \%$ & $23,12 \%$ & $19,50 \%$ & $0,00 \%$ \\
\hline REVISTA BRASILEIRA DE ENFERMAGEM & $42,49 \%$ & $40,30 \%$ & $38,59 \%$ & $0,43 \%$ \\
\hline $\begin{array}{l}\text { REVISTA BRASILEIRA DE ENGENHARIA AGRICOLA E } \\
\text { AMBIENTAL }\end{array}$ & $95,34 \%$ & $95,68 \%$ & $95,27 \%$ & $92,73 \%$ \\
\hline REVISTA BRASILEIRA DE ENSINO DE FISICA & $91,84 \%$ & $83,33 \%$ & $100,00 \%$ & $100,00 \%$ \\
\hline REVISTA BRASILEIRA DE ENTOMOLOGIA & $87,53 \%$ & $91,15 \%$ & $94,03 \%$ & $96,06 \%$ \\
\hline REVISTA BRASILEIRA DE FARMACOGNOSIA & $84,19 \%$ & $88,12 \%$ & $89,26 \%$ & $98,47 \%$ \\
\hline REVISTA BRASILEIRA DE FRUTICULTURA & $97,45 \%$ & $97,27 \%$ & $97,53 \%$ & $97,87 \%$ \\
\hline
\end{tabular}




\begin{tabular}{|c|c|c|c|c|}
\hline REVISTA BRASILEIRA DE GESTAO DE NEGOCIOS & $60,38 \%$ & $60,87 \%$ & $54,55 \%$ & $66,67 \%$ \\
\hline REVISTA BRASILEIRA DE GINECOLOGIA E OBSTETRICIA & $24,50 \%$ & $25,39 \%$ & $24,01 \%$ & $0,00 \%$ \\
\hline REVISTA BRASILEIRA DE HISTORIA & $87,10 \%$ & $75,00 \%$ & $100,00 \%$ & $100,00 \%$ \\
\hline REVISTA BRASILEIRA DE MEDICINA DO ESPORTE & $71,68 \%$ & $75,36 \%$ & $77,36 \%$ & $84,06 \%$ \\
\hline REVISTA BRASILEIRA DE OFTALMOLOGIA & $87,75 \%$ & $88,83 \%$ & $91,04 \%$ & $96,92 \%$ \\
\hline REVISTA BRASILEIRA DE PARASITOLOGIA VETERINARIA & $47,20 \%$ & $50,95 \%$ & $50,93 \%$ & $0,00 \%$ \\
\hline REVISTA BRASILEIRA DE POLITICA INTERNACIONAL & $95,93 \%$ & $95,92 \%$ & $100,00 \%$ & $97,35 \%$ \\
\hline REVISTA BRASILEIRA DE PSIQUIATRIA & $65,36 \%$ & $71,97 \%$ & $79,61 \%$ & $93,26 \%$ \\
\hline REVISTA BRASILEIRA DE REUMATOLOGIA & $83,69 \%$ & $87,78 \%$ & $92,26 \%$ & $94,80 \%$ \\
\hline REVISTA BRASILEIRA DE ZOOTECNIA & $97,72 \%$ & $97,46 \%$ & $98,07 \%$ & $99,51 \%$ \\
\hline REVISTA CAATINGA & $96,13 \%$ & $97,89 \%$ & $100,00 \%$ & $0,00 \%$ \\
\hline REVISTA CIENCIA AGRONOMICA & $96,60 \%$ & $96,62 \%$ & $95,15 \%$ & $100,00 \%$ \\
\hline REVISTA DA ASSOCIACAO MEDICA BRASILEIRA & $67,01 \%$ & $70,37 \%$ & $70,62 \%$ & $100,00 \%$ \\
\hline REVISTA DA ESCOLA DE ENFERMAGEM DA USP & $56,52 \%$ & $60,32 \%$ & $65,07 \%$ & $95,82 \%$ \\
\hline $\begin{array}{l}\text { REVISTA DA SOCIEDADE BRASILEIRA DE MEDICINA } \\
\text { TROPICAL }\end{array}$ & $25,99 \%$ & $27,23 \%$ & $22,07 \%$ & $0,07 \%$ \\
\hline REVISTA DE ADMINISTRACAO DE EMPRESAS & $18,00 \%$ & $16,95 \%$ & $10,26 \%$ & $5,53 \%$ \\
\hline REVISTA DE NUTRICAO & $56,30 \%$ & $58,78 \%$ & $60,64 \%$ & $0,00 \%$ \\
\hline REVISTA DE SAUDE PUBLICA & $43,37 \%$ & $43,41 \%$ & $41,42 \%$ & $0,10 \%$ \\
\hline REVISTA DIREITO GV & $88,24 \%$ & $95,83 \%$ & $85,71 \%$ & $100,00 \%$ \\
\hline $\begin{array}{l}\text { REVISTA DO INSTITUTO DE MEDICINA TROPICAL DE SAO } \\
\text { PAULO }\end{array}$ & $24,03 \%$ & $25,39 \%$ & $21,74 \%$ & $0,00 \%$ \\
\hline REVISTA LATINO-AMERICANA DE ENFERMAGEM & $34,98 \%$ & $34,08 \%$ & $33,86 \%$ & $40,59 \%$ \\
\hline $\begin{array}{l}\text { REVISTA LATINOAMERICANA DE PSICOPATOLOGIA } \\
\text { FUNDAMENTAL }\end{array}$ & $91,10 \%$ & $90,00 \%$ & $73,68 \%$ & $92,71 \%$ \\
\hline SAO PAULO MEDICAL JOURNAL & $41,25 \%$ & $39,24 \%$ & $35,56 \%$ & $73,21 \%$ \\
\hline SAUDE E SOCIEDADE & $94,15 \%$ & $94,04 \%$ & $95,15 \%$ & $99,67 \%$ \\
\hline SCIENTIA AGRICOLA & $97,84 \%$ & $97,67 \%$ & $100,00 \%$ & $100,00 \%$ \\
\hline SOLDAGEM \& INSPECAO & $93,50 \%$ & $92,94 \%$ & $91,89 \%$ & $94,02 \%$ \\
\hline TEMPO & $95,45 \%$ & $88,89 \%$ & $100,00 \%$ & $100,00 \%$ \\
\hline TEMPO SOCIAL & $83,82 \%$ & $95,00 \%$ & $100,00 \%$ & $94,74 \%$ \\
\hline TEXTO \& CONTEXTO - ENFERMAGEM & $38,28 \%$ & $37,29 \%$ & $32,66 \%$ & $0,12 \%$ \\
\hline THEORETICAL AND EXPERIMENTAL PLANT PHYSIOLOGY & $100,00 \%$ & $100,00 \%$ & $100,00 \%$ & $0,00 \%$ \\
\hline TOPOI (RIO DE JANEIRO) & $90,91 \%$ & $100,00 \%$ & $0,00 \%$ & $0,00 \%$ \\
\hline TRANS/FORM/ACAO & $86,67 \%$ & $100,00 \%$ & $100,00 \%$ & $90,00 \%$ \\
\hline TRANSINFORMACAO & $95,24 \%$ & $96,55 \%$ & $100,00 \%$ & $100,00 \%$ \\
\hline TROPICAL PLANT PATHOLOGY & $98,73 \%$ & $99,46 \%$ & $100,00 \%$ & $100,00 \%$ \\
\hline ZOOLOGIA (CURITIBA) & $93,69 \%$ & $94,08 \%$ & $97,28 \%$ & $100,00 \%$ \\
\hline Total Geral & $69,06 \%$ & $69,38 \%$ & $68,72 \%$ & $65,21 \%$ \\
\hline
\end{tabular}


Apêndice B - Citações recebidas pelos periódicos da amostra

\begin{tabular}{|c|c|c|c|c|}
\hline \multirow{2}{*}{ Periódico } & \multicolumn{2}{|c|}{ Não-normalizadas } & \multicolumn{2}{|c|}{ Normalizadas } \\
\hline & citações & $\%$ & citações & $\%$ \\
\hline $\begin{array}{l}\text { ABCD. ARQUIVOS BRASILEIROS DE CIRURGIA DIGESTIVA (SÃO } \\
\text { PAULO) }\end{array}$ & 217 & $49,77 \%$ & 219 & $50,23 \%$ \\
\hline ACTA AMAZONICA & 185 & $14,88 \%$ & 1058 & $85,12 \%$ \\
\hline ACTA BOTANICA BRASILICA & 53 & $2,37 \%$ & 2184 & $97,63 \%$ \\
\hline ACTA CIRURGICA BRASILEIRA & 590 & $39,18 \%$ & 916 & $60,82 \%$ \\
\hline ACTA ORTOPÉDICA BRASILEIRA & 115 & $43,89 \%$ & 147 & $56,11 \%$ \\
\hline ACTA PAULISTA DE ENFERMAGEM & 725 & $32,85 \%$ & 1482 & $67,15 \%$ \\
\hline ACTA SCIENTIARUM. AGRONOMY & 27 & $1,68 \%$ & 1578 & $98,32 \%$ \\
\hline ANAIS BRASILEIROS DE DERMATOLOGIA & 550 & $22,62 \%$ & 1882 & $77,38 \%$ \\
\hline ANAIS DA ACADEMIA BRASILEIRA DE CIÊNCIAS & 632 & $28,73 \%$ & 1568 & $71,27 \%$ \\
\hline ARCHIVES OF CLINICAL PSYCHIATRY (SÃO PAULO) & 142 & $39,66 \%$ & 216 & $60,34 \%$ \\
\hline ARCHIVES OF ENDOCRINOLOGY AND METABOLISM & 73 & $48,34 \%$ & 78 & $51,66 \%$ \\
\hline $\begin{array}{l}\text { ARQUIVO BRASILEIRO DE MEDICINA VETERINÁRIA E } \\
\text { ZOOTECNIA }\end{array}$ & 1623 & $45,00 \%$ & 1984 & $55,00 \%$ \\
\hline ARQUIVOS BRASILEIROS DE CARDIOLOGIA & 447 & $14,03 \%$ & 2740 & $85,97 \%$ \\
\hline $\begin{array}{l}\text { ARQUIVOS BRASILEIROS DE ENDOCRINOLOGIA \& } \\
\text { METABOLOGIA }\end{array}$ & 553 & $62,63 \%$ & 330 & $37,37 \%$ \\
\hline ARQUIVOS BRASILEIROS DE OFTALMOLOGIA & 78 & $11,24 \%$ & 616 & $88,76 \%$ \\
\hline ARQUIVOS DE NEURO-PSIQUIATRIA & 1121 & $79,90 \%$ & 282 & $20,10 \%$ \\
\hline BIOTA NEOTROPICA & 564 & $19,26 \%$ & 2365 & $80,74 \%$ \\
\hline BOLEMA: BOLETIM DE EDUCAÇÃO MATEMÁTICA & 7 & $4,83 \%$ & 138 & $95,17 \%$ \\
\hline BOLETIM DE CIÊNCIAS GEODÉSICAS & 3 & $11,54 \%$ & 23 & $88,46 \%$ \\
\hline BRAGANTIA & 23 & $1,15 \%$ & 1985 & $98,85 \%$ \\
\hline BRAZILIAN ARCHIVES OF BIOLOGY AND TECHNOLOGY & 693 & $54,57 \%$ & 577 & $45,43 \%$ \\
\hline BRAZILIAN JOURNAL OF BIOLOGY & 111 & $4,42 \%$ & 2400 & $95,58 \%$ \\
\hline BRAZILIAN JOURNAL OF BOTANY & 8 & $1,92 \%$ & 409 & $98,08 \%$ \\
\hline BRAZILIAN JOURNAL OF CARDIOVASCULAR SURGERY & 1345 & $71,20 \%$ & 544 & $28,80 \%$ \\
\hline BRAZILIAN JOURNAL OF CHEMICAL ENGINEERING & 34 & $6,53 \%$ & 487 & $93,47 \%$ \\
\hline BRAZILIAN JOURNAL OF GEOLOGY & 23 & $38,98 \%$ & 36 & $61,02 \%$ \\
\hline BRAZILIAN JOURNAL OF INFECTIOUS DISEASES & 568 & $43,33 \%$ & 743 & $56,67 \%$ \\
\hline $\begin{array}{l}\text { BRAZILIAN JOURNAL OF MEDICAL AND BIOLOGICAL } \\
\text { RESEARCH }\end{array}$ & 136 & $14,73 \%$ & 787 & $85,27 \%$ \\
\hline BRAZILIAN JOURNAL OF MICROBIOLOGY & 465 & $30,79 \%$ & 1045 & $69,21 \%$ \\
\hline BRAZILIAN JOURNAL OF OCEANOGRAPHY & 44 & $11,49 \%$ & 339 & $88,51 \%$ \\
\hline BRAZILIAN JOURNAL OF OTORHINOLARYNGOLOGY & 652 & $75,64 \%$ & 210 & $24,36 \%$ \\
\hline BRAZILIAN JOURNAL OF PHARMACEUTICAL SCIENCES & 204 & $21,18 \%$ & 759 & $78,82 \%$ \\
\hline BRAZILIAN JOURNAL OF PHYSICAL THERAPY & 490 & $38,34 \%$ & 788 & $61,66 \%$ \\
\hline BRAZILIAN ORAL RESEARCH & 162 & $23,79 \%$ & 519 & $76,21 \%$ \\
\hline CADERNOS DE SAÚDE PÚBLICA & 2468 & $32,92 \%$ & 5029 & $67,08 \%$ \\
\hline CERNE & 20 & $1,80 \%$ & 1094 & $98,20 \%$ \\
\hline CIÊNCIA \& SAÚDE COLETIVA & 6412 & $54,59 \%$ & 5333 & $45,41 \%$ \\
\hline CIÊNCIA E AGROTECNOLOGIA & 88 & $4,73 \%$ & 1773 & $95,27 \%$ \\
\hline CIÊNCIA FLORESTAL & 109 & $6,08 \%$ & 1683 & $93,92 \%$ \\
\hline CIÊNCIA RURAL & 277 & $5,10 \%$ & 5158 & $94,90 \%$ \\
\hline CLINICS & 540 & $55,79 \%$ & 428 & $44,21 \%$ \\
\hline COMPUTATIONAL \& APPLIED MATHEMATICS & & $0,00 \%$ & 2 & $100,00 \%$ \\
\hline CROP BREEDING AND APPLIED BIOTECHNOLOGY & 20 & $3,49 \%$ & 553 & $96,51 \%$ \\
\hline DADOS & 40 & $21,16 \%$ & 149 & $78,84 \%$ \\
\hline ECLÉTICA QUÍMICA & 4 & $5,71 \%$ & 66 & $94,29 \%$ \\
\hline EDUCAR EM REVISTA & 22 & $14,77 \%$ & 127 & $85,23 \%$ \\
\hline EINSTEIN (SÃO PAULO) & 278 & $40,35 \%$ & 411 & $59,65 \%$ \\
\hline ENGENHARIA AGRÍCOLA & 155 & $4,50 \%$ & 3293 & $95,50 \%$ \\
\hline ENGENHARIA SANITARIA E AMBIENTAL & 76 & $19,54 \%$ & 313 & $80,46 \%$ \\
\hline
\end{tabular}




\begin{tabular}{|c|c|c|c|c|}
\hline ESTUDOS DE LITERATURA BRASILEIRA CONTEMPORÂNEA & 2 & $25,00 \%$ & 6 & $75,00 \%$ \\
\hline FOOD SCIENCE AND TECHNOLOGY & 109 & $6,40 \%$ & 1595 & $93,60 \%$ \\
\hline GENETICS AND MOLECULAR BIOLOGY & 101 & $18,30 \%$ & 451 & $81,70 \%$ \\
\hline HISTÓRIA, CIÊNCIAS, SAÚDE-MANGUINHOS & 125 & $14,67 \%$ & 727 & $85,33 \%$ \\
\hline HORTICULTURA BRASILEIRA & 43 & $1,80 \%$ & 2352 & $98,20 \%$ \\
\hline IHERINGIA. SÉRIE ZOOLOGIA & 128 & $11,70 \%$ & 966 & $88,30 \%$ \\
\hline INTERNATIONAL BRAZ J UROL & 88 & $22,62 \%$ & 301 & $77,38 \%$ \\
\hline JORNAL BRASILEIRO DE PNEUMOLOGIA & 310 & $20,65 \%$ & 1191 & $79,35 \%$ \\
\hline JORNAL DE PEDIATRIA & 1055 & $73,57 \%$ & 379 & $26,43 \%$ \\
\hline JOURNAL OF AEROSPACE TECHNOLOGY AND MANAGEMENT & 8 & $29,63 \%$ & 19 & $70,37 \%$ \\
\hline JOURNAL OF APPLIED ORAL SCIENCE & 40 & $5,63 \%$ & 670 & $94,37 \%$ \\
\hline JOURNAL OF SEED SCIENCE & 11 & $1,89 \%$ & 571 & $98,11 \%$ \\
\hline JOURNAL OF THE BRAZILIAN CHEMICAL SOCIETY & 148 & $7,30 \%$ & 1880 & $92,70 \%$ \\
\hline $\begin{array}{l}\text { JOURNAL OF THE BRAZILIAN SOCIETY OF MECHANICAL } \\
\text { SCIENCES AND ENGINEERING }\end{array}$ & 40 & $36,70 \%$ & 69 & $63,30 \%$ \\
\hline $\begin{array}{l}\text { JOURNAL OF VENOMOUS ANIMALS AND TOXINS INCLUDING } \\
\text { TROPICAL DISEASES }\end{array}$ & 679 & $76,46 \%$ & 209 & $23,54 \%$ \\
\hline KRITERION: REVISTA DE FILOSOFIA & 1 & $14,29 \%$ & 6 & $85,71 \%$ \\
\hline LATIN AMERICAN JOURNAL OF SOLIDS AND STRUCTURES & 5 & $41,67 \%$ & 7 & $58,33 \%$ \\
\hline MANA & 86 & $82,69 \%$ & 18 & $17,31 \%$ \\
\hline MANUSCRITO & & $0,00 \%$ & 1 & $100,00 \%$ \\
\hline MATÉRIA (RIO DE JANEIRO) & 28 & $16,67 \%$ & 140 & $83,33 \%$ \\
\hline MATERIALS RESEARCH & 49 & $18,92 \%$ & 210 & $81,08 \%$ \\
\hline MEMÓRIAS DO INSTITUTO OSWALDO CRUZ & 4808 & $86,41 \%$ & 756 & $13,59 \%$ \\
\hline MOTRIZ: REVISTA DE EDUCAÇÃO FÍSICA & 62 & $10,54 \%$ & 526 & $89,46 \%$ \\
\hline NEOTROPICAL ENTOMOLOGY & 134 & $37,96 \%$ & 219 & $62,04 \%$ \\
\hline NEOTROPICAL ICHTHYOLOGY & 405 & $22,71 \%$ & 1378 & $77,29 \%$ \\
\hline PERSPECTIVAS EM CIÊNCIA DA INFORMAÇÃO & 38 & $16,59 \%$ & 191 & $83,41 \%$ \\
\hline PESQUISA AGROPECUÁRIA BRASILEIRA & 59 & $1,34 \%$ & 4349 & $98,66 \%$ \\
\hline PESQUISA VETERINÁRIA BRASILEIRA & 405 & $11,78 \%$ & 3032 & $88,22 \%$ \\
\hline PLANTA DANINHA & 246 & $8,93 \%$ & 2509 & $91,07 \%$ \\
\hline POLÍMEROS & 191 & $43,91 \%$ & 244 & $56,09 \%$ \\
\hline PSICOLOGIA: REFLEXÃO E CRÍTICA & 38 & $5,37 \%$ & 669 & $94,63 \%$ \\
\hline QUÍMICA NOVA & 332 & $7,92 \%$ & 3858 & $92,08 \%$ \\
\hline REM: REVISTA ESCOLA DE MINAS & 105 & $65,22 \%$ & 56 & $34,78 \%$ \\
\hline REVISTA ÁRVORE & 84 & $2,71 \%$ & 3014 & $97,29 \%$ \\
\hline REVISTA BRASILEIRA DE ANESTESIOLOGIA & 96 & $22,64 \%$ & 328 & $77,36 \%$ \\
\hline REVISTA BRASILEIRA DE CIÊNCIA AVÍCOLA & 169 & $19,98 \%$ & 677 & $80,02 \%$ \\
\hline REVISTA BRASILEIRA DE CIÊNCIA DO SOLO & 5638 & $74,92 \%$ & 1887 & $25,08 \%$ \\
\hline REVISTA BRASILEIRA DE ENFERMAGEM & 2008 & $56,63 \%$ & 1538 & $43,37 \%$ \\
\hline $\begin{array}{l}\text { REVISTA BRASILEIRA DE ENGENHARIA AGRÍCOLA E } \\
\text { AMBIENTAL }\end{array}$ & 292 & $4,66 \%$ & 5976 & $95,34 \%$ \\
\hline REVISTA BRASILEIRA DE ENSINO DE FÍSICA & 5 & $9,62 \%$ & 47 & $90,38 \%$ \\
\hline REVISTA BRASILEIRA DE ENTOMOLOGIA & 188 & $14,62 \%$ & 1098 & $85,38 \%$ \\
\hline REVISTA BRASILEIRA DE FARMACOGNOSIA & 310 & $17,36 \%$ & 1476 & $82,64 \%$ \\
\hline REVISTA BRASILEIRA DE FRUTICULTURA & 104 & $2,55 \%$ & 3970 & $97,45 \%$ \\
\hline REVISTA BRASILEIRA DE GESTÃO DE NEGÓCIOS & 21 & $39,62 \%$ & 32 & $60,38 \%$ \\
\hline REVISTA BRASILEIRA DE GINECOLOGIA E OBSTETRÍCIA & 1200 & $75,05 \%$ & 399 & $24,95 \%$ \\
\hline REVISTA BRASILEIRA DE HISTÓRIA & 4 & $11,76 \%$ & 30 & $88,24 \%$ \\
\hline REVISTA BRASILEIRA DE MEDICINA DO ESPORTE & 334 & $27,88 \%$ & 864 & $72,12 \%$ \\
\hline REVISTA BRASILEIRA DE OFTALMOLOGIA & 121 & $12,55 \%$ & 843 & $87,45 \%$ \\
\hline REVISTA BRASILEIRA DE PARASITOLOGIA VETERINÁRIA & 984 & $60,59 \%$ & 640 & $39,41 \%$ \\
\hline REVISTA BRASILEIRA DE POLÍTICA INTERNACIONAL & 5 & $4,07 \%$ & 118 & $95,93 \%$ \\
\hline REVISTA BRASILEIRA DE PSIQUIATRIA & 276 & $33,74 \%$ & 542 & $66,26 \%$ \\
\hline REVISTA BRASILEIRA DE REUMATOLOGIA & 138 & $16,55 \%$ & 696 & $83,45 \%$ \\
\hline REVISTA BRASILEIRA DE ZOOTECNIA & 125 & $2,28 \%$ & 5356 & $97,72 \%$ \\
\hline REVISTA CAATINGA & 12 & $3,87 \%$ & 298 & $96,13 \%$ \\
\hline REVISTA CIÊNCIA AGRONÔMICA & 120 & $3,45 \%$ & 3357 & $96,55 \%$ \\
\hline REVISTA DA ASSOCIAÇ̃̃O MÉDICA BRASILEIRA & 491 & $32,84 \%$ & 1004 & $67,16 \%$ \\
\hline
\end{tabular}




\begin{tabular}{|c|c|c|c|c|}
\hline REVISTA DA ESCOLA DE ENFERMAGEM DA USP & 2136 & $43,03 \%$ & 2828 & $56,97 \%$ \\
\hline REVISTA DA SOCIEDADE BRASILEIRA DE MEDICINA TROPICAL & 4385 & $76,96 \%$ & 1313 & $23,04 \%$ \\
\hline REVISTA DE ADMINISTRAÇÃO DE EMPRESAS & 205 & $81,35 \%$ & 47 & $18,65 \%$ \\
\hline REVISTA DE NUTRIÇÃO & 532 & $42,94 \%$ & 707 & $57,06 \%$ \\
\hline REVISTA DE SAÚDE PÚBLICA & 1904 & $56,40 \%$ & 1472 & $43,60 \%$ \\
\hline REVISTA DIREITO GV & 4 & $11,43 \%$ & 31 & $88,57 \%$ \\
\hline $\begin{array}{l}\text { REVISTA DO INSTITUTO DE MEDICINA TROPICAL DE SÃO } \\
\text { PAULO }\end{array}$ & 2109 & $79,98 \%$ & 528 & $20,02 \%$ \\
\hline REVISTA LATINO-AMERICANA DE ENFERMAGEM & 2249 & $64,42 \%$ & 1242 & $35,58 \%$ \\
\hline $\begin{array}{l}\text { REVISTA LATINOAMERICANA DE PSICOPATOLOGIA } \\
\text { FUNDAMENTAL }\end{array}$ & 16 & $10,13 \%$ & 142 & $89,87 \%$ \\
\hline SAO PAULO MEDICAL JOURNAL & 392 & $58,33 \%$ & 280 & $41,67 \%$ \\
\hline SAÚDE E SOCIEDADE & 137 & $5,90 \%$ & 2186 & $94,10 \%$ \\
\hline SCIENTIA AGRICOLA & 17 & $2,15 \%$ & 773 & $97,85 \%$ \\
\hline SOLDAGEM \& INSPEÇÃO & 8 & $6,35 \%$ & 118 & $93,65 \%$ \\
\hline TEMPO & 1 & $4,55 \%$ & 21 & $95,45 \%$ \\
\hline TEMPO SOCIAL & 14 & $17,28 \%$ & 67 & $82,72 \%$ \\
\hline TEXTO \& CONTEXTO - ENFERMAGEM & 2175 & $60,82 \%$ & 1401 & $39,18 \%$ \\
\hline THEORETICAL AND EXPERIMENTAL PLANT PHYSIOLOGY & & $0,00 \%$ & 32 & $100,00 \%$ \\
\hline TOPOI (RIO DE JANEIRO) & 3 & $10,71 \%$ & 25 & $89,29 \%$ \\
\hline TRANS/FORM/AÇÃO & 2 & $13,33 \%$ & 13 & $86,67 \%$ \\
\hline TRANSINFORMAÇÃO & 4 & $4,65 \%$ & 82 & $95,35 \%$ \\
\hline TROPICAL PLANT PATHOLOGY & 4 & $1,27 \%$ & 310 & $98,73 \%$ \\
\hline ZOOLOGIA (CURITIBA) & 70 & $6,26 \%$ & 1049 & $93,74 \%$ \\
\hline Total Geral & 62143 & $31,48 \%$ & 135258 & $68,52 \%$ \\
\hline
\end{tabular}

